4 nordon 



\section{Occurrence and use of hallucinogenic mushrooms containing psilocybin alkaloids}

Christer Andersson - National Food Administration, Uppsala, Sweden.

Jakob Kristinsson - Department of Pharmacology, University of Iceland.

Jørn Gry - National Food Institute, Technical University of Denmark

TemaNord 2008:606 
Occurrence and use of hallucinogenic mushrooms containing psilocybin alkaloids

TemaNord 2008:606

(C) Nordic Council of Ministers, Copenhagen 2009

ISBN 978-92-893-1836-5

Print: Kailow Express ApS

Cover:

Layout:

Cover photo:

Copies: 200

Printed on environmentally friendly paper

This publication can be ordered on www.norden.org/order. Other Nordic publications are available at www.norden.org/publications

Printed in Denmark

Nordic Council of Ministers

Store Strandstræde 18

DK-1255 Copenhagen K

Phone (+45) 33960200

Fax (+45) 33960202
Nordic Council

Store Strandstræde 18

DK-1255 Copenhagen K

Phone (+45) 33960400

Fax (+45) 33111870

www.norden.org

\section{Nordic co-operation}

Nordic cooperation is one of the world's most extensive forms of regional collaboration, involving Denmark, Finland, Iceland, Norway, Sweden, and three autonomous areas: the Faroe Islands, Greenland, and Åland.

Nordic cooperation has firm traditions in politics, the economy, and culture. It plays an important role in European and international collaboration, and aims at creating a strong Nordic community in a strong Europe.

Nordic cooperation seeks to safeguard Nordic and regional interests and principles in the global community. Common Nordic values help the region solidify its position as one of the world's most innovative and competitive. 


\section{Content}

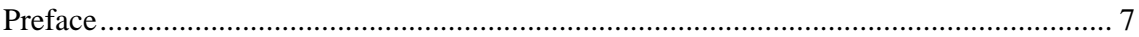

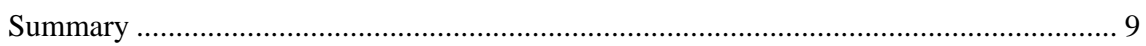

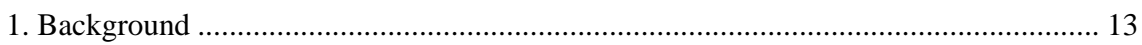

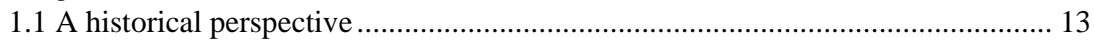

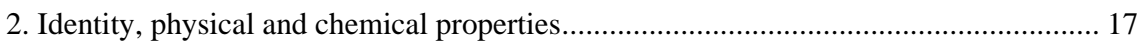

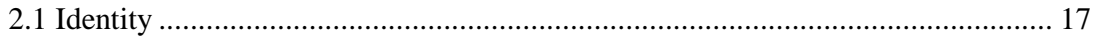

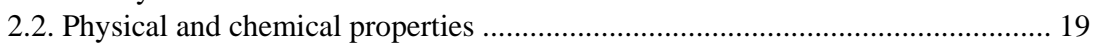

2.2.1. Chemical synthesis of psilocybin and psilocin ............................................. 19

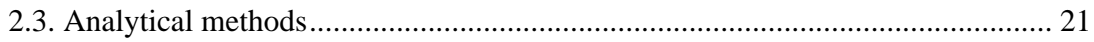

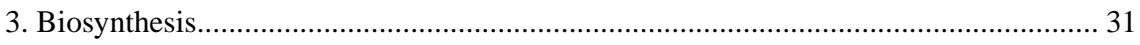

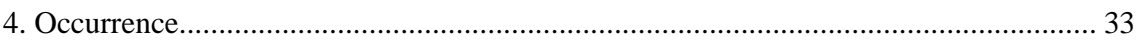

4.1. Content of psilocybin and related compounds in various mushroom species...... 33

4.2. Influence of cultivation, storage and processing................................................ 56

4.3. Wild mushrooms in the Nordic countries that contain psilocybin and/or related

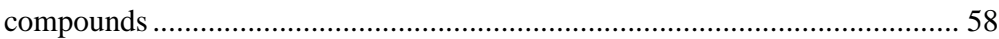

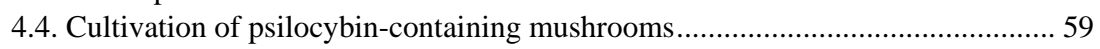

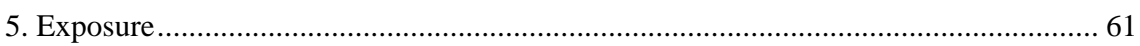

5.1. The habit of consuming hallucinogenic mushrooms ........................................ 61

5.2. Legal aspects of hallucinogenic mushrooms and/or psilocybin and related

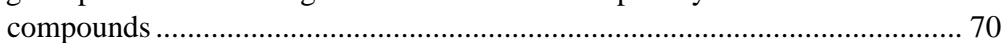

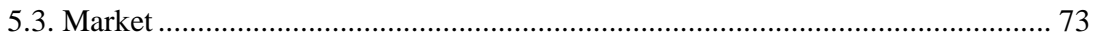

6. Summary of biological effects of psilocybin and psilocin .......................................... 75

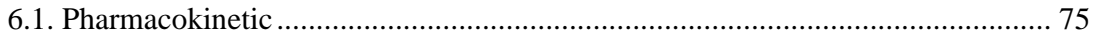

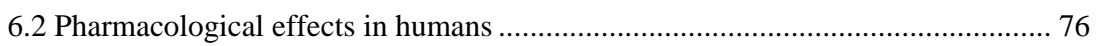

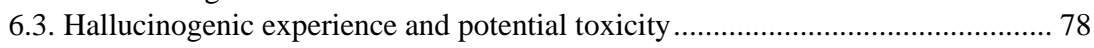

6.4. Hallucinogenic mushroom use in the Nordic countries ....................................... 88

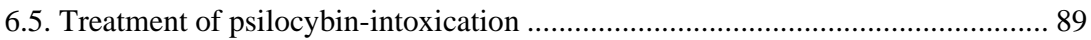

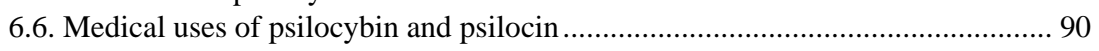

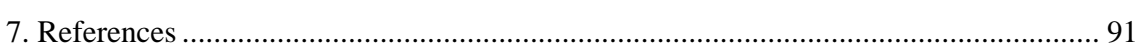

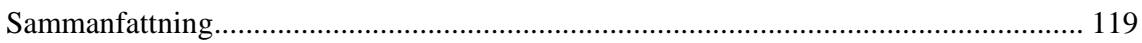





\section{Preface}

The Nordic Committee of Senior Officials for Food Issues is an advisory body of the Nordic Council of Ministers which co-ordinates Nordic work in the field of food and nutrition. The Nordic Working Group on Food Toxicology and Risk Evaluation (NNT) was until 2006 given the responsibility by the Committee to promote co-operation and co-ordination among Nordic countries in matters relating to food toxicology and risk assessment.

Assessment of health risk connected with naturally occurring toxicants in foodstuffs has become an important area for NNT. A series of Nordic reports based on the work performed by the Nordic project group on inherent natural toxicants in food plants and mushrooms has been published:

Gry, J. and Pilegaard, K. (1991) Hydrazines in the Cultivated Mushroom (Agaricus bisporus). Vår Föda 43;Supplement 1

Uggla, A. and Busk, L. (1992) Ethyl carbamate (urethane) in alcoholic beverages and foodstuffs - A Nordic View. Nordiske Seminar- og Arbejdsrapporter 1992:570.

Størmer, F.C., Reistad, R. and Alexander, J. (1993) Adverse health effects of glycyrrhizic acid in licorice. A risk assessment. Nordiske Seminar- og Arbejdsrapporter 1993:526.

Andersson, C., Slanina, P. And Koponen, A. (1995) Hydrazones in the false morel. TemaNord 1995:561.

Søborg, I., Andersson, C. and Gry, J. (1996) Furocoumarins in Plant Food - exposure, biological properties, risk assessment and recommendations. TemaNord 1996:600.

Gry, J. and Andersson, H.C. (1998) Nordic seminar on phenylhydrazines in the Cultivated Mushroom (Agaricus bisporus). TemaNord 1998:539.

Andersson, H.C. (2002) Calystegine alkaloids in Solanaceous food plants. TemaNord 2002:513.

Andersson, C., Wennström, P. and Gry, J. (2003) Nicotine in Solanaceous food plants. TemaNord 2003:531.

Andersson, H.C. and Gry, J. (2004) Phenylhydrazines in the cultivated mushroom (Agaricus bisporus) - occurrence, biological properties, risk assessment and recommendations. TemaNord 2004:558.

Gry, J., Søborg, I. and Andersson, H:C: (2006) Cucurbitacins in plant food. TemaNord 2006:556.

Beckman Sundh, U., Rosén, J. and Andersson, H.C. (2007) Analysis, occurrence, and toxicity of $\beta$-methylaminoalanine (BMAA). TemaNord 2007:561.

Pilegaard, K. and Gry, J. (2008) Alkaloids in edible lupin seeds. A toxicological review and recommendations. TemaNord 2008 (in press) 
Mushrooms containing psilocybin and related hallucinogenic compounds have been used in the Nordic countries for recreational purposes since the 1970 's. During the last decade Internet has given both an easy assess to information about hallucinogenic mushrooms and possibilities to purchase mushroom products. At the end of the 1990's the number of phone calls to National Poison Information centres and the number of epicrises from hospitals related to hallucinogenic mushrooms increased significantly. It was decided to initiate a risk assessment of hallucinogenic mushrooms as at the time mushrooms of this type were defined as food in some Nordic countries. As subsequently national legislations have been introduced, defining hallucinogenic mushrooms as illegal products, it was decided to instead review the 'Occurrence and use of hallucinogenic mushrooms'.

The literature reviewed in this report has been found in searches on Medline, Toxline and FSTA (- August 2007), and not least in the reference lists of the publications found in the searches.

The Nordic Project Group on Natural Toxins consisting of members of the NNT has reviewed and accepted the present document in January 2008.

The Project Group consisted of the following members:

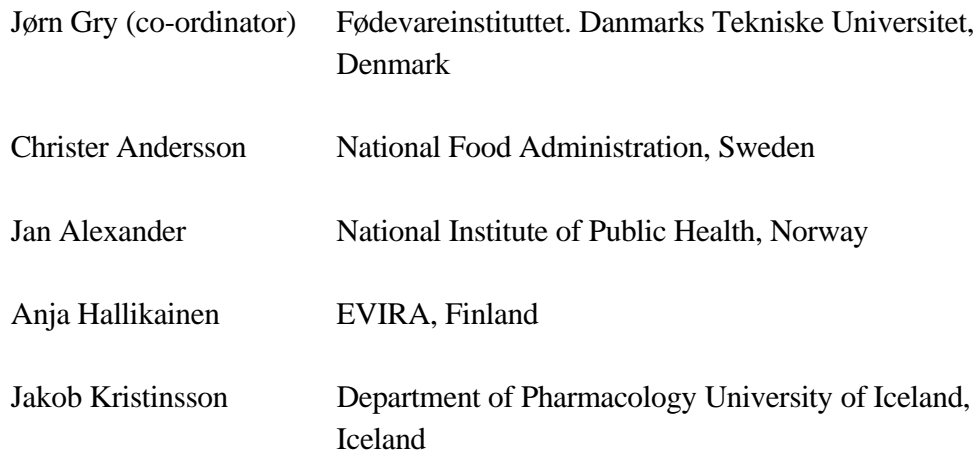

The Project Group and NNT like to acknowledge the contribution of Henning Knudsen, Natural History Museum of Denmark, University of Copenhagen, for the momenclature of psilocybin/psilocin-containing mushrooms growing in the Nordic countries. 


\section{Summary}

From having been used in ritual religious ceremonies over thousands of years, hallucinogenic mushrooms started to be used as a recreational drug late in the 1960's. Which the hallucinogenic mushrooms used in religious ceremonies by Indian tribes in Mexico were, became known from ethonomycological investigations in the 1930s and 1940s, but the first list of hallucinogenic mushrooms of Mexico was not published until 1961. At that time, chemists working for the Swiss pharmaceutical company Sandoz had already identified the compound in the mushroom responsible for the effect. It was a phosphorylated alkaloid, given the name psilocybin (a phosphoric acid ester of 4-dihydroxymethyltryptamine) after the mushroom species from which it was originally isolated, Psilocybe mexicana. Subsequent studies showed that the real hallucinogenic compound is psilocin, which is formed from psilocybin by dephosphorylation. The dephosphorylation can take place in the mushroom after harvest or when damaged, or in the body of the consumer.

Mycological investigations have identified a large number of mushrooms able to produce psilocybin. The compound has been chemically identified in about 90 different mushrooms belonging to the genera Agrocybe, Conocybe, Copelandia*, Gymnopilus*, Hypholoma, Inocybe, (Panaeolina), Panaeolus*, Pluteus, Psathyrella*, Psilocybe, and Stropharia (*most species do not contain psilocybin/psilocin). In addition, several other species have been reported to be hallucinogenic. The studies on the mushroom chemistry has also identified that psilocybin/psilocin is not the only hallucinogenic compound of this type in the mushrooms. Three other phosphoric acid ester of 4-hydroxytryptamine with one, zero or three methyl groups on the tryptamine side chain - baeocystin, norbaeocystin, and aeruginascin - also have hallucinogenic properties. However, these compounds occur at lower levels and in a much more limited set of mushroom species.

Critical steps in the chemical analysis of psilocybin and related substances in mushrooms are the method of extraction, the chromatographic method used to separate compounds, and the method used to identifying the hallucinogens. GC-MS and LC-MS are common methods used in human biological samples to identify psilocybin/psilocin.

The chemical analysis of hallucinogenic mushrooms has identified modest levels in the mycelium, and higher levels in the fruit bodies. In the latter, caps contain higher amounts than the stalk. No correlation between psilocybin level and size of fruit bodies has been found. 
Species with high psilocybin/psilocin content include Agrocybe praecox (Pers.) Fayod., Copelandia cambodginiensis (Ola'h et Heim) Singer and Weeks, Inocybe aeruginascens Babos, Panaeolus cyanescens (Berk. \& Br.) Sacc., Panaelous subbalteatus (Berk. \& Br.) Sacc., Pluteus salicinus (Pers. Ex Fr.) Kummer, Psilocybe arcana Bor et Hlav., Psilocybe azurescens Stamets and Gartz, Psilocybe baeocystis Singer and Smith, Psilocybe bohemica Sebek, Psilocybe cubensis (Earle) Singer, Psilocybe cyanescens Wakefield, Psilocybe liniformans Guzmán \& Bas var. americana Guzmán \& Stamets, Psilocybe pelliculosa (Smith) Singer and Smith, Psilocybe samuiensis Guzmán, Bandala and Allen, Psilocybe semilanceata (Fr.) Kummer, Psilocybe semperviva Heim and Cailleux, and Psilocybe subcubensis Guzmán. The highest levels, more than 15000 $\mathrm{mg} / \mathrm{kg}$ dry weight, have been identified in Pluteus salicinus (Pers. Ex Fr.) Kummer, Psilocybe cyanescens Wakefield, and Psilocybe semilanceata (Fr. Ex Secr.) Kummer.

Baeocystin is found only in some of the species synthesizing psilocybin, usually at levels bellow $1000 \mathrm{mg} / \mathrm{kg}$ dry weight. High levels, up to more than $5000 \mathrm{mg} / \mathrm{kg}$ dry weight have been found in Inocybe aeruginascens Babos. The same species contains up to $3500 \mathrm{mg} / \mathrm{kg}$ dry weight aeruginascin.

Of the about 90 psilocybin and/or psilocin-containing mushrooms identifyied, about 30 have been found in the Nordic countries. Among these are 6 Psilocybe species, 6 Panaeolus species, 3 Gymnopilus species, 2 Conocybe species, 2 Inocybe species, 2 Pluteus species and one Psathyrella species. Many of them are rare but some can be found in considerable quantities.

Collecting hallucinogenic mushrooms requires substantial mycological knowledge as there are many look-a-likes. Some of these look-a-likes are toxic. Only experienced mushroom pickers should therefore collect these types of mushrooms. An alternative way to get hands on hallucinogenic mushrooms is to cultivate them at home or buy samples over internet. Most of the latter types of mushroom are dried. Being hard to chew, dried mushrooms are frequently prepared in a drink, eg. tea, coffee or Coca Cola. Another way of using dried hallucinogenic mushrooms is to smoke them like a cigarette. As psilocybin may be extracted by heating, but is not degraded, the total amount of psilocybin in the cooking water and in the mushroom corresponds to the level in the mushroom before household processing.

Hallucinogenic mushrooms are most frequently used by young people, mainly men, and particularly users of other drugs. However, such use of mushrooms is infrequent. In the Nordic countries, use of hallucinogenic mushrooms has mainly been studied in Denmark. Three percent of highschool students had used psilocybin-containing mushrooms (1\% had tried LSD) in a recreational atmosphere, whereas the corresponding figure in university students and pupils at a school for journalists was nine percent. 
This suggests that mushrooms are the most commonly used hallucinogenic substance in Denmark.

Although it has been difficult to demonstrate toxic effects of hallucinogenic mushroom use, it is well established that such use can induce uncontrolled action in the user. In rare cases, when the intake of such mushrooms has been substantial, flash-backs of adverse experiences have been reported. For these reasons, and perhaps due to the fact that the use of hallucinogenic mushrooms is not uncommon in users of other drugs, many countries, including the Nordic countries, have wished to restrict the use of these mushrooms. 



\section{Background}

\subsection{A historical perspective}

It is no longer possible to view mankind's contacts with mushrooms solely in terms of food gathering and food production. Historical texts, anthropological literature, and present day drug culture shows that mushrooms have been used, and still are used to allow the human mind to transit natural borders. This is discussed by Stamets (1978) in the book "Psilocybe Mushrooms and their Allies", where he splits the history of the hallucinogenic fungi into four periods of time. The first phase, constituting the historic era, corresponds the period when hallucinogenic mushrooms were used in traditional and cultural settings by various populations around the world - most notably the indigenous tribes in Mexico. The second phase was a time of confusion, before the mushrooms mentioned in the early texts were identified. This period lasted from the early 1900s to the 1950s. The third phase consisted of mycological and ethnomycological expeditions proposing to taxonomically identify the hallucinogenic mushrooms and to become acquainted with the indigenous groups who used them. Also the elucidation of the chemistry of the active compounds and their role in medicine belongs to this period, which therefore makes this period the gold era of hallucinogenic mushroom research. Finally, the last phase, still ongoing, is characterised by making use of the mushrooms in recreational settings.

Botanical and anthropological literature contains many references to mushrooms, which have been employed to link the earthly life to the divine state by some of the Indian tribes of Mexico in ritual ceremonies. The Aztecs and the Chichimecas were the earliest recorded users of such mushrooms, which they called 'teonanacatl'. This Middle American cult of divine mushrooms can be traced back to about B.C. 1500 (Wasson, 1961), but is first mentioned in Andrés de Olmos' work "Antigüedades Mexicanas" from 1453. The Spaniards returning from Mexico after the conquest during the early part of the 16th century, described the effect of using 'teonanacatl', and spread the knowledge about the mushroom use in sacred rituals. In most users the mushrooms gave rise to altered perception of time and space, and a sense of elation and joy or bliss, whereas other users responded with anxiety and depression and even deep unconsciousness (e.g. de Sahagun, 16th century). The effects described by the Spanish conquerors are comparable to those experienced today after intake of lysergic acid dimethylamide, LSD (Subramanian, 1995).

It is possible that the mushroom-formed stones found in Guatemala, and to some extent also in El Salvador and Mexico, have had a role in 
this type of ritual a long time ago. Some of these stones seems to have been produced as early as $2000 \mathrm{BC}$ but the habit of forming stones to mushrooms reached its zenith in Central America some time between 200 BC and 300 AD. Since miniature metates (grinding stones) have been found in the vicinity of such mushroom stones, it has been suggested that they have been used to crush and prepare mushrooms (Wasson, 1966). For several centuries, however, the identity of 'teonanacatl' remained obscure. Recurring references to it have mystified biological and anthropological investigators, inasmuch as careful search had failed to reveal any Mexican fungus possessing properties used to induce a narcosis. It was suggested that the reports which associate 'teonanacatl' with a mushroom are misleading or erroneous, although the sources from which they come are in other respects dependable and credible (Schultes, 1939).

During the end of the 1930s and the1940s Dr Schultes of Harvard University, USA, and colleagues began ethno-botanical investigations among the Mazatec Indians of north-eastern Oaxaca and brought back mushrooms claimed to be narcotic from Mexico to USA (Schultes, 1939). This material stimulated the pioneering and exciting studies of Gordon Wasson and his wife Valentina, mycologist Roger Heim of the Museum Cryptogamie in Paris, and Dr. Albert Hofmann, biochemist with Sandoz in Basel to focus their scientific studies on the ritual use, taxonomy and chemistry of these mushrooms (Wasson, 1957; Hofmann et al., 1959).

In 1952 the Wasson couple learnt from the documents of Spanish conquerors and priests that a 16th century mushroom cult had existed in Mexico and spent several seasons there searching for surviving traces of this cult. During these studies Gordon Wasson and one of his colleagues, along with 18 Mayan Indians, in 1955 participated in a ritual ceremony in Huautla de Jiménez in Mexico where the Mexican sacred mushroom, 'teonanacatl', was consumed. The ceremony was lead by a shaman. Wasson received six pairs of mushrooms which he consumed and the shaman kept 13 pairs for herself. After a while the lights were extinguished and about half an hour later Wasson and his colleague Richardson started having harmonious visions (vivid in colour) which became quite intense late in the night and remained for around four hours. It is not known whether this cult was a surviving relic from the mushroom cult that occurred in Guatemala centuries ago.

It was early recognised that more than one mushroom species were used in the rituals. The mushroom brought back to USA from Mexico by Dr. Schultes (1939) and co-workers was identified as Panaeolus campanulatus L. var. sphinctrinus (Fr.) Bresadola by Dr. David Linder, Harvard University. Subsequent studies of Roger Heim identified Wasson's collections of hallucinogenic mushrooms from Mexico as various species belonging to the genus Psilocybe, e.g. Psilocybe mexicana. Later on also other hallucinogenic mushrooms have been identified. 
In 1961 Gordon Wasson published the first list on the hallucinogenic mushrooms of Mexico. The list appeared as an appendix to a lecture of the Mycological Society of America, published in the Botanical Museum Leaflets of the Harvard University, and was one of the earliest comprehensive catalogue of hallucinogenic mushrooms in the scientific literature. It was soon to be followed by similar types of information aimed for the non-scientific audience. Magic mushroom is the most common term applied to psychoactive fungi. It was invented by a Life magazine editor in 1957. 



\section{Identity, physical and chemical properties}

\subsection{Identity}

The original successful isolation and identification of hallucinogenic compounds from Psilocybe mexicana became possible when large quantities of fruit bodies, sclerotia and mycelium of the mushroom could be produced in laboratory cultures (Heim and Hofmann, 1958a, b). The dried fruit bodies, sclerotia and mycelium of $P$. mexicana were in self-tests shown to possess the same psychoactive activity as fresh fruit bodies.

The psychoactive principle of Psilocybe mexicana was isolated in crystalline form in 1958 by Hofmann and co-workers, and identified as the phosphoric acid ester of 4-hydroxy-dimethyltryptamine (Fig. 1a), which was given the name psilocybin (Hofmann et al., 1958a, b: Heim et al., 1958). It is the first natural phosphorylated indole-compound detected. A second substance closely related to psilocybin but found only in traces was isolated and identified in parallel with psilocybin (Hofmann et al., 1956a). This compound was 4-hydroxy-dimethyltryptamine, which was given the trivial name psilocin (Fig. 1b). Subsequently these compounds were identified also in other mushroom species (see section 5.1.).

The structure of psilocybin was confirmed by total chemical synthesis (Hofmann et al., 1958b). Using the oxalylchloride method (Speeter and Anthony, 1954), 4-hydroxy-dimethyltryptamine was produced from 4benzyloxy-indole. The phenolic hydroxyl group of 4-hydroxydimethyltryptamine was subsequently esterified with dibenzylphosphorylchloride, after which reductive debenzylation produced psilocybin (Hofmann et al., 1958b, 1958c).

In 1968 Leung and Paul isolated two new compounds from methanolextracts of submerged cultures of Psilocybe baeocystis. The structures of these compounds were determined as the monomethyl and demethyl analogues of psilocybin by thin layer chromatography characteristics, colour reactions, UV, IR, and mass spectral analysis (Leung and Paul, 1967; 1968). They were given the names baeocystin (monomethyl) and norbaeocystin (demethyl), respectively. Their chemical structure is shown in Fig. 1c and 1d, respectively. Both compounds have subsequently been identified in various hallucinogenic mushrooms.

The latest analogue of psilocybin identified is aeruginascin, the trimethyl analogue of psilocybin (Fig. 1e). Also this compound obtained its name from the mushroom species were it was identified Inocybe aeruginascens after extraction with polar solvents (Gartz, 1989a; Jensen et al., 2006). 
Although the molecule contains a quarternary ammonium group, aeruginascin (N,N,N- trimethyl-4-phosphoryloxytryptamine) seems to be stable in dried mushrooms at room temperature for years. The authors speculate that aeruginascin is likely to be enzymatically dephosphorylated in vivo when aeruginascin- containing mushrooms are consumed. Due to the quaternary ammonium group aeruginacin as such is unlikely to pass the blood-brain barrier, a requirement for centrally mediated hallucinogenic effects. Aeruginascin is structurally related to the frog skin toxin bufotenidine ( $\mathrm{N}, \mathrm{N}, \mathrm{N}$-trimethylserotonin).<smiles>CCCCc1c[nH]c2cccc(OP(=O)(O)O)c12</smiles>

a) psilocybin<smiles>CNCCc1c[nH]c2cccc(OP(=O)(O)O)c12</smiles>

c) baeocystin<smiles>CCCc1c[nH]c2cccc(OP(=O)(O)O)c12</smiles>

e) aeruginascin<smiles>CN(C)CCc1c[nH]c2cccc(O)c12</smiles>

b) psilocin<smiles>NCCc1c[nH]c2cccc(OP(=O)(O)O)c12</smiles>

d) nor-baeocystin

Figure 1. Chemical structure of a) psilocybin; b) psilocin; c) baeocystin; d)nor-baeocystin; and e) aeruginascin occurring in various hallucinogenic mushrooms. 


\subsection{Physical and chemical properties}

Psilocybin, re-crystallised from water, is made up of white, soft, crystalwater containing needles that melts at $220-228^{\circ} \mathrm{C}$. From boiling methanol, psilocybin produces massive prisms that contain crystal-methanol and melts at $185-195^{\circ} \mathrm{C}$. Psilocybin is soluble in 20 parts boiling water or in 120 parts methanol, but is poorly soluble in ethanol. The compound is practically insoluble in chloroform and benzene. A $1 \%$ solution of psilocybin dissolved in 50\% ethanol has a pH of 5.2 (Hofmann et al., 1959). The degradation product psilocin forms white crystals in methanol (m.p. $173-176^{\circ} \mathrm{C}$ ) and is quite insoluble in water but dissolves in most organic solvents. However, it is unstable in solution (Shulgin, 1980). The chemical and physical properties of psilocybin and psilocin are summarised in Table 1.

Isolated and chromatographically separated psilocybin and psilocin were visualised by coupling the compounds with Keller-Reagent (iron chloride in concentrated acetic acid and sulphuric acid) or Van-Urk Reagent (p-dimethylbenzaldehyde). Reagent- coupled psilocybin produced a violet colour-reaction and reagent-coupled psilocin a blue one (Hofmann et al., 1958a, 1959).

Since psilocybin has similar pharmacological effects to LSD, the possibility of psilocybin forming a hydrogen bond between the ammonium nitrogen atom and an oxygen atom of the 4-phosphoryloxy group of the indole ring, to form a ring analogous to ring C of LSD, has been investigated. X-ray crystallographic studies have revealed that such a hydrogen bond neither is formed in psilocybin, nor in any of the other tested tryptamine derivatives (Baker et al., 1973).

\subsubsection{Chemical synthesis of psilocybin and psilocin}

To be able to analyse for the occurrence of hallucinogenic compounds in mushrooms, as well as in experimental animals and humans that have ingested such mushrooms, chemical standards are required for the analytical methods. The compounds were originally synthesized by chemists at the Sandoz laboratories in Switzerland (Hofmann et al., 1958; Troxler et al., 1959). Several investigators have subsequently reported on the chemical 
Table 1. Chemical and physical properties of psilocybin and psilocin.

\begin{tabular}{|c|c|}
\hline \multicolumn{2}{|l|}{ Psilocybin } \\
\hline Synonyms: & $\begin{array}{l}\text { 3-[2-(dimethylamino)ethyl]-1H-indol-4-ol-dihydrogen phosphate } \\
\text { ester; O-phosphoryl-4-hydroxy- } \mathrm{N}, \mathrm{N} \text { - dimethyltryptamine; indocybin }\end{array}$ \\
\hline \multicolumn{2}{|c|}{$\begin{array}{l}\text { IUPAC System. Name: } \\
\text { Chem. Abst. Name: }\end{array}$} \\
\hline CAS reg. No.: & $520-52-5$ \\
\hline Molecular formula: & $\mathrm{C}_{12} \mathrm{H}_{17} \mathrm{~N}_{2} \mathrm{O}_{4} \mathrm{P}$ \\
\hline Chemical structure: & See, figure $1 \mathrm{a}$. \\
\hline Molecular weight: & 284.27 \\
\hline $\begin{array}{l}\text { Chemico-physical } \\
\text { characteristics: }\end{array}$ & A water/ethanol solution of psilocybin has a pH of 5.2. \\
\hline Density: & $\alpha_{D}^{20}=0^{\circ}$ \\
\hline Solubility: & $\begin{array}{l}\text { Soluble in } 20 \text { parts boiling water, } 120 \text { parts boiling methanol; only } \\
\text { slightly soluble in ethanol. Practically insoluble in chloroform, benzene. }\end{array}$ \\
\hline $\begin{array}{l}\text { Melting point: } \\
\text { Boiling point: }\end{array}$ & $185-195^{\circ} \mathrm{C}$ \\
\hline \multicolumn{2}{|l|}{ Psilocin } \\
\hline Synonyms: & $\begin{array}{l}\text { 3-[2-(dimethylamino)ethyl]-1H-indol-4-ol; 4-hydroxy- } \mathrm{N}, \mathrm{N} \text { - } \\
\text { dimethyltryptamine; psilocin }\end{array}$ \\
\hline \multicolumn{2}{|c|}{$\begin{array}{l}\text { IUPAC System. Name: } \\
\text { Chem. Abst. Name: }\end{array}$} \\
\hline CAS reg. No.: & $520-53-6$ \\
\hline Molecular formula: & $\mathrm{C}_{12} \mathrm{H}_{16} \mathrm{~N}_{2} \mathrm{O}$ \\
\hline Chemical structure: & See, figure $1 \mathrm{~b}$. \\
\hline Molecular weight: & 204.27 \\
\hline $\begin{array}{l}\text { Chemico-physical } \\
\text { characteristics: }\end{array}$ & $\begin{array}{l}\text { Plates from methanol, mp } 173-176^{\circ} \mathrm{C} \text {. Amphoteric substance. } \\
\text { Unstable in solution, especially alkaline solutions. }\end{array}$ \\
\hline Density: & \\
\hline $\begin{array}{l}\text { Solubility: } \\
\text { Melting point: } \\
\text { Boiling point: }\end{array}$ & Very slightly soluble in water. \\
\hline
\end{tabular}

synthesis of psilocybin (Ono et al., 1973; Repke et al., 1981; Ametamey et al., 1998; Yamada et al., 1998; Nichols and Frescas, 1999; Sakagami and Ogasawara, 1999; Yamada, 2000; Shirota et al., 2003), but only a few on the synthesis of psilocin (Nichols and Frescas, 1999; Shirota et al., 2003).

In 1998, Yamada and co-workers suggested a method that in five steps synthesizes psilocin from indole-3-carbaldehyde. The starting point for this synthesis is indole-3-carbaldehyde (Yamada et al., 1998; Yamada, 2000). Gathergood and Scammelis (2003) suggested an alternative method to synthesise psilocin. They prepared the mushroom hallucinogen via palladium-catalysed cyclization of protected N-tert-butoxycarbonyl-2-iodo-3methoxyaniline and appropriately substituted silyl acetylene. Subsequent removal of the protecting groups gave good yields of psilocin.

Shirota et al. (2003) recently reported on a concise large-scale synthesis of both psilocybin and psilocin. The synthesis started with protection of the hydroxyl group of commercially available 4-hydroxyindole by addition of an acetyl group. The 4-acetylindole formed was allowed to react with oxalyl chloride to yield yellow crystals of the oxalyl-group 
coupled to the 4-acetylindole at the 3-position. A subsequent amidation step produced 3-dimethylaminooxalyl-4-acetylindole, which could be converted to psilocin in high yields by reduction. Psilocybin was produced in high yields from psilocin via a zwitterionic $\mathrm{N}$,O-dibenzyl phosphate intermediate. The newly described method allows gram scale synthesis of psilocybin and psilocin.

\subsection{Analytical methods}

\subsubsection{Extraction methods}

When Hofmann and co-workers isolated psilocybin from Psilocybe mexicana they observed that the substance was only extracted by very polar solvents like methanol or mixtures of ethanol and water (Hofmann et al., 1958a, Hofmann et al., 1959). Due to the polar properties of the phosphate group (Figure 1) the substance is soluble in water and methanol but not in less polar solvents. Psilocin on the other hand is less polar and readily soluble in less polar solvents like 1-chlorobutane (Lee, 1985).

As shown in Table 2 most investigators have used methanol for the quantitative extraction of psilocybin and psilocin from mushroom samples. Most of the methods involve some kind of mechanical mixing of the finely ground mushroom material with the solvent (Table 2). Extraction times have ranged from 2 minutes to 24 hours. Only a few studies have investigated the effect of the extraction conditions on recovery. Perkal et al. (1980) found that homogenization of finely ground samples of Psilocybe subaeruginosa with 30 parts of methanol for no more than 2 minutes gave maximum yield of the alkaloids. Christiansen et al. (1981a) found this method inadequate when analysing samples of Norwegian Psilocybe semilanceata. They extracted the samples twice with $10 \% 1 \mathrm{~N}$ ammonium nitrate in methanol in a centrifuge tube by rotating the tubes in a rotary mixer for 30 minutes. Almost quantitative (98\%) yield of psilocybin was obtained by this method. The role or effect of ammonium nitrate in the extraction solvent was not discussed. 


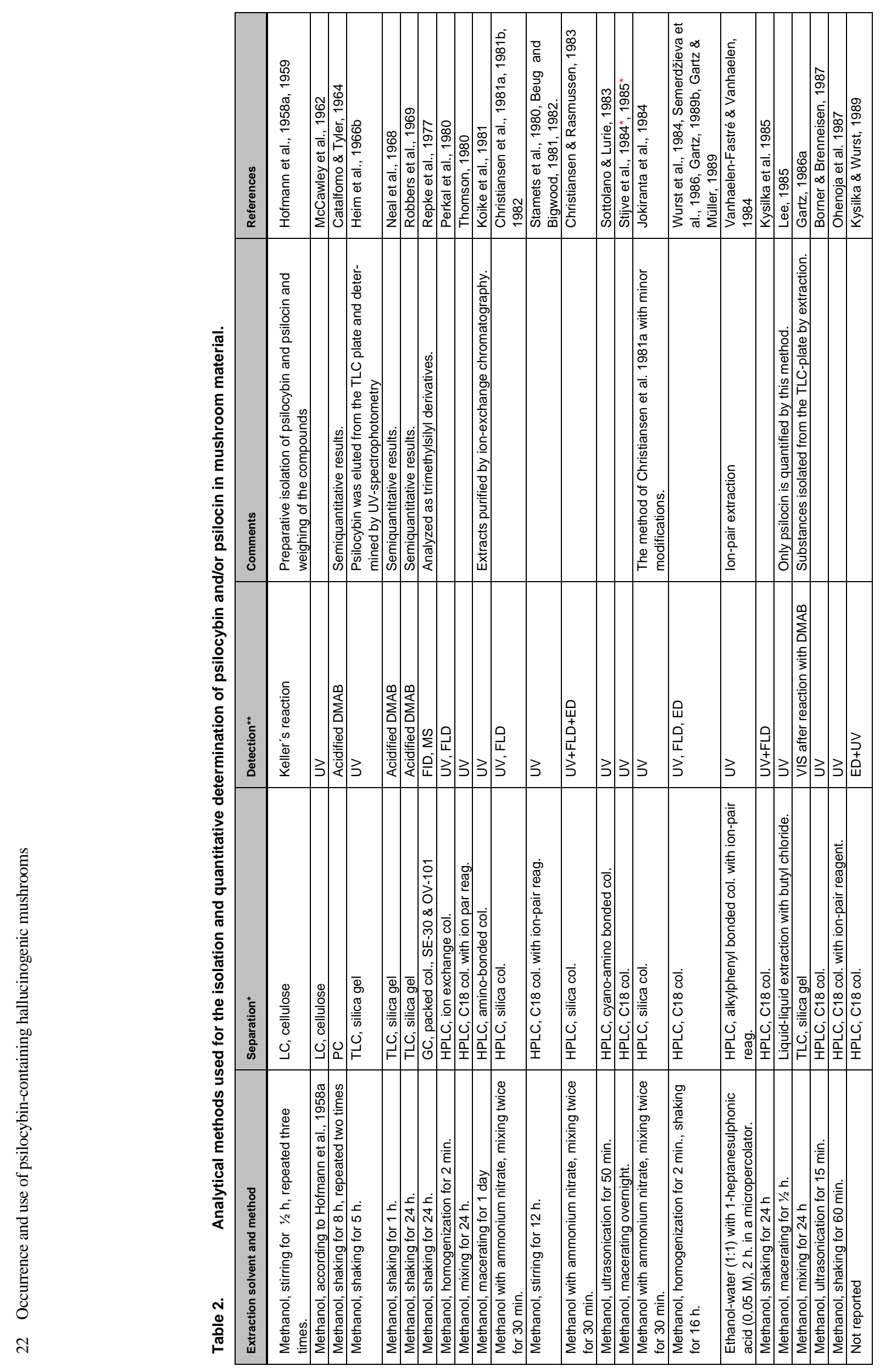




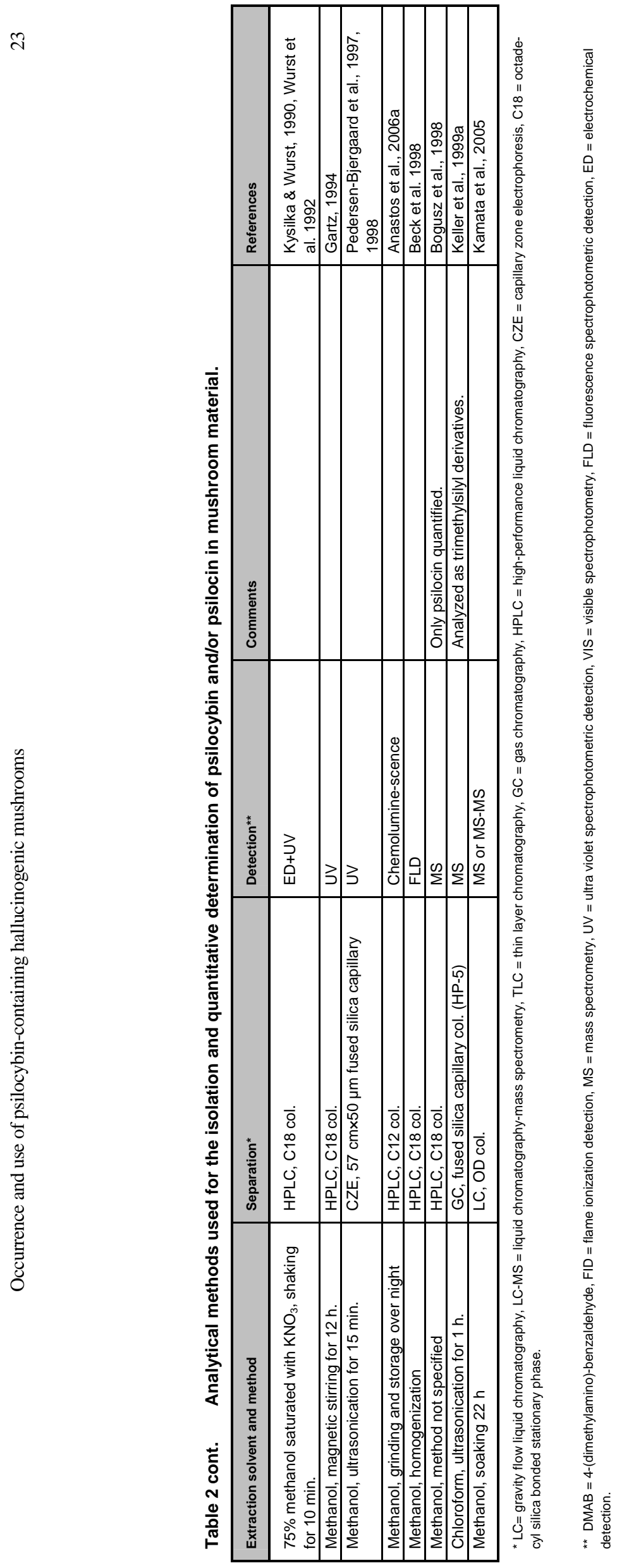


Beug and Bigwood (1981) obtained quantitative extraction of psilocybin and psilocin from powdered freeze-dried mushrooms by magnetic stirring for 12 hours in methanol. Recoveries were tested by adding known amounts of psilocin and psilocybin to Psathyrella foenisecii and Psathyrella baeocystis. The effectiveness of this method was later confirmed by Gartz (1994). He studied the time course of the extraction in six different mushroom species and found that the time to maximal yield differed between the species. None was completely extracted in 30 minutes and two needed more than six hours. Maximum yield was obtained for all species in 12 hours.

Sottolano and Lurie (1983) investigated the effect of ultrasonication on the extraction yield of psilocybin. They found that treatment of finely powdered mushroom material with methanol, in an ultrasonic water bath breaks up the mushroom tissue matrix sufficiently to allow over $95 \%$ extraction yield in less than 1 hour. The mushroom species used in this experiment was not specified.

Vanhaelen-Fastré and Vanhaelen (1984) extracted psilocin, psilocybin and baeocystin as ion pairs with 1-heptanesulphonic acid in a mixture of ethanol and water. Finely ground dried specimens of Psilocybe semilanceata were allowed to macerate for 2 hours in a micropercolator. After percolation of the first solvent fraction, the percolation was repeated with a fresh solvent. The yield of psilocybin by this method was $99 \%$.

Kysilka and Wurst (1990) reported a new extraction method for psilocybin and psilocin in mushroom samples (Psilocybe bohemica). They investigated the influence of the composition of the extraction solvent on the extraction yield and found that these compounds are best extracted separately. The optimal solvent for the extraction of psilocybin was $75 \%$ methanol saturated with potassium nitrate and $75 \%$ ethanol for psilocin. They stated that conventional extraction with methanol would only extract $76 \%$ of the psilocybin content and $8 \%$ of the psilocin content as compared to the new method. The study was criticized by Gartz (1994), who was unable to confirm their findings. He found that more psilocin but less psilocybin was constantly extracted with aqueous mixtures of methanol or ethanol compared to pure methanol. At the same time he found high phosphatase activity in the aqueous extracts but not in extracts from pure methanol. It has previously been demonstrated that psilocybin is readily hydrolysed to psilocin by phosphatases (Horita and Weber, 1961, 1961a). Although he did not confirm it by experiments he ascribed the high yield of psilocybin reported by Kysilka and Wurst (1990) to hydrolytic cleavage of psilocybin to psilocin by phosphatases extracted from the mushrooms. Unfortunately Kysilka and Wurst (1990) did not investigate whether extraction of psilocin from the samples had any effect on the psilocybin content of the same samples.

Anastos et al. (2006a) extracted psilocybin and psilocin with methanol, separated the compounds on a C12 column using a methanol/ ammo- 
nium formate mixture as mobile phase, and detected the compounds through a dual reagent chemiluminescence detection system of acidic potassium permanganate and tris(2,2' - bipyridyl)ruthenium (II). During these studies it was observed that the aquous chemical standards of psilocybin and psilocin are prone to be degraded by light. However, taking care of protecting the standards from light, they are stable for at least one week (Anastos et al., 2006b).

From these studies it can be seen that the extraction of psilocybin and psilocin from mushroom samples deserves further investigation. It still remains unclear whether the high psilocin content reported by Kysilka and Wurst (1990) and Wurst et al. (1992) in some species is an artefact. Moreover the time course of the extraction under different experimental conditions needs to be thoroughly studied.

\subsubsection{Quantitative determination of psilocybin and psilocin in mushroom samples}

As shown in Table 2 almost all published methods for the quantitative determination psilocybin and psilocin have utilized some kind of chromatography to separate them from other co-extracted compounds. In their original identification of psilocybin and psilocin in Psilocybe mexicana, Hofmann and co-workers (1958a) used chromatography on a cellulose column. After a further purification and crystallization procedure, the isolated substances were quantitated by weighing. McCawley et al. (1962) adopted this method when analysing samples of Psilocybe baeocystis. Instead of weighing the isolated substances they quantified them by ultraviolet spectrophotometry.

Although paper and thin-layer chromatography have mostly been used for the qualitative analysis of these substances, some authors have used them quantitatively. Catalfomo and Tyler (1964) used a serial dilution procedure to quantify psilocybin on paper chromatograms after reaction with 4-dimethylaminobenzaldehyde. Robbers et al. (1969) used the same method to quantify psilocybin on thin-layer chromatograms and a similar approach was used by Neal et al. (1968). Gartz (1986a) extracted psilocybin and baeocystin from thin-layer chromatograms and quantified them by measuring the colour formed after reaction with 4-(dimethylamino)benzaldehyde.

Due to its versatility high-performance liquid chromatography is the most popular method for the determination of psilocybin and psilocin in mushroom samples. Normal phase chromatography on a silica column is the simplest form of this technique. It was used qualitatively by White (1979) and for quantitative analysis by Christiansen et al. (1981a, 1981b, 1982), Christiansen and Rasmussen (1983) and Jokiranta et al. (1984). By this method Christiansen and Rasmussen obtained an excellent separation of the indole alkaloids present in Norwegian Psilocybe semilanceata. It 
has been stated that silica columns are susceptible to contamination from polar materials that shorten column life and are less reproducible than bonded columns (Thomson, 1980; Lindsay, 1987). This may explain why they have not gained popularity in the analysis of these substances.

The most versatile bonded columns are those with non-polar groups like octyl (C8) or octadecyl (C18) hydrocarbon chains attached. As can be seen in table 2 C18 is the most widely used column for these purposes. Because of the hydrophobic nature of the stationary phase psilocybin is only weakly retained on this type of column and therefore prone to interference from coextracted, water soluble impurities. Another disadvantage of using these columns is that the different polarity of psilocybin and psilocin makes simultaneous analysis difficult. The problem may be solved, at least in part, by using a mobile phase gradient (Borner and Brenneisen, 1987) or by using two different solvent systems for these two compounds (Kysilka and Wurst 1990). In none of the published methods using C18 columns under isocratic conditions was it confirmed whether these systems were able to separate psilocibin and its demethylated analogue, baeocystin (Stijve et al., 1984, 1985; Wurst et al. 1984; Semerdžieva et al., 1986; Gartz, 1987a, 1989b; Kysilka et al., 1985; Kysilka and Wurst 1989; Gartz \& Müller, 1989; Kysilka \& Wurst, 1990; Wurst et al. 1992).

Several authors (Thomson, 1980; Stamets et al., 1980; Beug and Bigwood, 1981, 1982; Vanhaelen-Fastré and Vanhaelen, 1984; Ohenoja et al., 1987) have separated these substances as ion-pairs with ion-pair reagents on hydrocarbon bonded phase columns. However, it should be kept in mind that it is virtually impossible to remove completely an ionpair reagent from such columns and they are therefore not reusable with other mobile phases (Gill 1986).

Psilocybin and psilocin have excellent absorption characteristics in the ultraviolet region, both exhibit native fluorescence and they are electrochemically active. These features have all been used to monitor the effluent from the chromatographic column. Although ultraviolet spectrophotometry is the most commonly used method (Table 2) greater sensitivity may be obtained by other methods (Perkal et al., 1980; Wurst et al., 1992). Increased specificity has been obtained by connecting two or more of these detectors in series (Christiansen and Rasmussen, 1983; Wurst et al., 1992).

Only three authors have described gas chromatographic methods to quantify psilocybin and psilocin in mushroom samples (Repke et al., 1977; Keller et al., 1999a, 1999b; Kikura-Hanajiri et al., 2005). The reason is, without doubt, the low volatility of psilocybin, which makes derivatization necessary prior to analysis. This technique is therefore rather impractical as compared to high-performance liquid chromatography. Both authors used silylation, where psilocybin was converted to its tris-(trimethylsilyl) derivative and psilocin to its bis-(trimethylsilyl) derivative. 
Recently Pedersen-Bjergaard et al. $(1997,1998)$ developed a capillary zone electrophoretic method to determine psilocybin and other indole alkaloids in Psilocybe semilanceata. Although this method seems to be a promising alternative to high-performance liquid chromatography it did not allow a simultaneous determination of psilocybin and psilocin.

This review shows that none of the published methods seems to offer a totally satisfactory solution to the analysis of psilocybin and psilocin in mushroom samples. Further research in this field is therefore needed.

\subsubsection{Qualitative analysis of psilocybin and psilocin in mushroom samples}

Although the aforementioned instrumental chromatographic techniques are all usable for screening of mushroom samples for psilocybin and related substances, most authors have used thin-layer chromatography. It offers the possibility of using more or less group specific detection reagents, which makes it even more versatile and specific than most of the quantitative methods. In Table 3 are listed the thin-layer chromatographic systems reported for the identification of psilocybin and closely related substances. The most commonly used system is n-butanol-acetic acid-water (2:1:1). It has the disadvantage that psilocybin and baeocystin are not well separated. A mixture of these solvents in the proportions 12:3:5 gives a better separation of these two substances. However, the systems cyclohexane:chloroform (1:1) (Leung et al., 1965) and n- propanol-acetic-acidwater (10:3:3) (Vanhaelen-Fastré and Vanhaelen, 1984) seem to give the best overall separation of psilocybin, psilocin and baeocystin.

Paper chromatography, the forerunner of thin-layer chromatography, was the most commonly used screening method in the first years after the discovery of psilocybin and psilocin (Hofmann et al. 1958a, 1958b). Tyler (1961) used paper chromatography with three different solvent systems to identify indole derivatives in certain North American mushrooms. He identified psilocybin in Psilocybe pelliculosa on a filter paper buffered to $\mathrm{pH}$ 5. The mobile phase was n-butanol saturated with water. This same system was later used by Benedict et al. (1962a, 1962b, 1967), Picker and Rickards (1970), and Ott and Guzmán (1976). The other systems described by Tyler (1961) were the upper phase of n-butanol-acetic acid-water (4:1:5) and n-propanol-ammonia (5:1) (see also Benedict et al. (1962a, 1962b, 1967)). Other solvent systems that have been used for these purposes are n-butanol-acetic acid-water (12:3:5) (Ott and Guzmán, 1976) and n-butanol-acetic acid-water-isopropanol (8:2:5:3) (Michaelis, 1977). 


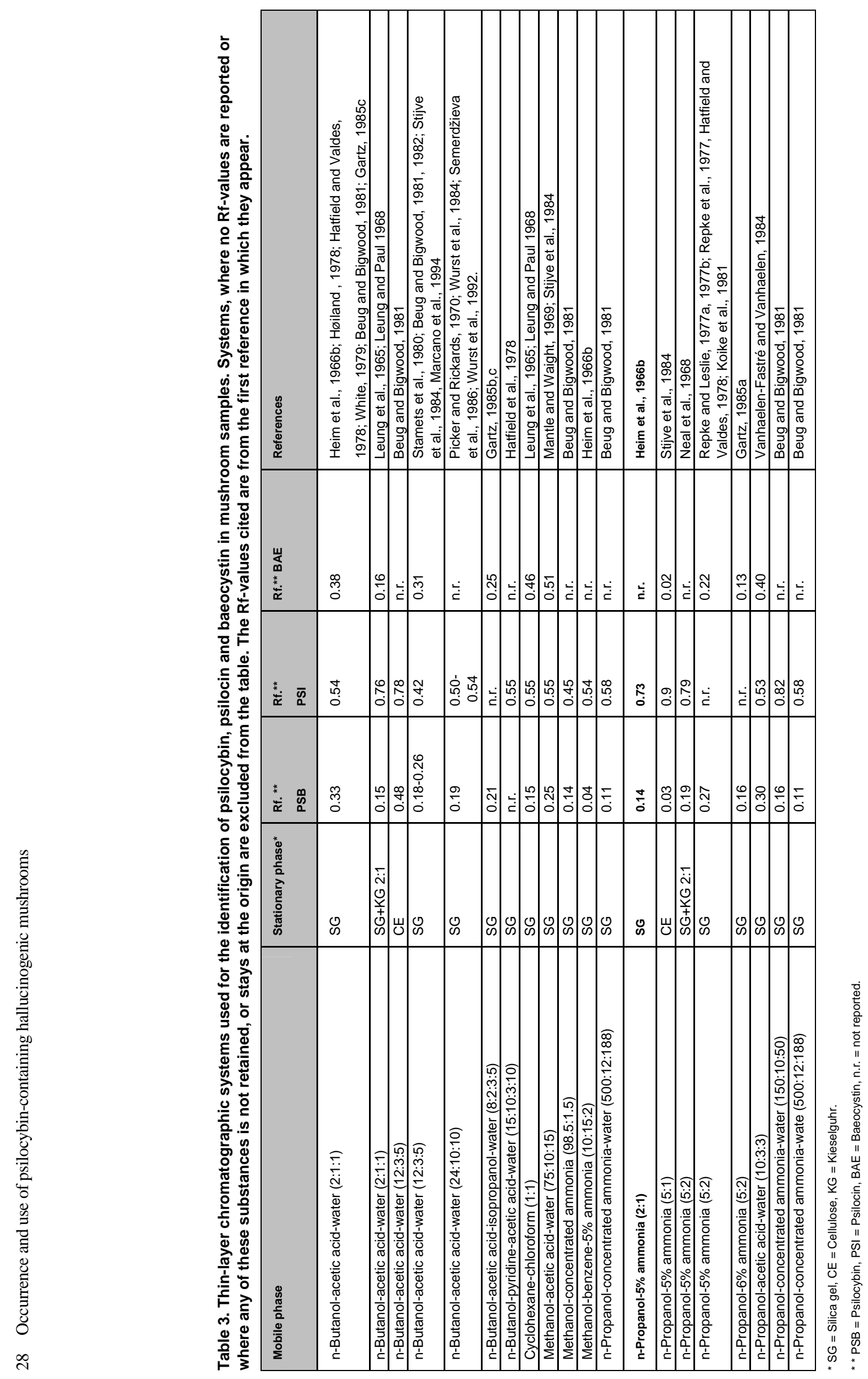


The most commonly used reagent to detect indole alkaloides on paper or thin-layer chromatograms is 4-(dimethylamino)-benzaldehyde (DMAB). It is usually applied in a mixture with strong hydrochloric acid (Ehrlich's reagent) or followed by exposition to hydrogen chloride fumes. DMAB reacts at position 3 in the indole ring to form a coloured derivative (Jork et al., 1994). An alternative to this reagent is 4-(dimethylamino)-cinnamaldehyde in a mixture with strong hydrochloric acid. This reagent was found more sensitive than the Ehrlich's reagent and gave more varied colours (Stijve et al., 1984, 1985). Among other reagents that have been reported for the localisation of psilocybin and related alkaloids are diazotized sulfanilic acid (Pauly's reagent) (Tyler, 1961; Benedict et al., 1962a, 1967), ceric sulphate and an alkaline solution of Fast Blue B (Heim et al., 1966b).

Finally it should be mentioned that non-chromatographic techniques have also been used to identify psilocybin and other indole alkaloids in mushroom samples. Unger and Cooks (1979) used mass spectrometry/mass spectrometry (MS/MS) to identify psilocybin in powdered mushrooms and mushroom extracts. Lee (1985) isolated and identified psilocin from psilocin/psilocybin containing mushrooms by UV and IRspectrophotometry. The method is based on the hydrolysis of psilocybin to psilocin and a selective extraction of psilocin from the extracts by 1chlorobutane. Recently Keller et al. (1999a, 1999b, 2006) used ion mobility spectrometry to identify psilocybin and psilocin in finely cut samples of Psilocybe subcubensis. The method is highly sensitive but not entirely specific since psilocybin is thermally degraded to psilocin during analysis. In line with developments in analytical methodology also liquid chromatography-mass spectrometry (LC-MS) and liquid chromatography-tandem mass spectrometry (LC-MS-MS) have been used to determine psilocybin and psilocin in samples of 'magic mushrooms' (Kamata et al., 2005). In particular the tandem mass spectrometry provided improved specificity and accuracy.

\subsubsection{Analysis of psilocybin and psilocin in human fluids and tissues}

Moeller and Kraemer (2002) described procedures for detection of drugs of abuse in whole blood, plasma, and serum. Reviewing what is known about psilocybin/psilocin they identify Sticht and Käferstein (2000) to be first to report the identification of psilocin in serum in a subject after magic mushroom intake. However, the amount was to low to be quantified by common analytical methods.

Psilocybin can not be detected with GC-MS because of its phosphoric acid structure. The analysis has to focus on psilocin but as psilocin is thermally labile, it requires derivatization before being analysed by GCMS (Ondra et al., 2006; Tiscione and Miller, 2006). To quantify the internal dose of mushroom hallucinogens, psilocin conjugates should be cleaved enzymatically, extracted and, if required, derivatized (silylated) 
before being determined by suitable instrumentation. Sticht and Käferstein (2000) found $18 \mathrm{ng} / \mathrm{ml}$ free psilocin in serum, but the total psilocin content was $52 \mathrm{ng} / \mathrm{ml}$.. It is to be expected that LC-MS will be a suitable technique for determination of psilocybin and psilocin in various biomatrices (Drummer, 1999; Polettini, 1999; Bogusz, 2000). For example, Bogusz et al. (2000) reported a limit of detection of $1 \mu \mathrm{g}$ psilocin/L serum using a LC-electrospray ionization (ESI)-MS system.

Exposure to psilocybin-containing mushrooms or drugs can also be documented by urinary analysis. As psilocin glucuronide is an important excretion product in urine, Kamata et al. (2003) developed an optimized glucuronide hydrolysis method for the detection of psilocin by LC-MSMS in human urine. Recently, Ramirez Fernandez et al. (2007) reported a validated LC-MS-MS method for the simultaneous analysis of multiple hallucinogens, including psilocin, in urine of subjects that have ingested hallucinogenic mushrooms.

In addition to the GC-MS and LC-MS methods developed, a single immunoassay for analysis of psilocin in serum and blood samples has been published (Albers et al., 2004). This method makes use of a polyclonal rabbit antisera developed against a psilocin hapten conjugate (Albers et al., 2002). Cross-reactivity of structurally related compounds were usually limited but reached close to $20 \%$ for tricyclic neuropeptics with a (dimethylamino)ethyl side-chain. This method is, however, unlikely to become important in the analysis of forensic samples potentially containing psilocybin/psilocin. 


\section{Biosynthesis}

Experimental evidence regarding the biosynthesis of psilocybin and psilocin is limited. The structural similarity between these compounds and tryptophan indicate they might be derived from that amino acid. In 1961 Brack and co-workers showed that labelled tryptophan was incorporated into psilocybin by cultured mycelium of Psilocybe semperviva. Subsequently, labelled tryptophan was found to be incorporated into psilocybin also in submerged cultures of Psilocybe cubensis (Agurell et al., 1966). Separate studies showed that addition of tryptophan to the culture medium had no influence on the biosynthesis of psilocybin in Psilocybe cubensis and Psilocybe baeocystis (Catalfomo and Tyler, 1964; Leung and Paul, 1969). It is not known to what extent the data obtained from studies on mycelial cultures are representative for the biosynthesis in fruit bodies grown in the wild.

To produce psilocybin, the tryptophan molecule has to be modified by decarboxylation, methylation of the amino group, hydroxylation of the 4position of the indole moiety, and phosphorylation of the 4-hydroxyindole moiety; although not necessarily in the above order. Since tryptamine functioned as a better precursor for psilocybin synthesis than tryptophan in cultured Psilocybe cubensis, it seems probable that decarboxylation of tryptophan to tryptamine is the first step in the biosynthesis of psilocybin (Agurell et al., 1966). In agreement with this observation, 4hydroxytryptophan was found to be a very poor precursor to psilocybin (Agurell and Nilsson, 1968a).

The biosynthetic route from tryptamine to psilocybin is much more controversial. Available data (Agurell and Nilsson, 1968a; 1968b; Chilton et al., 1979) from studies on Psilocybe cubensis are consistent with the psilocybin biosynthes shown in Figure 2.

Using mini-cultures of Psilocybe cubensis and deuterium-labelled precursor solutions, Chilton et al. (1979) found that a wide range of tryptamines were readily absorbed by mycelia and translocated into developing mushrooms. Deuterated tryptamine was incorporated more efficiently into psilocin and psilocybin than were monomethyltryptamine and dimethyltryptamine. Both of the latter two compounds were incorporated, however, without prior demethylation to tryptamine. These data suggests that the hydroxylation enzyme operates normally on tryptamine, but may be sufficiently flexible to oxidise dimethyltryptamine or other natural substrates forced on it at high concentration. The hydroxylation of dimethyltryptamine in mini-cultures to give psilocin was observed to occur with NIH shift. Thus a tryptamine-4,5-epoxide is the probable intermediate between tryptamine and psilocin. 
In studies on mycelial cultures of Psilocybe cubensis, which are capable of forming psilocybin and psilocin de novo, german investigators, in agreement with the above referred findings, observed a high capacity for hydroxylation of tryptamine and tryptamine derivatives at the 4-position. Although no data was shown on the hydroxylation of $\mathrm{N}, \mathrm{N}-$ dimethyltryptamine to psilocin, the mushroom efficiently hydroxylated tryptamine to psilocin (and much less efficiently to psilocybin) (Gartz, 1989c), and N,N- diethyltryptamine to 4-hydroxy-N,N-diethyltryptamine (up to $33000 \mathrm{mg} / \mathrm{kg}$ dry weight) (Gartz, 1989b). Parallel investigations with mycelial cultures of Psilocybe semilanceata revealed that also this mushroom was able to biotransform N-methyltryptamine to 4phosphoryloxy-N-methyltryptamine (baeocystin). Comparatively little psilocin was produced. These observations indicate that surface cultures of Psilocybe semilanceata have a high hydroxylation and phosphorylation capacity, although the ability to methylate tryptamine derivatives is low. Thus, the latter observation agree with the finding of Agurell and Nilsson (1968b) that psilocybin may be formed from 4-hydroxytryptamine (in cultures of Psilocybe cubensis), were this compound to be formed in the mushrooms.

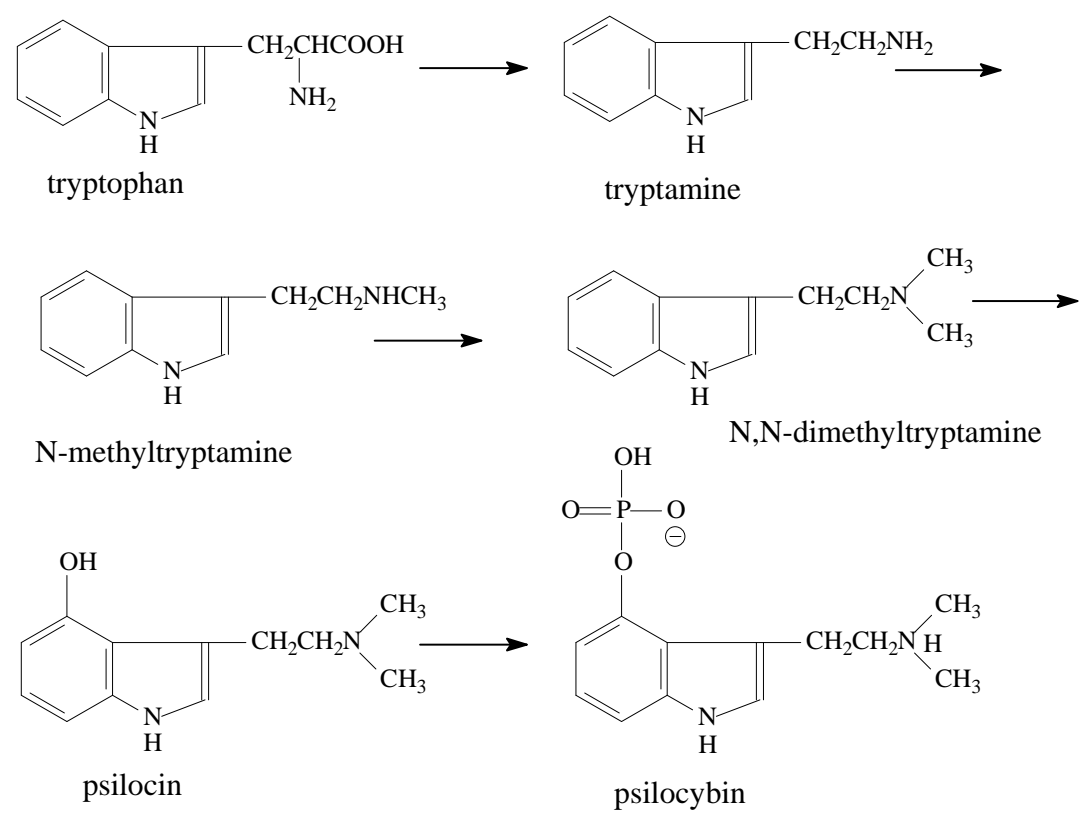

Fig. 2.A tentative pathway for the biosynthesis of psilocybin from tryptophan. The model is based on data obtained in studies on submerged cultures of Psilocybe cubensis (Agurell and Nilsson, 1968a, 1968b; Chilton et al., 1979). 


\section{Occurrence}

The first identification of ritual 'teonanácatl' samples took place in 1939 and revealed that more than one mushroom species was used by the shamans. The identified mushrooms were Panaeolus campanulatus var. sphinctrinus, Panaeolus acuminatus, Psilocybe cubensis and Psilocybe caerulescens (Guzmán, 1983). After psilocybin, psilocin, baeocystin, norbaeocystin and aeruginacin initially being identified in Psilocybe mexican, Psilocybe baeocystis and Inocybe aeruginascens (Hofmann et al., 1958a; Leung and Paul, 1968; Gartz, 1989a), respectively, the hallucinogenic compounds were also detected in other mushrooms growing in various parts of the world.

\subsection{Content of psilocybin and related compounds in various mushroom species}

Table 4 tabulates the analytical data on psilocybin, psilocin and/or baeocystin content in various mushrooms available in the litterature. Lists of this type require correct identification of the mushrooms. In practise, this is unlikely due to the sometimes poorly developed and often progressivly developing taxonomy, and the difficulties in accurately identifying the various mushroom species. The present authors have not changed the information of the original author unless this is obviously motivated, e.g. when it is commonly accepted that a mushroom has been transferred from one genus to another.

Psilocybin, psilocin and/or baeocystin have been identified in the genera Agrocybe, Conocybe, Copelandia, Geerronema, Gymnopilus, Hygrocybe, Hypholoma, Inocybe, (Panaeolina), Panaeolus, Pluteus, Psathyrella, Psilocybe and Stropharia. Of the about 190 different mushrooms which have been analysed for psilocybin, psilocin or beaocystin, about 90 have been identified to contain at least one of these hallucinogenic compounds and in more than 60 of the cases the levels have been quantified. In the genus Psilocybe 41 out of 55 species(or varieties) contain psilocybin or related compounds, whereas the corresponding figures for the genus Panaeolus are 9 out of 26 species. Hallucinogenic compounds also seem to be common in the genus Gymnophilus.

The table also states which analytical techniques have been used to identify and quantify the hallucinogens. Additional information available in Table 4 is a statement on whether the analysed mushrooms material were harvested from cultures in the laboratory as fruit bodies (C), scle- 
rotia (Sc), submerged mycelium culture (S) or mycelium (M). When collected in the wild, the country of origin is given. It should be noted that partial degradation of psilocybin, psilocin and/or baeocystin may have taken place in the dried materials from herbarial collections.

It has been argued that the ability to synthesise psilocybin and related compounds can be used as a toxonomic criterion. The background for this suggestion is that all mushroom samples of a species collected from different areas of the world contain the investigated compounds. For example, fruit bodies of Psilocybe cubensis grown from spores obtained from such different places as Mexico, Thailand and Cambodia all contained appreciable amounts of psilocybin and traces of psilocin (Heim and Hofmann, 1958a). However, in some species this character seems not to be stable. For these species there are both reports on the absence and the presence of psilocybin. Although it is clear that the ability to produce psilocybin and related compounds has a genetic background, not only genetic factors determine the level of these compounds in the mushrooms.

The complicated relationship between genetic closeness of different mushroom species and their ability to synthesise psilocybin has been explored for the genus Gymnophilus, since Gymnopilus spectabilis has been implicated in intoxications with hallucinogenic episodes (Hatfield et al., 1978; Walters, 1965; Buck, 1967; Romagnesi, 1964). The material in this investigation was 13 collections of mushrooms. In one toxiconomic treatment of Gymnopilus, the genus is divided into two subgenera (Аnnulati and Gymnopilus) based on the presence or absence of a persistent annulus. Of the 16 species in the Annulati group, five were screened for psilocybin. Whereas G. luteus, G. spectabilis and G. validipes contained psilocybin, it was absent from $G$. subspectabilis and $G$. ventricosus. The subgenus Gymnopilus has been subdivided into two sections - Microspori and Gymnopilus. Four of the 22 species found in section Microspori were screened and none contained psilocybin. The section Gymnopilus of subgenus Gymnopilus contains 33 species of which 10 were screened. Two of these, G. aeruginosus and G. viridans contained psilocybin, whereas the rest (G. aurantiophyllus, G. flavidellus, G. liquiritae, G. luteofolius, G. mitis, G. penetrans, G. picreus and G. sapineus) did not (Hatfield et al., 1978). The age of some of the collections (up to 21 years old) is likely in part responsible for the variability in psilocybin content measured in the various samples. However, this is probably not the only factor involved since psilocybin has been found to be quite stable in some dried herbarium samples. Another explanation of these results is that two or more subspecies exists in some of the Gymnopilus species (Hatfield et al., 1978).

Another illustration of the complicated relationship between genetic closeness and the ability to produce psilocybin is given by the taxa belonging to the genus Panaeolus, which are difficult to exactly identify. 
Differential anatomic criteria commonly used for identification do not permit a precise differentiation between the various species. Therefore, it is easy to understand that results of chemical studies on this genus are contradictory as they are done on poorly identified material (Ola' $\mathrm{h}$, 1968). In order to confirm the presence or absence of psilocybin and related compounds, chemical analyses were performed with wild fruit bodies, with fruit bodies from in vitro cultures, and with the dry matter of mycelial cultures (Ola'h, 1968). The results of these analyses indicate that the genus Panaeolus may be subdivided into three distinct groups, as far as their psychodysleptic power is concerned: the psilocybian species, the latent psilocybian species and the non-psilocybian species. The obvious problem here is the latent psilocybian species.

Genetic techniques based on polymerase chain reactions (PCR) of specific regions of the genomes have been developed to identify species and strains of various mushrooms (Lee et al., 2000a; Maruyama et al., 2003b). Using this approach, studies of ribosomal RNA genes (the large subunit) in Psilocybe and Panaeolus mushrooms have recently allowed the differentiation between psilocybin-producing and non-psilocybinproducing species, particularly of the genus Psilocybe (Moncalvo et al., 2002; Maruyama et al., 2003a, 2003b, 2006). The tested hallucinogenic mushrooms were classified into six groups (Maruyama et al., 2003b). The identification of psilocybin-producing and non-psilocybin-producing groups within Psilocybe might indicate that sometime during evolution an event such as loss of psilocybin biosynthetic enzymes or their transcription control factors might have occurred (Maruyama et al., 2003a). As DNA samples may be obtained from nearly all types of material, including forensic material, the method is useful with samples that do not allow identification of mushrooms by morphological methods. However, the fluorescence signal given in the TaqMan assay was influenced by the preservation time after harvest (Maruyama et al., 2003a). Lee et al. (2000b) have reported on another DNA-based test to identify hallucinogenic fungi. This test used the technique of amplified fragment length polymorphisms in combination with using a suitable set of different primers. Similarly, Nugent and Saville (2004) amplified and sequenced the internal transcribed spacer region of the rDNA (ITS-1) and a $5^{\prime}$ portion of the nuclear large ribosomal subunit of rRNA (nSLU rRNA) in 35 mushroom species belonging to hallucinogenic and non-hallucinogenic genera. Whereas the ITS-1 locus sequence data was highly variable and produced a phylogenetic resolution that was not consistent with morphological identification, the nLSU rRNA data clustred isolates from the same species and separated hallucinogen-containing and nonhallucinogen containing isolates into distinct clades. 


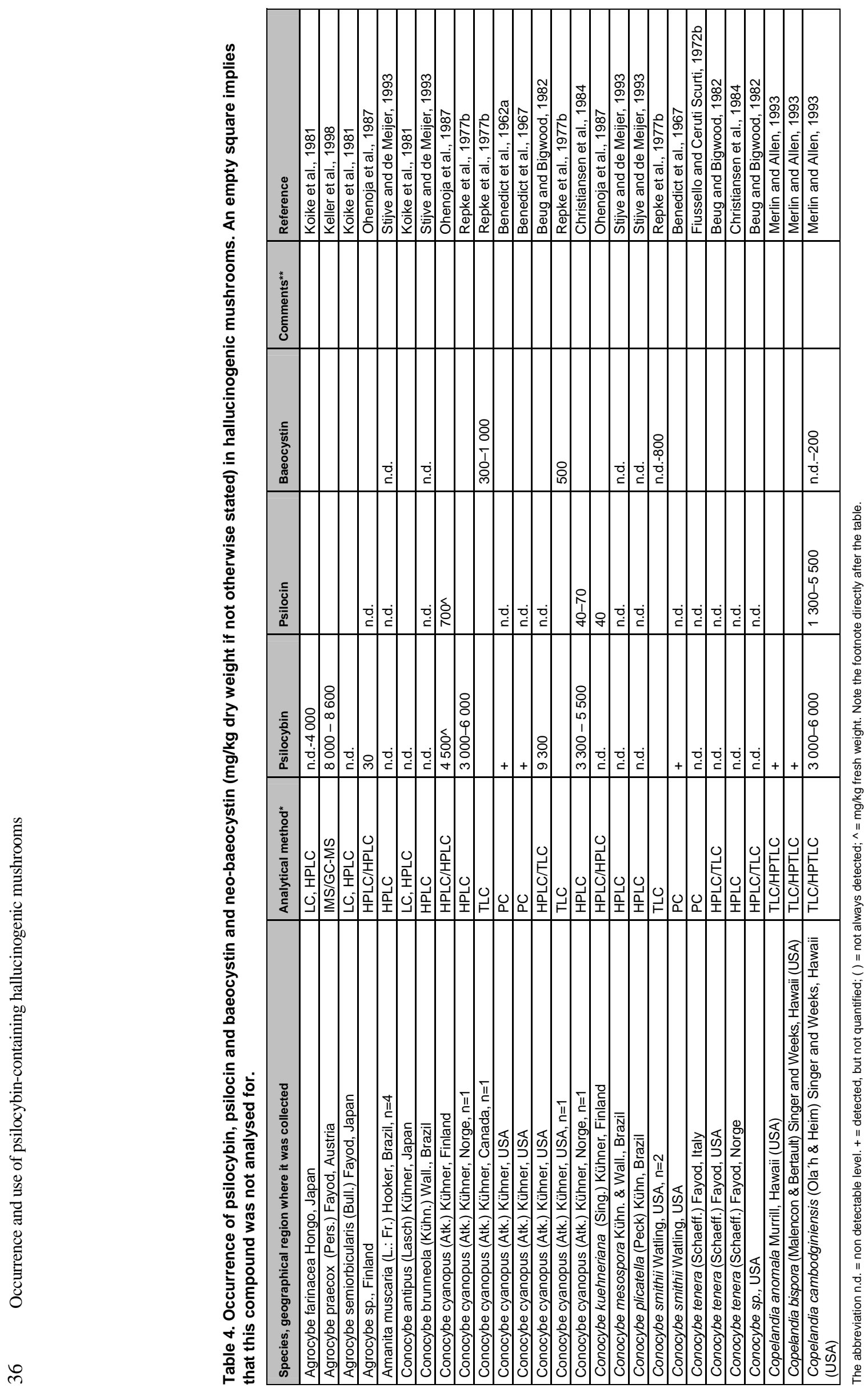


ले

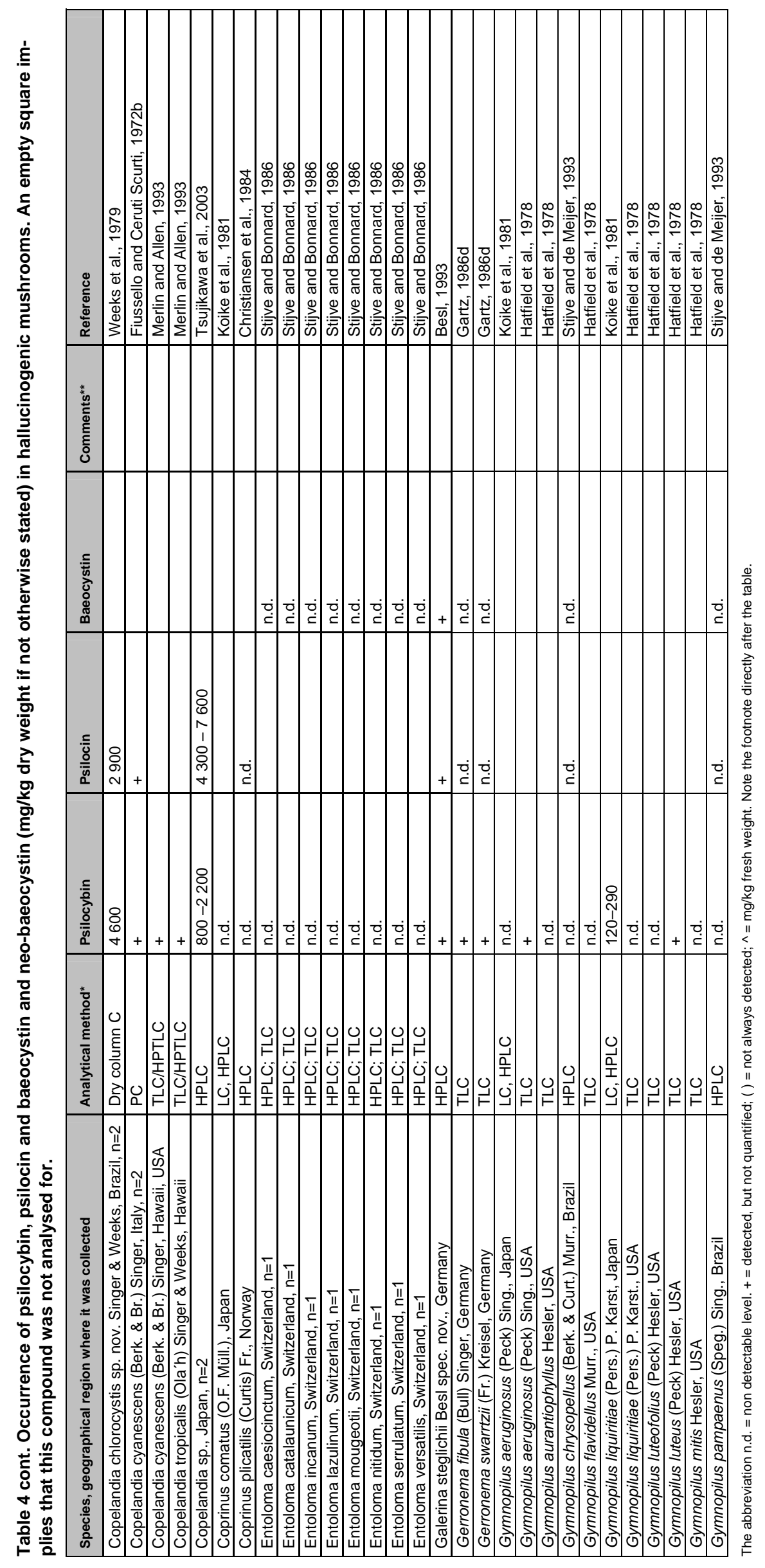




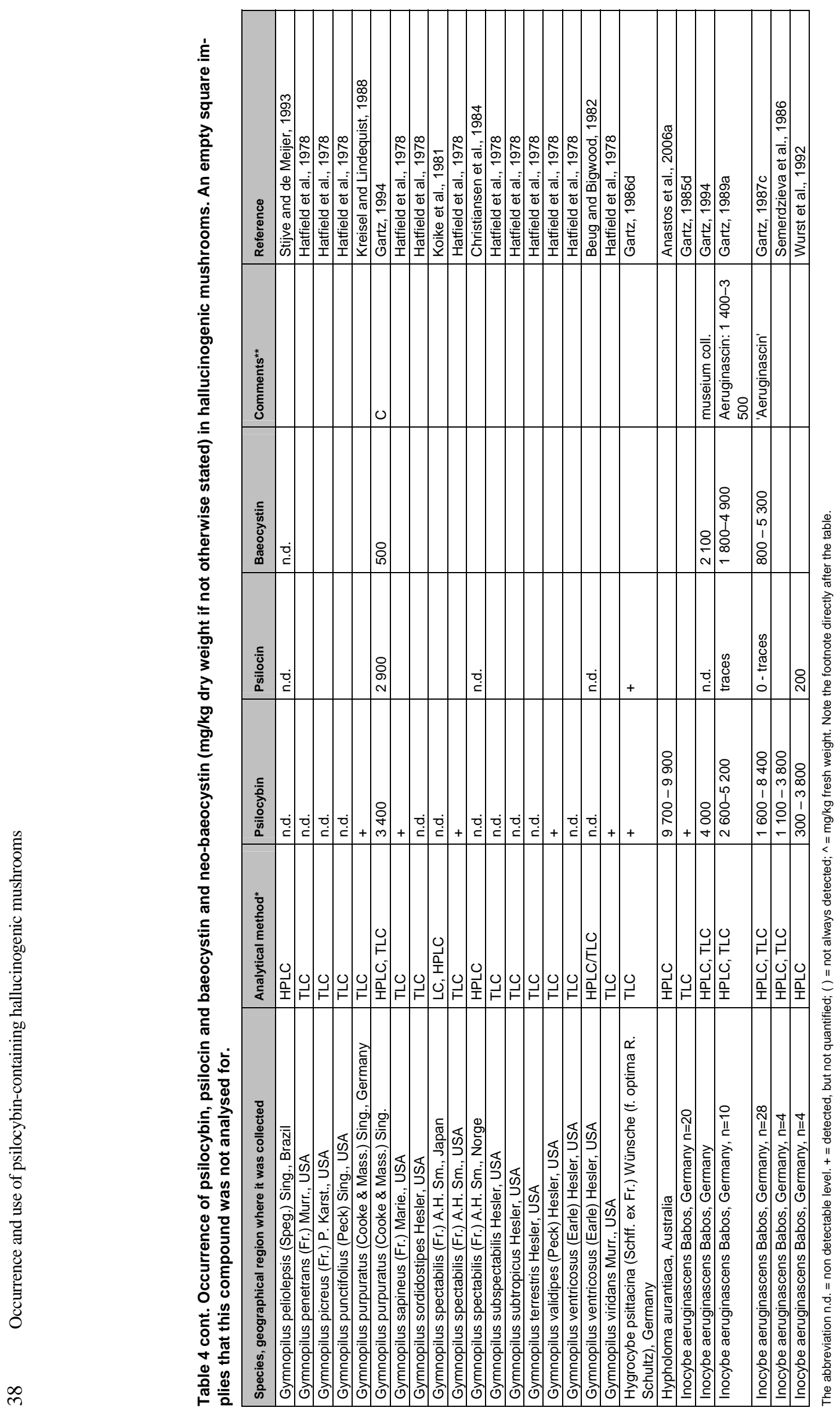


m

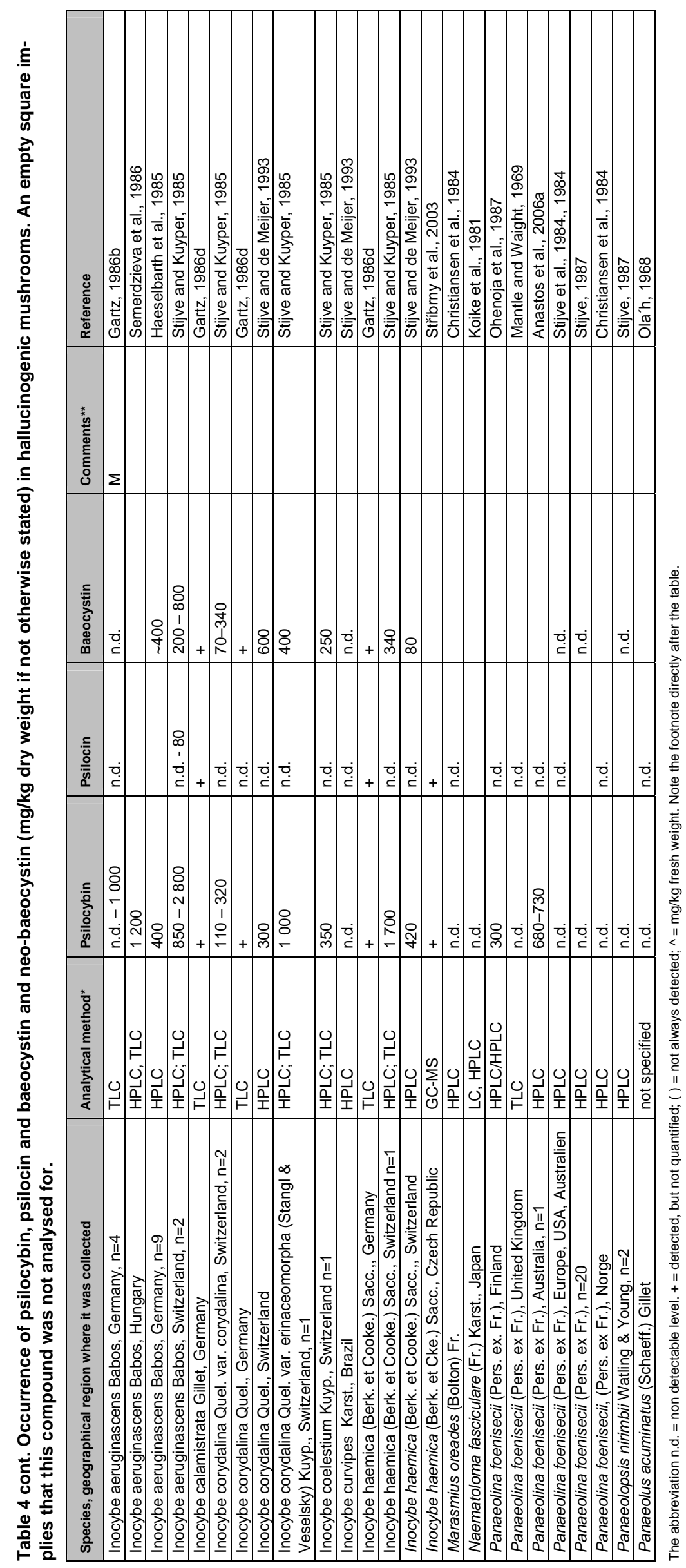




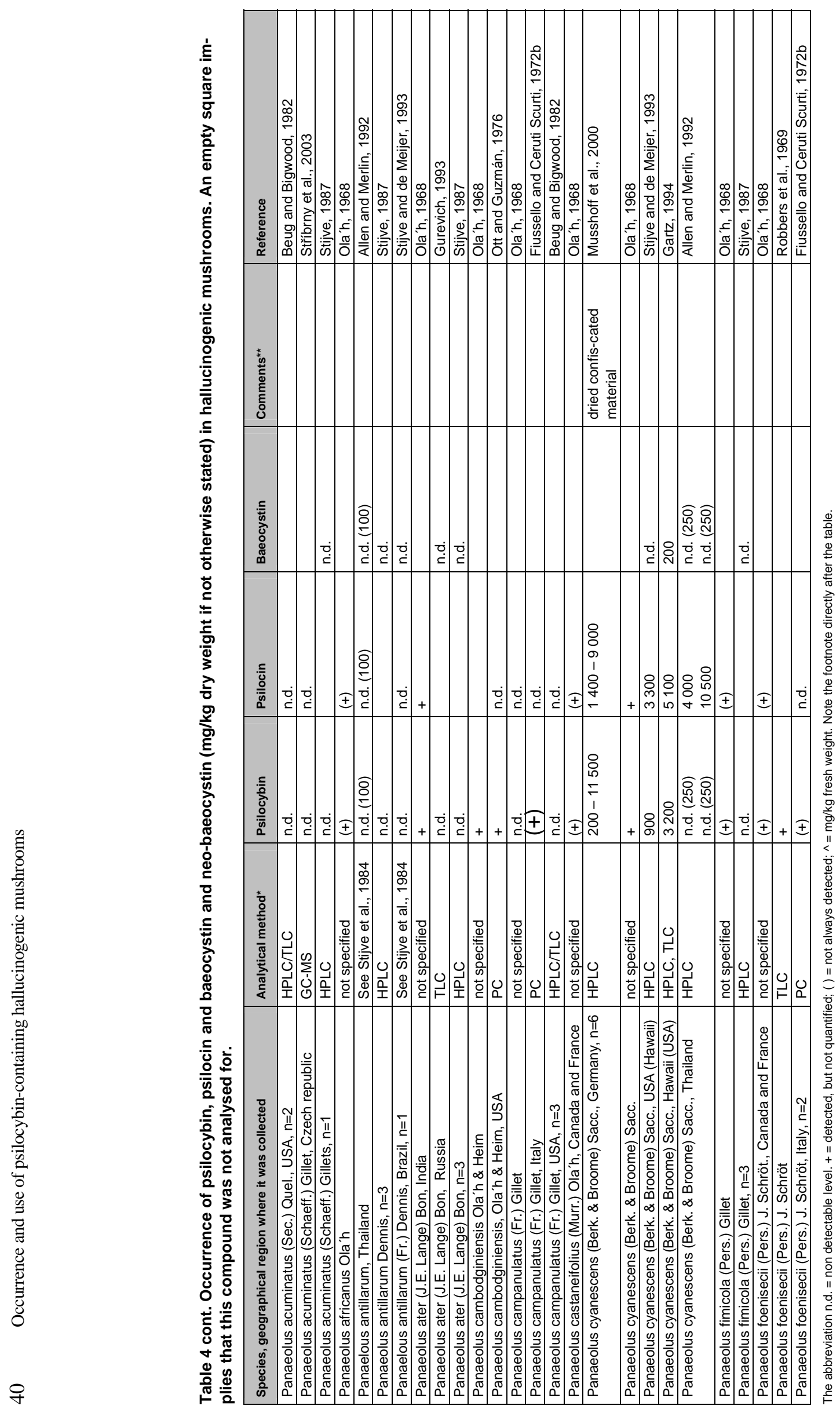




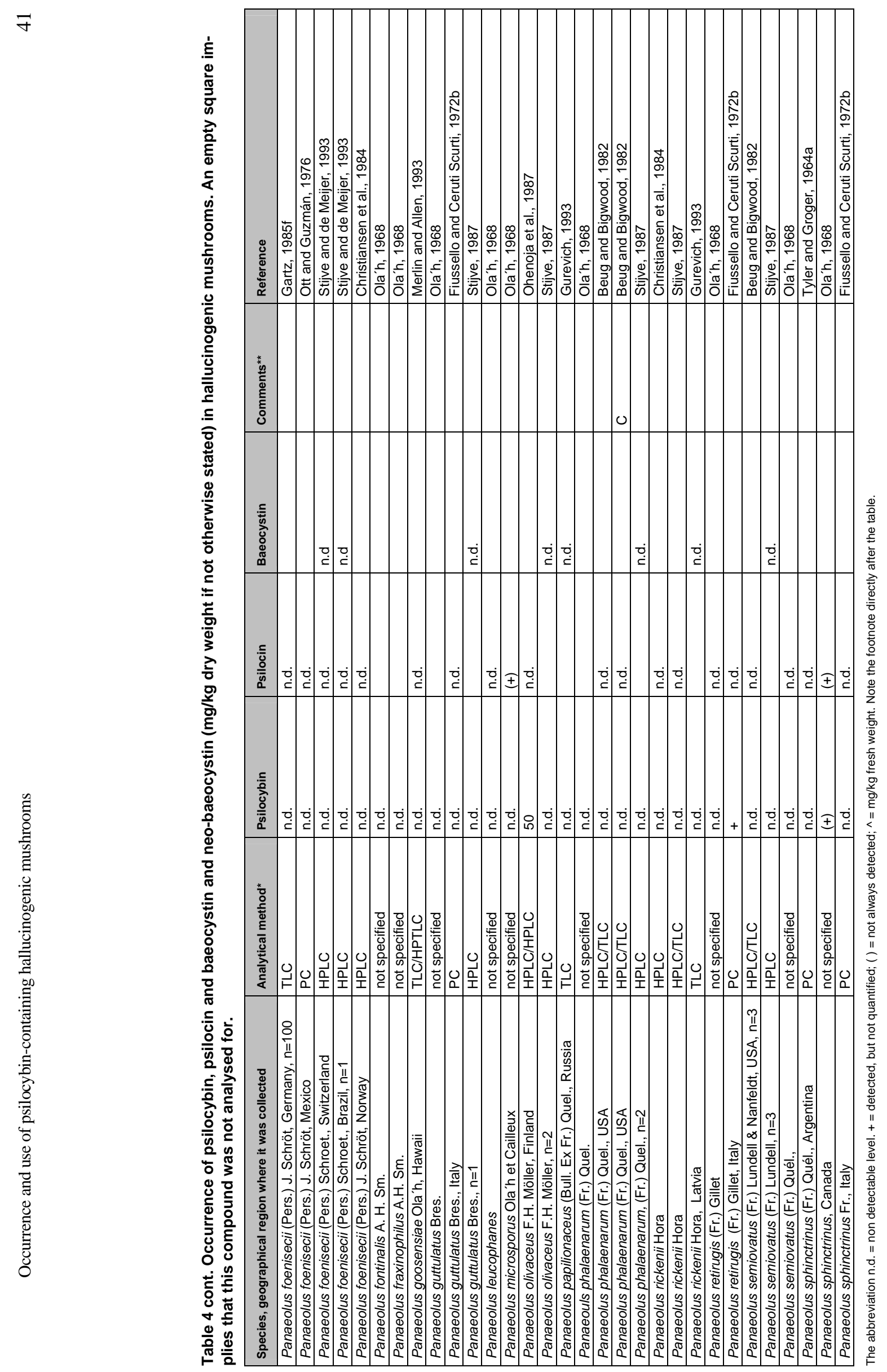




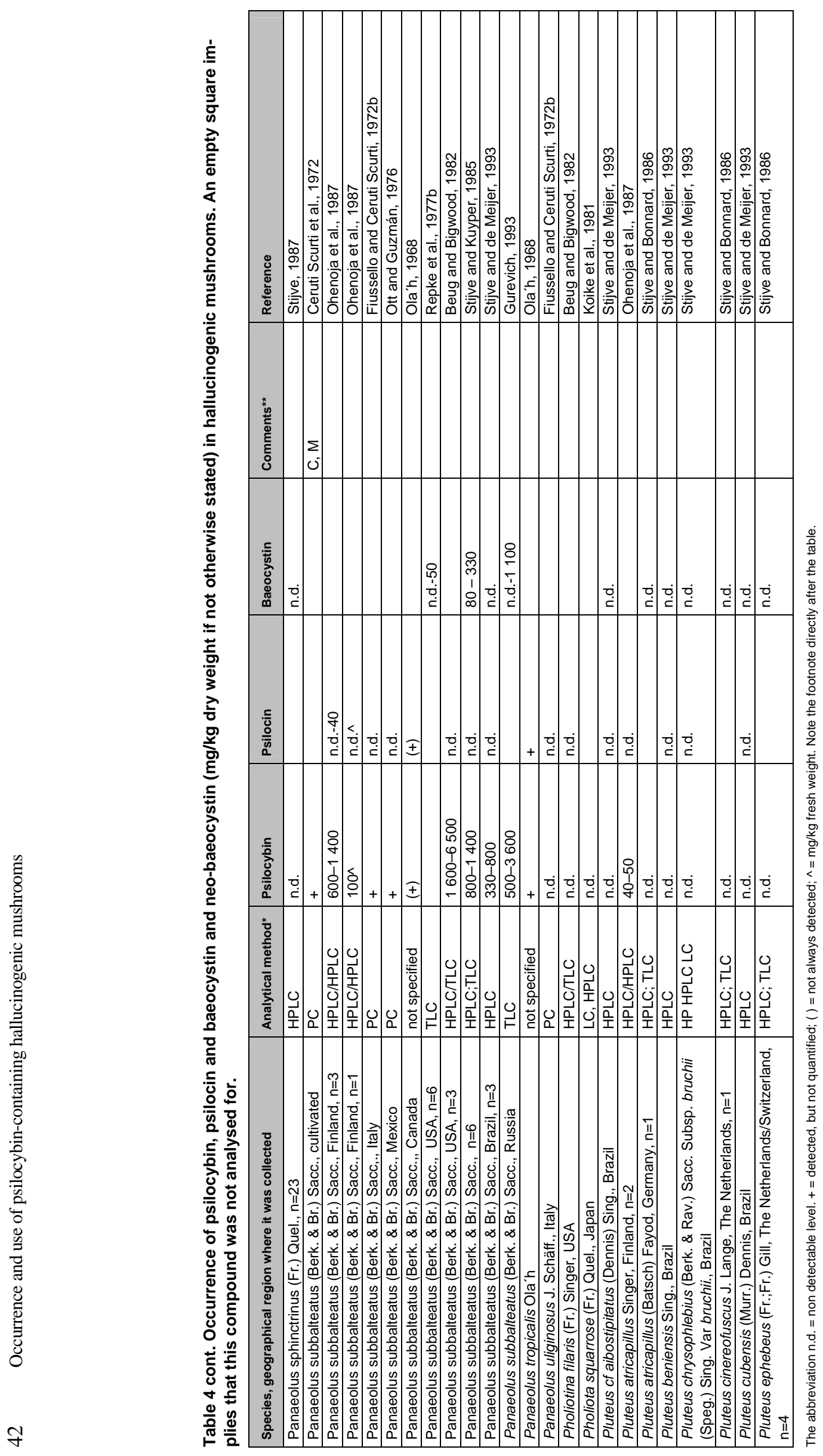




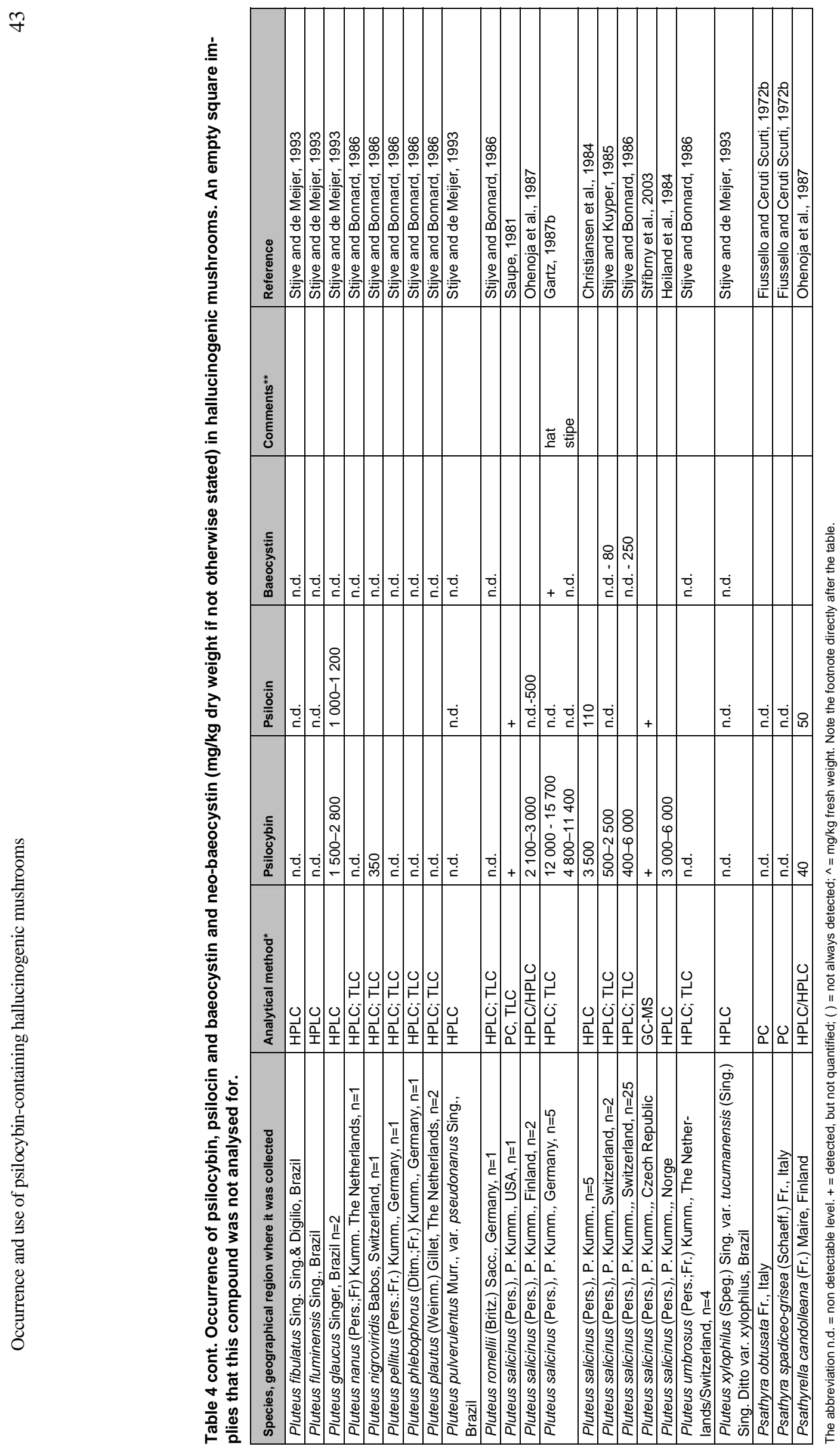




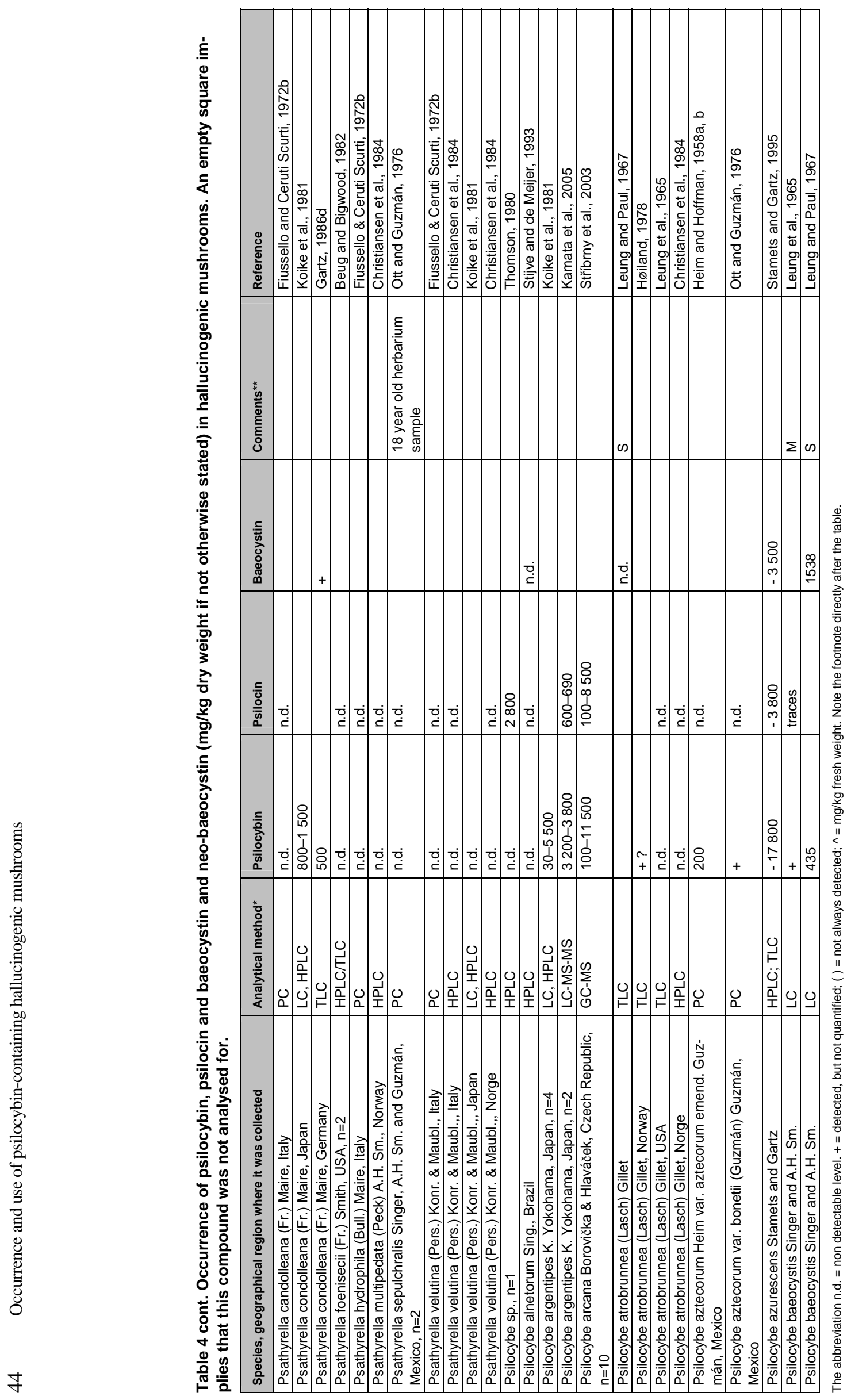




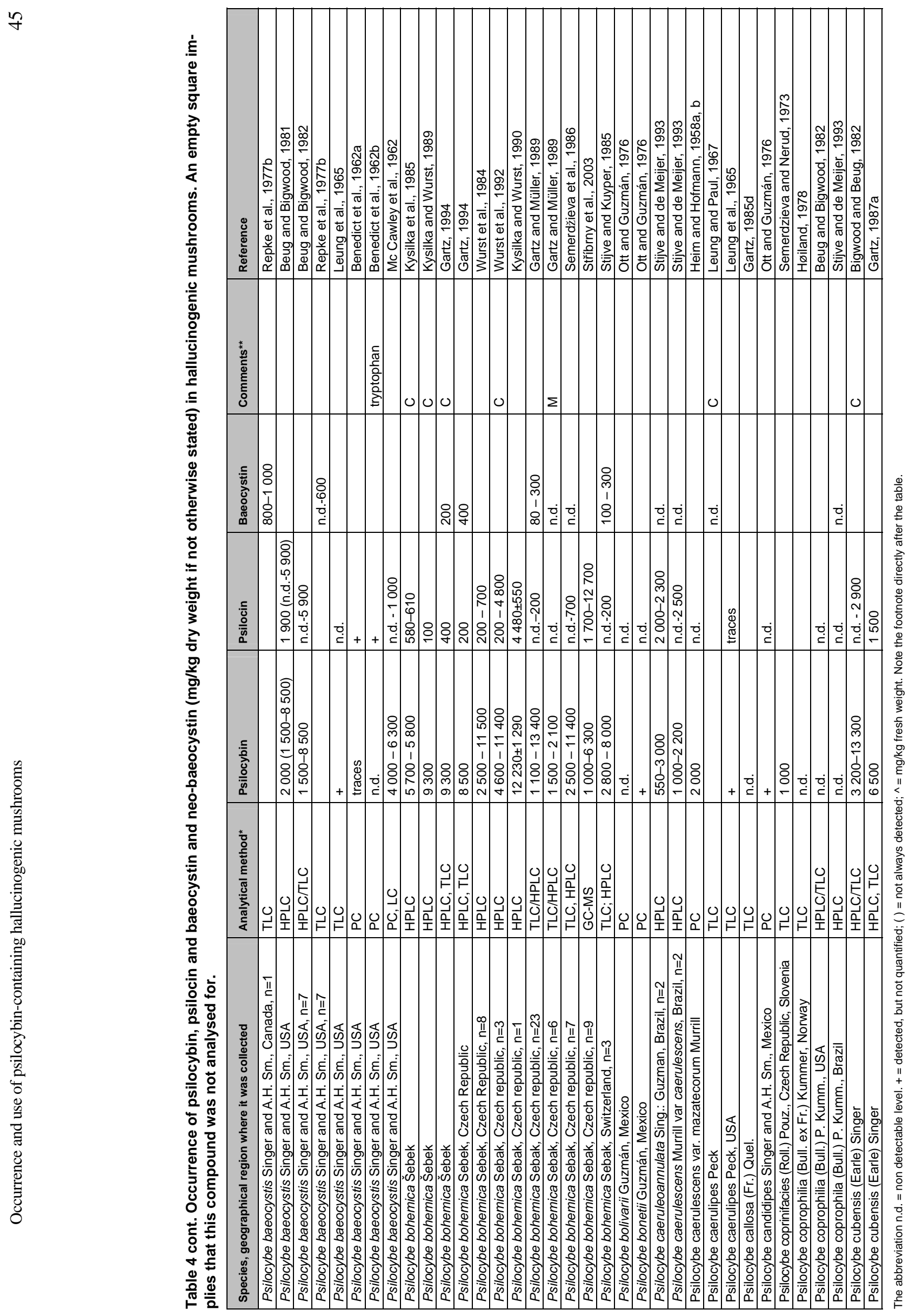




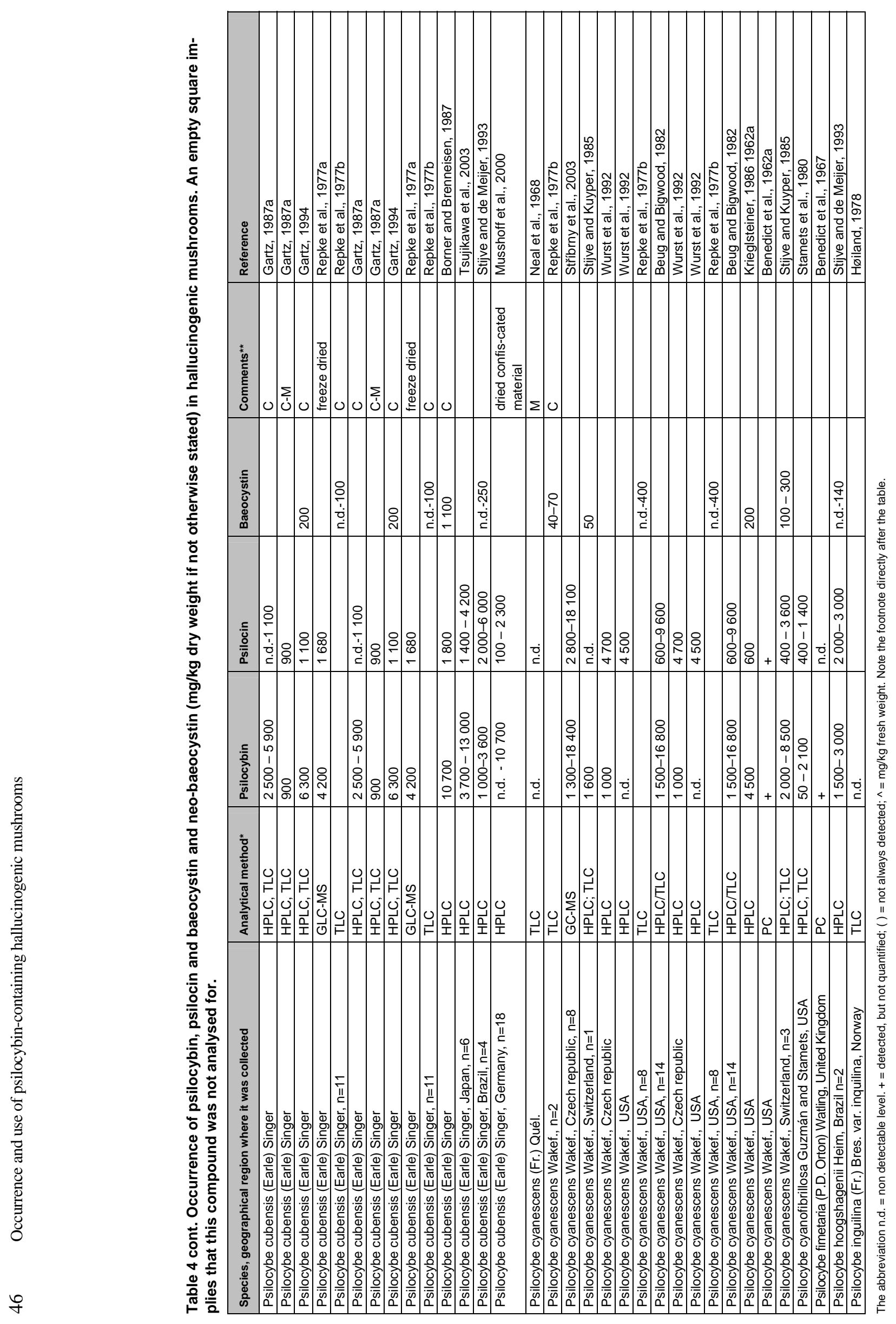




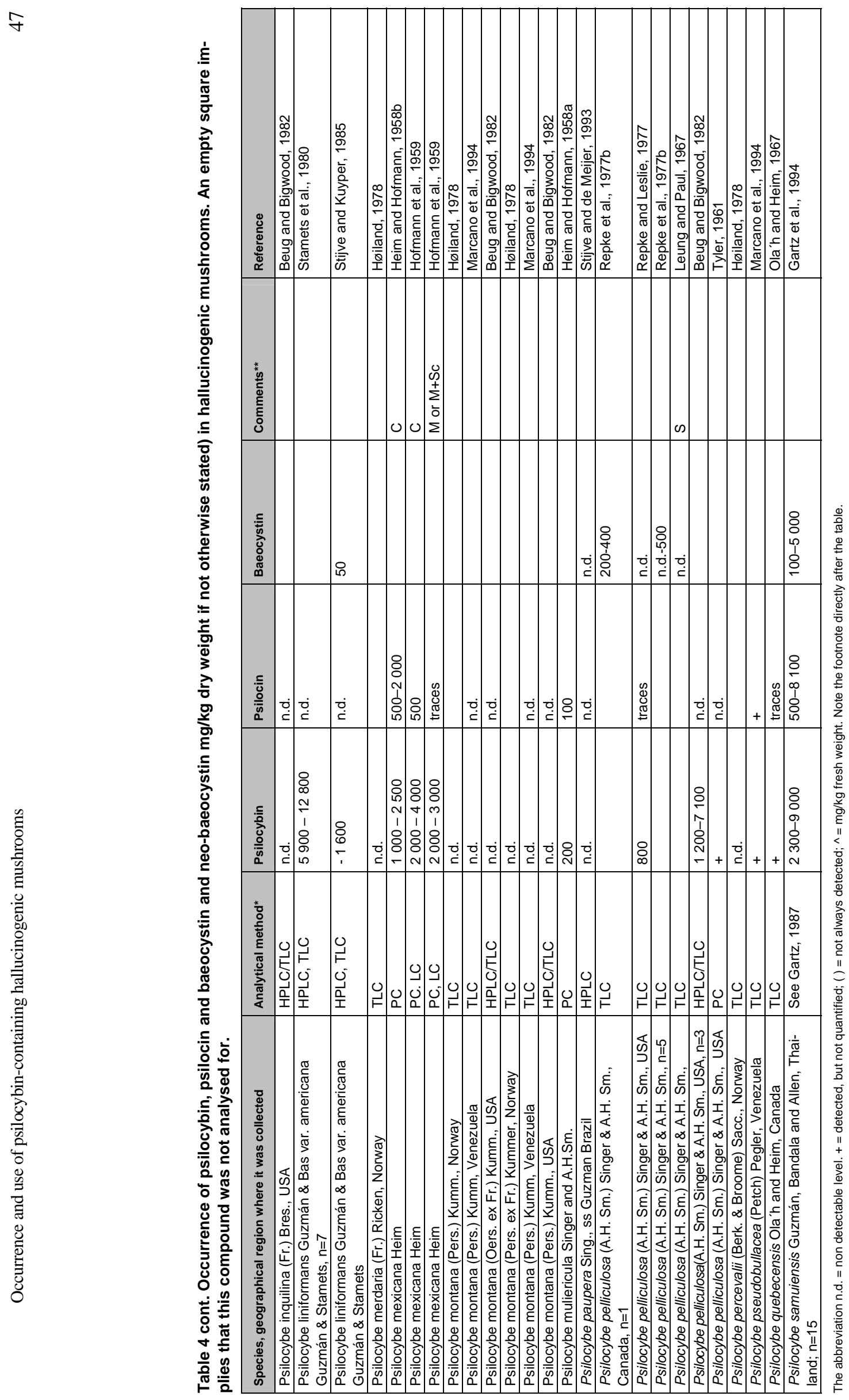




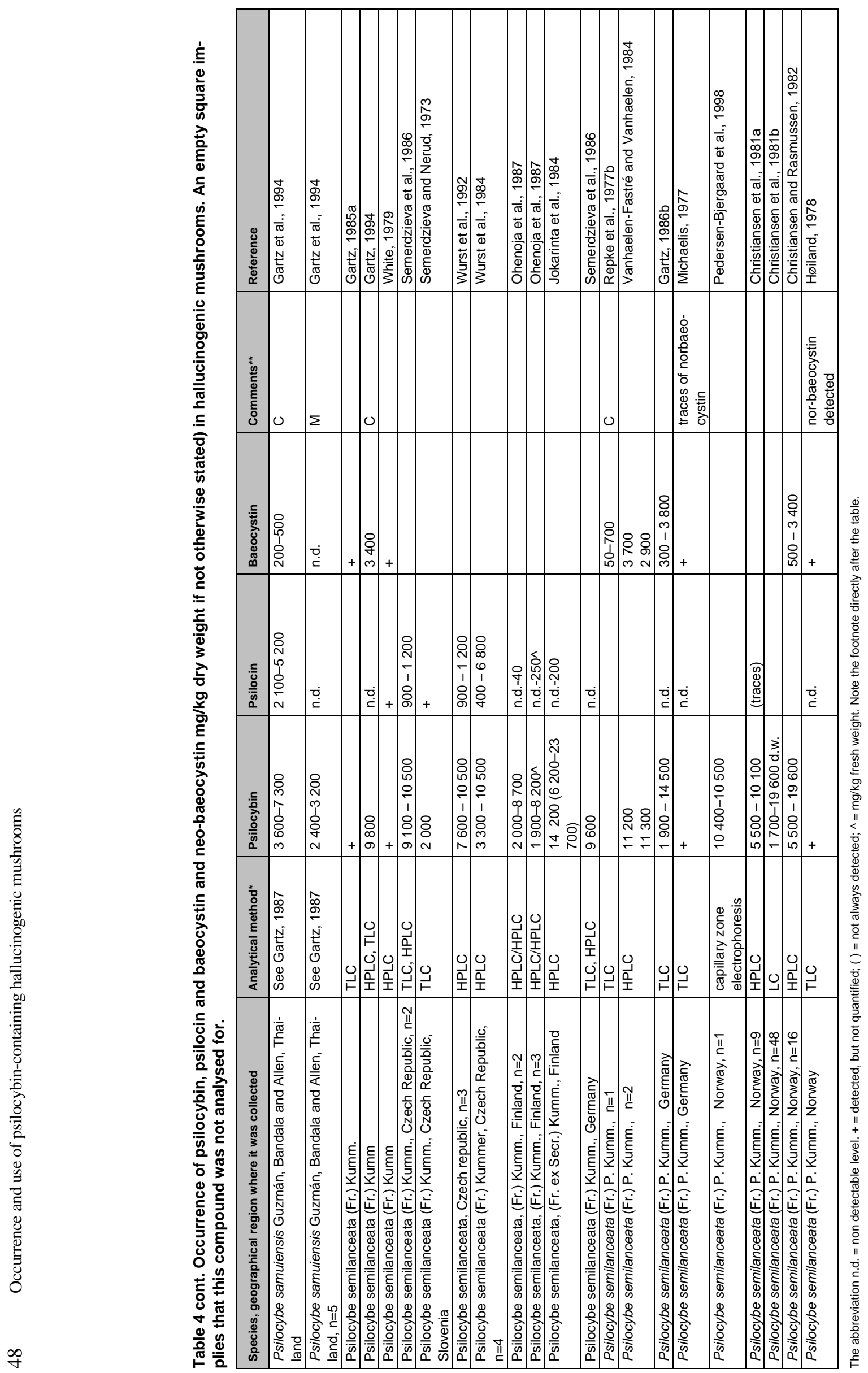


g

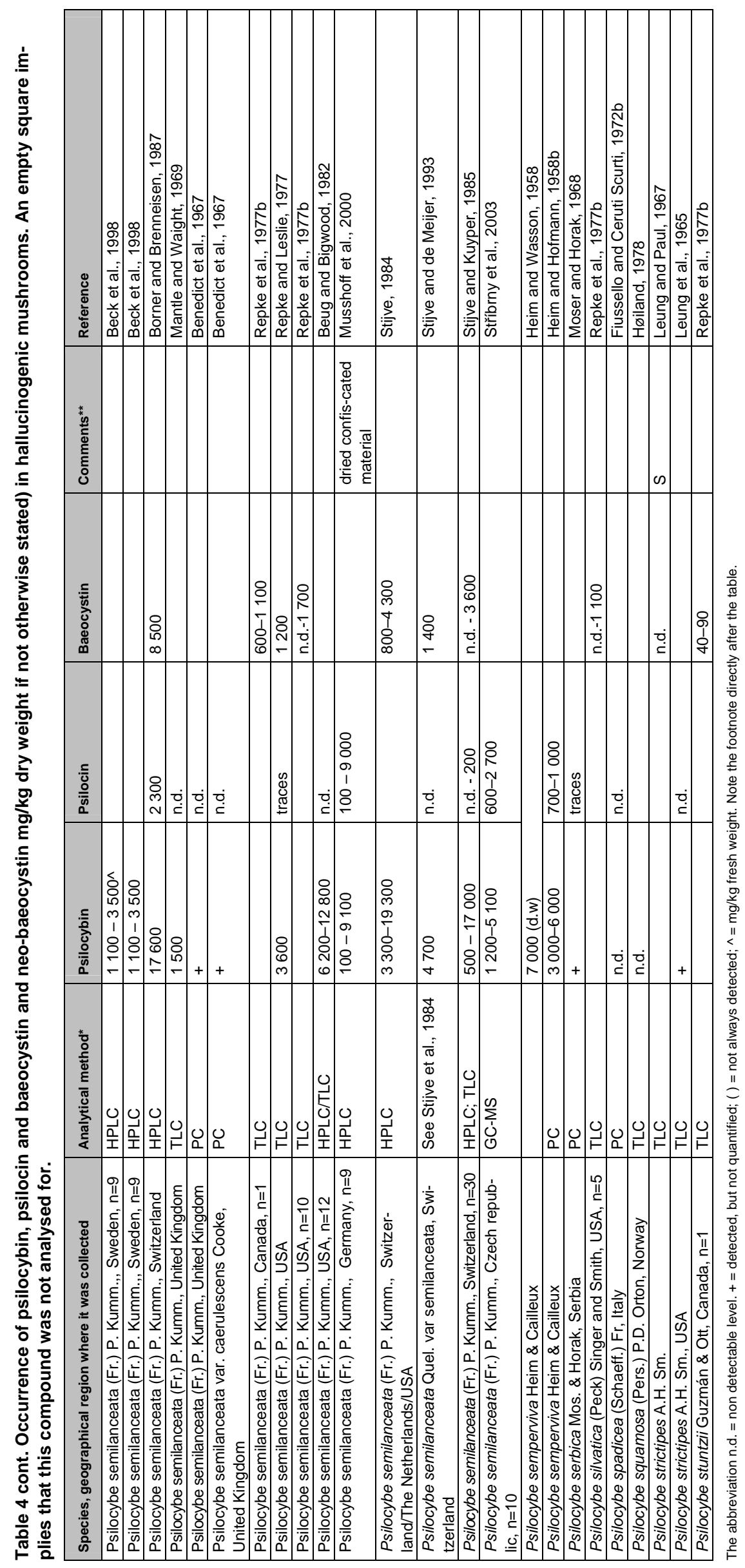




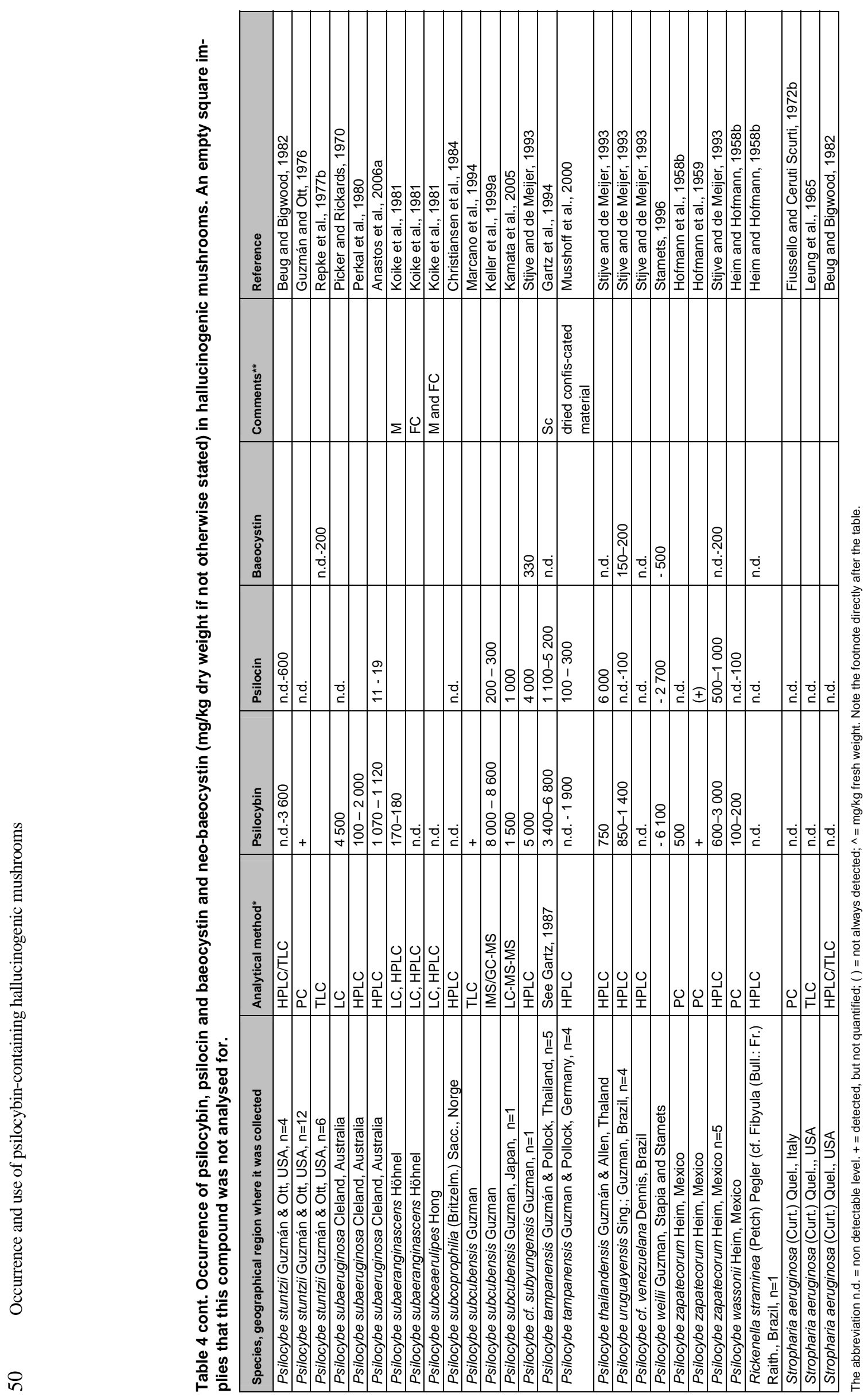




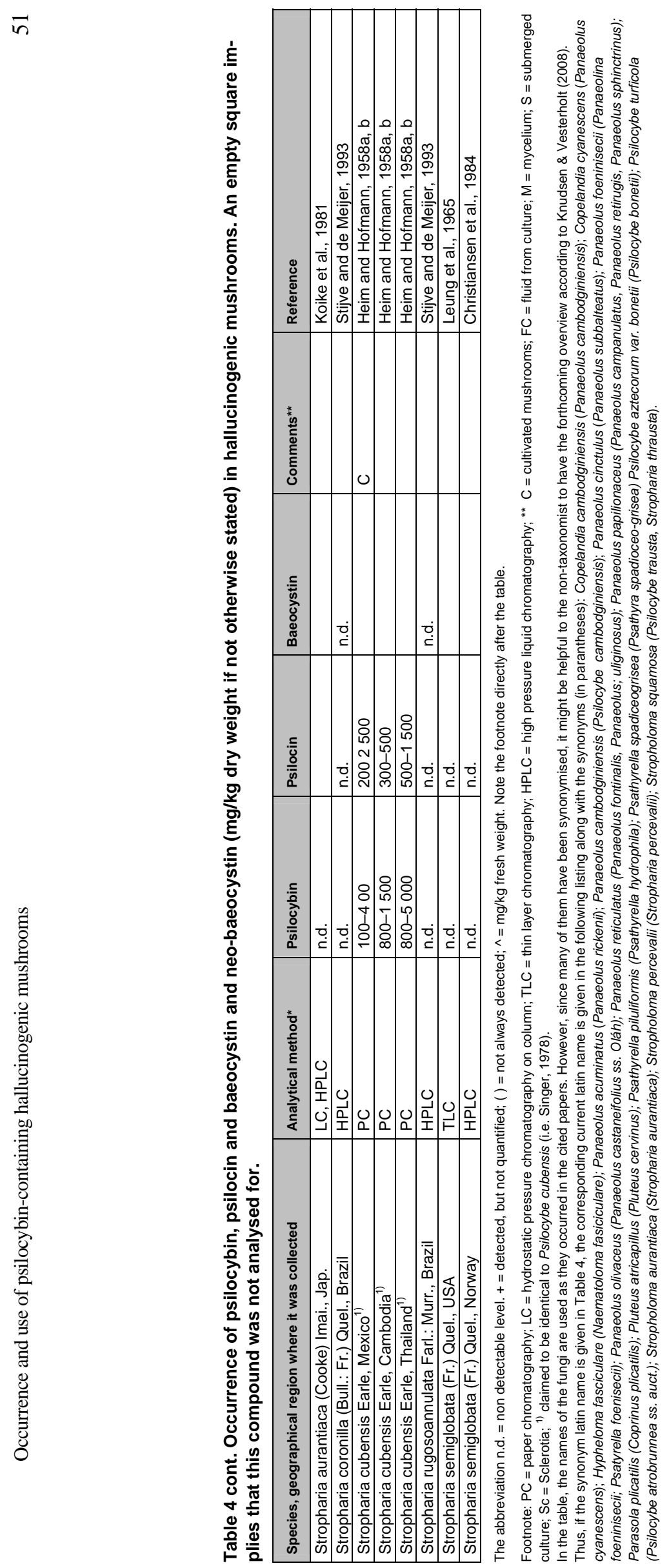


In 1983 Guzmán made a systematic revision of the genus Psilocybe, reviewing the history, distribution and chemistry of the hallucinogenic species (Guzmán, 1983). Psilocybe mushrooms are mostly small, brownish, conic-capped, slender-stalked, gilled mushrooms that fruit on or near dung, but can be found in wood litter, meadows, parks, and under sparsely scattered trees (Lincoff and Mitchel, 1977). The attached gills produce spores that on deposit are deep liliac to purple-brown. The hallucinogenic species of this genus can be found around the world and are distinguished by: i) a bluing reaction in the carpophore; ii) a farinaceous flavour; and iii) a farinaceous odour. Some of these characterisitcs become more difficult to observe, the older the sample is. Of the 144 species of Psilocybe mentioned by Guzmán (1983), no less than 81 have been identified as hallucinogenic. Of these, all the species of the sections Cordisporae (26 species), Semilanceatae (13 species), Brunneocystidiatae (10 species), Zapotecorum (9 species), Mexicanae (6 species), Cyanescens (5 species), Stuntzae (5 species), Aztecorum (4 species) and Cubensae (2 species) are hallucinogenic, but only one of the section Subaeruginosae (1 species). All these fungi together, belong to the old section Caerulescentes described by Singer (1958), and Singer and Smith (1958). Some species in the Psilocybe genus contain additional toxic compounds besides the indole derivatives.

The levels of psilocybin, psilocin and baeocystin in any one species of hallucinogenic mushroom have been found to be highly variable between samples. This is demonstrated by the data on some of the species belonging to the genus Psilocybe. Jokiranta et al. (1984) reported a mean psilocybin concentration of $14,200 \mathrm{mg} / \mathrm{kg}$ d.w. in a random sample (100 specimens) of Finnish Psilocybe semilanceata. The psilocybin concentration in the single samples varied from 6,200 to $23,700 \mathrm{mg} / \mathrm{kg}$ d.w.. Two larger pooled unselected samples contained 16,800 and 15,300 mg/kg dry weight, respectively. A variation in the levels of psilocybin, baeocystin and psilocin from one sample to another has also been observed in Psilocybe bohemica harvested from a single location (Gartz and Müller, 1989). Similar observations have been done in Psilocybe cubensis (Earle) Singer (Gartz, 1987a), Pluteus salicinus (Pers. ex. Fr.) Kumm. (Gartz, 1987b) and Inocybe aeruginascens (Gartz, 1987c). Beug and Bigwood (1982) reported that the observed levels of hallucinogenic compounds varied by a factor of two to more than six. The reason for this variation is not known, but it is surely to some extent influenced by the different conditions and times of storage between collection and chemical analysis (see section 5.2.). Other factors that might influence the content of hallucinogenic tryptamines are the size and the part of the fruit bodies analysed.

From these observations it can be inferred that reports on the absence of psilocybin and related compounds must be interpreted cautiously, especially when only limited amounts of material have been examined. The 
disappearance rate of psilocybin (and related compounds) from carpophores varies considerably.

No correlation between mushroom size (dry weight) and psilocybin content was found in Pluteus salicinus and Inocybe aeruginascens (Gartz, 1987b; 1987c). However, in absolute amounts, larger fruit bodies contain more psilocybin and baeocystin than smaller ones, showing that these compounds are continuously produced in the mushroom. In relative terms, small fruit bodies of $P$. semilanceata contain a higher percentage of psilocybin and baeocystin than larger fruit bodies (Gartz, 1986b; Christiansen et al., 1981b).

The part of the mushroom that has been analysed may also influence the level of psilocybin and related compound detected. Wurst et al. (1984) reported that caps contain more psilocybin than stems. Similar findings have been reported by Beug and Bigwood (1982), Gartz (1987a, 1987b), Keller et al. (1998), Gartz and Müller (1989), and Gurevich (1993). Even lower levels are found in the mycelium (Gartz, 1986b; Kysilka and Wurst, 1989; Keller et al., 1998). Other investigators have found marginal difference in psilocybin- and psilocin-content in the hat and the stipe for some mushroom species (Tsujikawa et al., 2003).

Using a new technique to extract the tryptamine derivatives from the mushroom, Kysilka and Wurst (1990) found much higher amounts of psilocybin and psilocin in Psilocybe bohemica than had previously been detected in this species. The original extraction procedure only extracted $76 \%$ of the psilocybin and $8 \%$ of the psilocin levels extracted by the new technology. According to the authors these observations pose the question whether the reported low contents of psilocin or absence of this compound in the presence of substantially higher values of psilocybin may not be an artefact induced by a non-proper extraction. Kysilka and Wurst (1990) found nearly comparable content of psilocybin and psilocin in Psilocybe bohemica, in contrast to current literature data. However, the studies of of Kysilka and Wurst (1990) have been critizised (Gartz, 1994).

In one of the early studies on the chemistry of hallucinogenic mushrooms, Hofmann and co-workers (1959) reported that dried fruit bodies of Psilocybe mexicana contained 2000-4000 mg psilocybin per kg dry weight, whereas mycelium contained $2000-3000 \mathrm{mg} / \mathrm{kg}$. The content of psilocin was $500 \mathrm{mg} / \mathrm{kg}$ in dried fruit bodies but much less, if any, in the mycelium.

Japanese workers studied the psilocybin content in cultured mycelium of Psilocybe subaerunginascens and in the culture fluid. Mycelium contained 170-180 mg psilocybin per kg dry weight, whereas no psilocybin could be detected in the culture fluid (Koike et al., 1981). Catalfomo and Tyler (1964) had earlier reported that psilocybin production correlated with mycelial growth in submerged cultures of Psilocybe cubensis. 
Maximum production of psilocybin occurred at acidic $\mathrm{pH}$, and reached levels between 2,200 and 5,200 mg/kg.

Hallucinogenic mushrooms are also found in Australia and New Zealand. It has been hypothesized that these mushrooms have been introduced to this continent with early settlers along with their livestock, mainly the cattle as probable dispersal mechanism (Margot and Watling, 1981). The first livestock arrived in Australia at the end of the 1700's. While the importation of cattle may have been responsible for introducing some hallucinogenic mushrooms, there are at least five indigenous species (Allen et al., 1991).

The Liberty cap, Psilocybe semilanceata, is the most important hallucinogenic mushroom growing in the Nordic countries. A number of studies on the occurrence of psilocybin in this species has been performed.

Of 48 mushroom samples freshly collected in Norway 1979-1980 and dried overnight at $50^{\circ} \mathrm{C}, 70 \%$ weighed between 20 and $60 \mathrm{mg}$ (Christiansen et al., 1981b). The average weight loss during drying was $92 \%$. The smaller mushrooms of the Norwegian samples contained higher tissue concentrations of psilocybin than the larger ones. Mushrooms weighing up to $20 \mathrm{mg}$ had an average tissue concentration of 12 $600 \mathrm{mg} / \mathrm{kg}$ whereas the ones weighing more than $60 \mathrm{mg}$ had an average tissue concentration of $5,700 \mathrm{mg} / \mathrm{kg}$ dry weight. Even if the tissue concentration in percent is higher in the smaller mushrooms than in the larger ones, the total psilocybin content is higher in the larger mushrooms, indicating that psilocybin is produced during growth (Christiansen et al., 1981b), in accordance with other studies (see above). These data have subsequently been confirmed by Gratz (1986a).

Beck and colleagues (1998) analysed Psilocybe semilanceata samples collected at three different locations in Sweden, together with three mushroom samples used by patients referred to hospital due to Psilocybe semilanceata intoxication. All samples contained psilocybin at levels between 1,100 and $3,500 \mathrm{mg} / \mathrm{kg}$ fresh weight.

Fresh specimens of many hallucinogenic mushrooms stain naturally blue or blue-green at the base of the stipe and often completely blue of the stipe apex when handled. Early studies found a good correlation between content of psilocybin and/or closely related indole derivatives and the blueing phenomenon (Benedict et al., 1962a). Psilocybin forms blue colour in solution. Levin (1967) suggested that the coloured compound is produced by psilocybin first being dephosphorylated to psilocin by a phosphatase, and then psilocin being oxidised by for example cytochrome oxidase, copper oxidase or $\mathrm{Fe}^{2+}$. In support of this suggestion, Horita and Weber (1961) showed that incubation of psilocybin with homogenates of rat kidney and other mammalian tissues causes a rapid liberation of psilocin through the action of alkaline phosphatase. The psilocin thus formed quickly undergoes further oxidative degradation to form a bluecoloured product. Weber and Horita (1963) subsequently concluded that 
cytochrome oxidase, a mitochondrial enzyme, is responsible for the rapid oxidation of psilocin (to a dark blue product) by tissue homogenates. It is conceivable that the blue colouring of these mushrooms result from an identical reaction.

Recreational users of hallucinogenic mushrooms sometimes regard the intensity of bluing as a guide to psilocybin and psilocin levels. Psilocybe connoseurs have experimented with metol (p-methylaminophenol) painted on the stalk or cap of a bruised mushroom as an indicator of the presence of hallucinogenic compounds (Chilton, 1978). Metol has a low oxidising potential and could be oxidised in the presence of any oxidases. Therefore, it is not a surprice that a poor correlation between metol blueing and psilocybin content has been found. Similarly, Beug and Bigwood (1982) found a poor correlation between degree of natural bluing and psilocybin or psilocin level. The variability of psilocybin and psilocin within each species as well as the difference in average level between species lead Beug and Bigwood (1982) to conclude that recreational users of these mushrooms are ingesting unpredictably varying amounts of psilocybin and psilocin. The variability of the bluing reaction further implies that this reaction is not a safe guide to psilocybin or psilocin levels. This has been confirmed by Gartz (1986b).

The data summarised in this section show that the ability to synthesise psilocybin and related compounds occurs in several mushroom genera, but in only some of the mushrooms species in each genus. The unclear role of tryptamine derivatives as taxonomic determinants is illustrated by the findings of Stijve and Kuyper (1985). These investigators studied around 100 different mushroom species, and found psilocybin, baeocystin, and/or psilocin in only 10 species. For example, in 10 species of Panaeolus, these compounds were only detected in Panaeolus subbalteatus. The Panaeolus species, however, characteristically contained appreciable amounts of serotonin and its precursor 5-hydroxytryptophan. Of twenty Inocybe species analysed for the hallucinogenic compounds, these were found in five species only. Of thirteen Pluteus species only Pluteus salicinus was positive for psilocybin. One of these, Pluteus villosus, contained tryptamine derivatives closely related to psilocybin. Too little material was available to isolate and identify the compound. Whereas Pleuteus salicinus was faintly bluish green at the lower part of the stipe, Pleuteus villosus had a definite bluish to violet colour. Working with five different Inocybe species containing hallucinogenic tryptamine derivatives and being characterized by a bluish-green zone on the stipe, Stijve and Kuyper (1985) concluded that although they contain high enough concentrations of psilocybin, baecystin, and/or psilocin to render them hallucinogenic when consumed, the likelihood this is going to happen is very low due to the rareness of these species and the trouble to separate them from poisonous mushrooms. Also Inocybe calamistrata had a bluegreen stipe, but this coloured zone was not influenced by bruising, and no 
tryptamine derivatives could be detected. The investigators concluded that psilocybin was restricted to two sections of Inocybe, viz. Lactiferae Heim and Fibrillosae Heim. None of the psilocybin-containing species of Inocybe contained muscarine witch is a toxic compound found in other species of Inocybe.

\subsection{Influence of cultivation, storage and processing}

The formation and distribution of psilocybin and related compounds in fruit bodies, mycelia and sklerotia have been studied in cultivated Psilocybe cubensis (Gartz, 1989d).

It has been speculated that the quantity of psilocybin and related compounds occurring in hallucinogenic mushrooms depends on whether it is an early or a late flush of fruit bodies developing from the mycelium. There is no information available on wild mushrooms to confirm this speculation. However, an Amazonian strain of Psilocybe cubensis have been grown in carefully controlled cultures and the variation of psilocybin and psilocin levels studied with time in culture (Bigwood and Beug, 1982). The first flush (fruiting) of mushrooms occurred four to five weeks after inoculation of the cultures. The levels of psilocybin varied somewhat unpredictably from one flush to the next, but generally were much the same on the last flush (5th or 6th flush) as they were on the first flush. The levels of psilocybin were between 3,200 and 13,300 mg/kg dry weight. Psilocin, on the other hand, generally was absent in the first one or two flushes, reached maximum by the fourth flush, and then appeared to start to decline. The levels of psilocin were between non-detectable levels and 2,900 $\mathrm{mg} / \mathrm{kg}$ dry weight. Were these findings with psilocin found to be general, it would partly explain the variation in psilocin levels observed in hallucinogenic mushrooms. Similar observations have been made by Gartz (1987a), who, however, noted that fruit bodies from later flushes contained somewhat higher amounts of psilocybin (and psilocin) than fruit bodies from early flushes. When Gartz repeated his studies, using Psilocybe semilanceata and Gymnopilus purpuratus (Cooke \& Mass.) Sing. as cultivated materials, no variation in psilocybin, psilocin and baeocystin levels between repeated flushes from a single culture was found (Gartz, 1991).

When Bigwood and Beug (1982) analysed five street samples of Psilocybe cubensis for which the flush number or the precise growing condition were unknown, variable levels of psilocybin (700-6 $200 \mathrm{mg} / \mathrm{kg}$ dry weight) and consistently low levels of psilocin were found (n.d.-300 mg/kg dry weight).

Psilocybin, psilocin and related compounds cannot be expected to be totally stable in a mushroom or a mushroom extract, particularly as they occur mixed with many other compounds, some of which have enzymatic 
activity. In those cases where dried 'fresh' mushrooms have been analysed for psilocybin and psilocin in parallel with dried stored museum samples, it has been noted that psilocybin has been slowly degraded and sometimes psilocin formed in the older stored samples (Semerdžieva et al., 1986). Reports that mushrooms do not contain psilocybin and related compounds must be interpreted cautiously, especially when only limited amounts of material have been examined. The disappearance rate of psilocybin (and related compounds) from carpophores varies considerably.

Therefore, the time running between collection of mushrooms and analysis, as well as the conditions at which the mushrooms are stored may influence the quality and quantity of compounds analysed. For example, the influence of the light conditions during storage has not been studied. Many investigators have not given this experimental factor enough consideration. Repke and co-workers (1977b), originally detected psilocybin, psilocin and baeocystin in fresh samples of Psilocybe baeocystis and Psilocybe cyanescens. However, after 66 weeks of storage at $22^{\circ} \mathrm{C}$ and $5-10 \%$ relative humidity, the compounds could no longer be detected in either species. Similarly, chemical analysis of cultivated Psilocybe cubensis grown on horse dung showed that psilocybin, psilocin, and baeocystin could not be detected in dried material stored at $22^{\circ} \mathrm{C}$ for 52 weeks (Repke et al., 1977). However, fragments of the same carpophore stored under anhydrous conditions at $-5^{\circ} \mathrm{C}$ for 52 weeks and the freshly dried material (14 days) both contained these compounds. A similar decrease in baeocystin content related to storage was observed for collections of Psilocybe semilanceata, Psilocybe silvatica, and Psilocybe stuntzii. By contrast, the amount of baeocystin (and psilocin) found in one collection of Panaeolus subbalteatus after 52 weeks storage was the same as that detected in freshly dried specimens from the same collection. The rate of decomposition of the studied compounds seemed to be irregular in the investigated material. Similar observations were made by Wurst et al. (1984). Although drying had no influence on the psilocybin level of fruit bodies of Psilocybe mushrooms, storage of the dried mushrooms reduced the levels significantly.

Beug and Bigwood (1982) studied how storage of mushroom samples may influence the psilocybin and psilocin content. They noted that freeze-dried samples showed no detectable loss of psilocybin and psilocin when stored at $-5^{\circ} \mathrm{C}$ or $-60^{\circ} \mathrm{C}$, but some freeze-dried samples lost both psilocybin and psilocin over periods of one to two years when stored at room temperature. Methanolic extracts were stable for over a year at $5^{\circ} \mathrm{C}$, but lost all psilocin and some psilocybin within six months when stored at room temperature. Some dried herbarium material had lost all psilocybin and psilocin after 1 year (Beug and Bigwood, 1981).

Ohenoja and co-workers (1987) analysed a series of dried herbarium specimens of Psilocybe semilanceata collected in the years 1843, 1869, 1954 and 1976 in order to determine the stability of psilocybin and psilocin 
in the dried fruit bodies. Psilocybin was found to be remarkably stable in this study. Even the 115 year-old sample from 1869 still contained a measurable amount of psilocybin, $140 \mathrm{mg} / \mathrm{kg}$ dry weight. The oldest specimen, on the other hand, did not show any activity. Psilocin seemed to be much less stable, and was only detected in fresh specimens or in species that contained high concentrations of psilocybin. By comparing the psilocybin content in fresh samples collected from nature with old herbarium samples, Stijve and Kuyper (1985) confirmed these observations by finding 10-20 times lower psilocybin levels in the stored samples.

Also pre-treatment of samples before chemical analysis may influence the amount of psilocybin and psilocin subsequently detected. Gartz (1994) revealed that the relatively high amounts of psilocin detected in Psilocybe bohemica by Kysilka and Wurst (1990) and Wurst and co-workers (1992) was an artefact caused by enzymatic destruction of psilocybin in aqueous solutions containing organic solvents. Extraction with pure methanol was found to be the safest method to retain the genuine indole derivatives occurring in the mushrooms. The question whether these phosphorylated tryptamine derivatives are most efficiently extracted by pure methanol has not been adequately settled (Kysilka and Wurst, 1990).

Stamets and co-workers (1980) pointed out that a marked variation in psilocybin and psilocin levels from one collection to another is typical of several species in the genus Psilocybe. The observation led the authors to conclude that neither the level of psilocybin and/or psilocin, nor the ratio of the two can be utilised as a chemotaxonomic tool. Further, when the authors analysed herbarium samples of Psilocybe they found that the samples had lost most of their psilocybin and psilocin, which made them conclude that collections should be analysed promptly. However, activity can be retained for at least two years by drying or freeze drying the collections, sealing them in plastic and storing them frozen.

Boiling of psilocybin-containing mushrooms in water, results in a quantitative extraction of psilocybin into the water. But no psilocybin is degraded. A subsequent extraction of the boiled fruit bodies with methanol did not yield any psilocybin (Wurst et al., 1984).

\subsection{Wild mushrooms in the Nordic countries that contain psilocybin and/or related compounds}

Of the about 125 psilocybin and/or psilocin containing mushrooms identified in Table 4, no less than about 60 have been found in the Nordic countries. Many of them are rare, but some can be found in considerable quantities in the right biotopes (Knudsen and Vesterholt, 2008).

Twenty-two species of the genus Psilocybe have been identified in the Nordic countries, but only 6 of these contain the hallucinogenic compounds. These species are: Psilocybe atrobrunnea (Lasch) Gillet., P. 
cyanescens Wakef., P. fimetaria (P.D. Orton) Watling, P. liniformans Guzman \& Bas var. americana Guzman \& Stamets, P. semilanceata (Fr.) Krumm., and $P$. silvatica (Peck) Sing. \& Smith.

The next most important group of psilocybin-containing mushrooms belongs to the genus Panaeolus. Eleven species of this genus have been described in the Nordic countries. Of these, the following six species have been reported to contain psilocybin and/or psilocin: Panaeolus olivaceus F.H. Møller, P. sphinctrinus (Fr.) Quél., $P$. foenisecii (Pers.) J. Schröt, $P$. subbalteatus (Berk. \& Broome) Sacc., P. fimicola (Pers.) Gillet, and P. ater (J.E: Lange).

Of the four Conocybe species identified as containing psilocybin, two have been described in the Nordic countries. These species are Conocybe cyanopus (Atk.) Kühner and C. kuehneriana (Sing.) Kühner.

Among the nine Gymnopilus species reported to contain psilocybin, Gymnopilus liquiritiae (Pers.) P. Karst.,.P. sapineus (Fr.) Maire, and G. spectabilis (Fr.) A.H. Sm. have been found in the Nordic countries, and among the three psilocybin-containing Inocybe species, the two species Inocybe corydalina Quél. and I. haemacta (Berk. \& Cooke) Sacc. occur in the Nordic countries (Knudsen and Vesterholt, 2008).

Other mushrooms in the Nordic countries reported to contain psilocybin and/or psilocin are Pluteus atricapillus (Batsch) Fayod, Pluteus salicinus (Pers.) P. Kumm., and Psathyrella candolleana (Fr.) Maire.

\subsection{Cultivation of psilocybin-containing mushrooms}

The sometimes poor and season-dependent availability of hallucinogenic mushrooms have stimulated the search for methods to cultivate these mushrooms. Actual culturing of the mushrooms did not become common until reports on the methodology occurred in both scientific literature and connoisseur books (Heim and Wasson, 1958; Singer and Smith, 1958; Brown, 1968; Enos, 1970; Oss and Oeric, 1986).

Home cultivation can be done almost everywhere with the most rudimentary equipment. Cultivation kits have been commercially available on the market for over 20 years. Home growers typically find that it is very easy to culture the mycelium (which also contain psilocybin), but find it hard to produce fruiting bodies in vitro. The Latin American species Psilocybe cubensis is an exception to this finding, apparently being very easy to culture and fruits readily in vitro.

Home culture of mushrooms in vitro, however, requires some care and attention. It is also feasible to induce hallucinogenic mushrooms normally indigenous to a certain area to grow outdoors in controlled conditions in that area. Of course, while this technique may require less care and attention than in vitro cultivation, it is seasonal; by culturing mushrooms in vitro, users may obtain a year-round supply of mushrooms. 



\section{Exposure}

\subsection{The habit of consuming hallucinogenic mushrooms}

Mind expanding or hallucinogenic drugs have been used throughout the world from prehistoric times. Since they have often been associated with religious rites, fortune telling and magic, they have been regarded as sacred and earlier never used with levity. The habit of using hallucinogenic mushrooms in the Western society is not older than around 30 years, and is mainly a recreational phenomenon.

During the early period of hallucinogen use in the 1960's, LSD was the drug receiving most attention. As time passed, interest in other compounds emerged and was stimulated by burgeoning literature as well as the availability of the drugs. Two other illicit chemicals that became popular at the end of the 60's and during the 70's were mescaline, found in Lophophora and a few other genera of cacti, and psilocybin, found in many mushroom species.

As is the case for many trends in society, the modern use of hallucinogenic mushrooms emanates from the west-coast of the United States, where it became relatively common during the middle of the 1970's and was sold as magic mushrooms. The epithet "magic mushroom" was invented by a Life magazine editor in 1957, and is the single most common name for the hallucingenic mushrooms (Allen et al., 1981). Some of the specific species in addition to being called magic mushrooms have received their own name, which varies from geographical region to geographical region or between the local drug circles. The habit of using hallucinogenic mushrooms in Australia most probably was brought to the island by surfers moving from America to Australia (Allen et al., 1991).

The users of hallucinogenic mushrooms can get their products from many sources. They can collect various species of hallucinogenic mushrooms growing in the wild and use them fresh or after being dried, they can grow the mushrooms themselves, or buy dried mushrooms on the open or the black market. The habit of collecting wild mushrooms was originally rather limited. Street samples of "magic" mushrooms, that is samples sold legally or not legally on the streets, were during these early years usually found to be non-psychoactive mushrooms treated with LSD. These findings were substantiated by reviews of street drug analysis programs. Although true psilocybin, or magic mushroom use was negligible in 1975 in the United States, the habit of using these products increased thereafter.

Eastern European countries has until recently been more or less a transit zone for drugs heading to Western Europe. A remarkably fast change 
has resulted in these countries now being more or less comparable with other EU countries. In the Slovak Republic sniffing of fluid drugs were previously the clearly dominating drug abuse, but now the traditional drugs in Western Europe are the common ones. In particular, during latter years plant drugs, including hallucinogenic mushrooms, have become popular, probably because of their easy availability, low price and quick spreading of information (Kresanek et al., 2005).

During the last years, Internet has become a major source of information on where to find hallucinogenic mushrooms and how to use them. Internet is also a forum for the enterprises selling magic mushrooms, mushroom-growing kits and similar products (Westberg and KarlsonStiber, 1999). Today a large number of different mushroom species have been claimed to have hallucinogenic properties (Table 5), assumingly due to its content of psilocin/psilocybin (Table 4 gives mushrooms known to contain these compounds).

Techniques for cultivation of psilocybin-containing mushrooms were first described in a book called "The Psychedelic Guide to Preparation of the Eucharist" (Brown, 1968). Several species of Psilocybe can be cultured, but it is not easy to get all species to produce fruiting bodies. Psilocybe cubensis is one of the most easy species to cultivate, whereas many other species only produce mycelia. An increased trade of hallucinogenic mushrooms and growing-kits over Internet has been registered by the customs authorities in all Nordic countries.

The psilocybin-containing mushrooms may be eaten fresh in the field, or later in the home, where they may be added to food such as soups, salads, or omelettes, or mixed as "smoothies" with juice and fruit (Ott, 1978).

According to Zimmer (1986) chocolate or honey are sometimes mixed with the mushroom to obtain products more easily ingested by the recreational drug users. One way of preserving the mushrooms is to freeze them. It is also common practice to dry these mushrooms, either in the air or in some type of drying apparatus. The mushroom so dried may be stored for a very long time, without loosing too much of its activity, if stored at lower temperatures (Hall, 1973). 
Table 5. Mushroom species reported to have hallucinogenic activity and to contain psilocybin and/or similar compounds.

\begin{tabular}{|c|c|}
\hline Species & Reference \\
\hline Conocybe siligineoides & Heim and Hofmann, 1958a \\
\hline Conocybe smithii Watling & Guzmán et al., 1976* \\
\hline Copelandia cyanescens & Pollock, 1976a; Southcott, 1974; Hall, 1973; McCarthy, 1971 \\
\hline Gymnophilus purpuratus & Allen et al., 1991 \\
\hline \multirow[t]{2}{*}{ Gymnophilus spectabilis } & Waters, 1965 \\
\hline & Allen et al., 1991 \\
\hline Inocybe aeruginascens & Drewitz, 1983 \\
\hline Inocybe patouillardii & Satora et al., 2005 \\
\hline Mycena pura & Allen et al., 1991 \\
\hline Mycena cyanorrhiza & Allen et al., 1991 \\
\hline Panaeolus antillarum & Allen et al., 1991 \\
\hline Panaeolus cambodginiensis & Pollock, 1975 \\
\hline Panaelous campanulatus & Pollock, 1974, 1976a \\
\hline Panaeolus castaneifolius & Guzmán et al., 1976*, Ott, 1978 \\
\hline Panaeolus fimicola & Ott, 1978 \\
\hline \multirow[t]{2}{*}{ Panaeolus foenisecii } & Cooles, 1980; Pollock, 1976a; Holden, 1965; Ott, 1978 \\
\hline & Southcott, 1974; Guzman et al., 1976*; Allen et al., 1991** \\
\hline Panaelous cyanescens & $\begin{array}{l}\text { Lincoff and Mitchell, 1977. Allen et al., 1991**; Pollock, 1974, } \\
\text { 1976; Ott, } 1978\end{array}$ \\
\hline Panaelous papilionnaceus & Pollock, 1974; Sanford, 1972 \\
\hline Panaeolus sphincrinus & Ott, 1975; Guzmán et al., 1976*; Schultes, 1939; Pollock, 1975 \\
\hline Panaeolus subbalteatus & Guzmán et al., 1976*; Pollock, 1976; Allen et al., 1991 \\
\hline Panaelous (Copelandia) subbalteatus & Jacobs, 1975; Allen et al., 1991 \\
\hline Pluteus cyanopus & Stamets, 1996 \\
\hline Pluteus glaucus & Stijve and de Meijer. 1993 \\
\hline Pluteus salicinus & Stamets, 1996 \\
\hline Pluteus villosus & Stamets, 1996 \\
\hline Psilocybe aucklandii & Guzmán et al., 1993 \\
\hline \multirow{2}{*}{ Psilocybe australiana } & Guzmán et al., 1993 \\
\hline & Allen et al., 1991 \\
\hline Psilocybe aztecorum var. aztecorum & Singer, 1958a; Guzmán, 1978 \\
\hline Psilocybe aztecorum var. bonetii & Guzmán, 1978 \\
\hline Psilocybe baeocystis & $\begin{array}{l}\text { Mc Cawley et al., 1962; Benedict et al., 1962b; Guzmán et al., } \\
\text { 1976* }\end{array}$ \\
\hline Psilocybe brasiliensis & Guzman, 1983 \\
\hline Psilocybe brunneocystidiata & Guzmán et al., 1993 \\
\hline Psilocybe caerulescens & Guzmán and Vergerr, 1978. Singer, 1958a \\
\hline Psilocybe caerulescens var. mazatecorum & Wasson, 1962a, 1962b \\
\hline Psilocybe campanulatus & Guzmán et al., 1976* \\
\hline Psilocybe caerulipes & Ott, 1978 \\
\hline Psilocybe candidipes & Singer, 1958a \\
\hline Psilocybe collybiodes & $\begin{array}{l}\text { Pollock, 1976a; Southcott, 1974; Hall, 1973; McCarthy, 1971; } \\
\text { Allen et al., } 1991\end{array}$ \\
\hline Psilocybe cophrophila & Allen et al., 1991 \\
\hline Psilocybe cubensis & Allen et al., 1991**; Singer, 1958a; Guzmán and Vergerr, 1978 \\
\hline \multirow[t]{2}{*}{ Psilocybe cyanescens } & Guzmán et al., 1976* \\
\hline & Guzmán and Vergerr, 1978 \\
\hline Psilocybe cyanofibrillosa & Guzmán and Vergerr, 1978 \\
\hline Psilocybe eucalypta & Guzmán et al., 1993. Allen et al., 1991 \\
\hline Psilocybe fagicola & Allen, 2001 \\
\hline Psilocybe fimentaria & Guzmán and Vergerr, 1978 \\
\hline Psilocybe goniospora & Guzman et al., 1993 \\
\hline Psilocybe hoogshageni & Stamets, 1996 \\
\hline Psilocybe inconspicua & Guzmán et al., 1993 \\
\hline Psilocybe kumaenorum & Guzmán et al., 1993; Allen et al., 1991 \\
\hline Psilocybe lonchoporus & Guzmán et al., 1993 \\
\hline
\end{tabular}


Table 5 cont. Mushroom species reported to have hallucinogenic activity and to contain psilocybin and/or similar compounds.

\begin{tabular}{|c|c|}
\hline Species & Reference \\
\hline Psilocybe mammillata & Guzmán et al., 1993 \\
\hline \multirow[t]{2}{*}{ Psilocybe mexicana } & Guzmán and Vergerr, 1978 \\
\hline & Singer, 1958a \\
\hline Psilocybe muliercula & Singer, 1958a \\
\hline Psilocybe novae-zelandiae & Allen et al., 1991 \\
\hline Psilocybe ochreata & Guzman et al., 1993 \\
\hline Psilocybe papuana & Guzmán et al., 1993 \\
\hline Psilocybe pelliculosa & Guzmán et al., 1976* \\
\hline Psilocybe quebecensis & Ola'h and Heim, 1967 \\
\hline Psilocybe samuiensis & Guzmán et al., 1993 \\
\hline \multirow[t]{3}{*}{ Psilocybe semilanceata } & Guzmán and Vergerr, 1978 \\
\hline & $\begin{array}{l}\text { Allen et al., 1991; Olsen and Knudsen, 1983; Guzmán et al., } \\
\text { 1976*; Heim et al., } 1963\end{array}$ \\
\hline & Allen et al., 1991 \\
\hline Psilocybe semperviva & Heim and Wasson, 1958 \\
\hline Psilocybe silvatica & Guzmán and Vergerr, 1978 \\
\hline Psilocybe strictipes & Guzmán et al., 1976* \\
\hline Psilocybe stuntzii & Guzmán et al., 1976* \\
\hline \multirow[t]{5}{*}{ Psilocybe subaeruginosa } & Allen et al., 1991 \\
\hline & Picker and Rickards, 1970 \\
\hline & Pollock, 1976a; Southcott,1974; Hall, 1973; McCarthy, 1971; \\
\hline & Guzmán et al., 1993 \\
\hline & Allen et al., 1991 \\
\hline \multicolumn{2}{|l|}{ Psilocybe subaeruginascens } \\
\hline Höhnel var. subaeruginascens & Guzmán et al., 1993 \\
\hline Psilocybe subcaerulipes & Yokoyama, 1973 \\
\hline Psilocybe subcubensis & Allen et al., 1991** \\
\hline Psilocybe subfimetaria & Stamets, 1996 \\
\hline Psilocybe tampanensis & Guzmán and Vergerr, 1978 \\
\hline Psilocybe tasmaniana & Guzmán et al., 1993 \\
\hline Psilocybe tasmaniana & Allen et al., 1991 \\
\hline Psilocybe venenata & Stamets, 1996 \\
\hline Psilocybe washingtonensis & Stamets, 1996 \\
\hline Psilocybe wassonii & Allen et al., 1991 \\
\hline Psilocybe wassoniorum & Stamets, 1996 \\
\hline Psilocybe yungensis & Allen et al., 1991 \\
\hline Psilocybe zapotecorum & Allen et al., 1991 \\
\hline Stropharia cubensis $\left({ }^{*}\right)$ & Singer, 1958a; Singer and Smith, 1958; Pollock, 1975 \\
\hline
\end{tabular}

Singer, 1958a; Singer and Smith, 1958; Pollock, 1975

* No information on psilocybin and psilocin in this report

** Allen and Merlin, 1992 
Being hard to chew, the dried mushrooms are often brewed into tea. This tea is subsequently drunk, and the mushrooms are then consumed. In Samoa, the caps of Copelandia cyanescens are steeped in boiling water to produce a black juice which is mixed with coffee and then drunk (Cox, 1981). The hot water extracts the mushroom toxins; and it has been observed that both the water and the remains of the mushrooms so prepared have hallucinogenic activity (Ott, 1978). The hot water can also be used to prepare foods such as rice or soups, discarding the remains of the mushrooms. Some persons chew the caps raw, others mixed together with Coca-cola as this method eliminates the somewhat undesirable taste of the raw or fried mushroom (Hall, 1973).

Dried mushrooms are sometimes smoked, a practice which no doubt comes from descriptions of this mode of ingestion in Castanedas book "The Teaching of Don Juan".

During ethnomycological explorations of southern Thailand, Allen and Merlin (1992) made observations of occurrence, harvesting, use, and marketing of psychoactive fungi by local Thai natives, foreign tourists, and German immigrants. Psychoactive fungi are prohibited plants according to Thai law. Nonetheless, numerous restaurants on the islands of Koh Samui and Koh Pha-ngan, in the southern part of the Gulf of Siam, served psychoactive omelettes, stews, soups, pizzas, teas, and blended juice beverages containing mind-altering, gilled fungi, referred to as 'magic mushrooms' (Guzmán, 1993). Purchase and use of foods containing psychoactive fungi occurred primarily among tourists and West German immigrants living on these islands. The fungi used in these dishes were picked from cattle dung and identified as Psilocybe cubensis, Psilocybe subcubensis and Panaeolus (Copelandia) cyanescens. In addition a new species, Psilocybe samuiensis, not growing on dung were used (Guzmán et al., 1993)

More recently, various mushroom-containing concoctions have become popular, especially grated or powdered mushrooms in chocolate. Because of the potential for interference of ingredients of these products in the standard analytical methods, new extraction method might be required to analyse these types of products for psilocybin and psilocin (Sarwar and McDonald, 2003).

There are some scientific studies on the use of hallucinogenic mushrooms. For historical reasons, most early studies were performed in the United States. Later on such studies have been performed also in Europe.

Thomson and colleagues in 1985 investigated the extent of hallucinogenic mushroom use among 1507 college students in California, USA. The major finding was that among the respondents who reported use of hallucinogenic drugs (17\%), over 85\% had used hallucinogenic (psilocybin) mushrooms and over half had used mushrooms but no other hallucinogens. Three times as many students had used hallucinogenic mushrooms as had used LSD. These data indicate a high level of experimental 
use of hallucinogenic mushrooms compared to the other hallucinogens. The observation was substantiated by the observation that $68 \%$ of the 223 students who reported mushroom use, had tried it four times or less.

In another survey of (1 500) American college students in 1986, 15\% admitted mushroom use compared to 5\% for LSD. The reported use of hallucinogenic mushrooms among high school students were somewhat less and ranged from $3.4 \%$ in the seventh grade (12 to 13 years old) to $8.8 \%$ in the eleventh grade (16 to 17 years old) (Schwartz and Smith, 1988). Alcohol and marijuana are the most commonly abused drugs by students on college campuses in the United States (Rimsza and Moses, 2005).

In the study of Thomson and colleagues (1985), referred to above, the use of hallucinogenic mushrooms or attitudes toward use of illicit drugs in general was correlated with the number of drug-involved friends. Mushroom users were more likely to have used each of nine other drugs studied than were non-users. One interesting observation made by Thompson and co-workers (1985) was that many of those who used mushrooms claimed that they would never take LSD, which suggests that researchers should differentiate mushrooms from other hallucinogens. It should be stressed that this has seldom been the case. Usually, investigations on use of hallucinogenic mushrooms have been done in connection with illicit drug use.

Not unexpectedly, use of hallucinogenic mushrooms is more common in drug users. In a study on 174 young American drug-users 26\% reported having used hallucinogenic mushrooms, frequently in conjunction with alcohol or other drugs (Schwartz and Smith, 1988). However, in general the use of mushrooms was infrequent; the majority of the adolescents reporting psilocybin-containing mushroom ingestion only one to three times. Ten persons had tried mushrooms at least ten times and two persons more than 50 times. Serious adverse effects during mushroom intoxication were reported by six (13\%) of the adolescents; three cases of head trauma, two cases of loss of consciousness, and flash-back experiences.

Trends in illicit drug use by undergraduate students has been studied both in a private southern university in the United States and in the Ontario Student Drug Use Survey in Canada. The American study compared results of similar surveys performed at the same university in 1986 and 1990 (Cuomo et al., 1994). Although the validity of the data may be questioned by the low response rate, they showed that the percentage of students that had used mescaline/psilocybin (grouped together on the questionnaires) increased from $8 \%$ to $24 \%$ during the five-year period of the study (Cuomo et al., 1994). Every two years since the early 1990's, the Addiction Research Foundation of Ontario, has sponsored the Ontario Student Drug Use Survey. The survey is based on a questionnaire to Ontario public school students enrolled in grades $7,9,11$, and 13, and investigates the self-reported prevalence of use of 20 types of drugs and other 
substances over the previous 12 months. After a substantial long-term decline in drug use among adolescents during the 1980s, this and other epidemiological surveys observed an increase in drug use in this segment of the population in North America during the 1990s. In 1993 around $3.1 \%$ of the students used mescaline or psilocybin, and two years later 7.6\%. The significant increase continued and were 10.1\% in 1997 (Adlaf and Ivis, 1998), and 13.6\% in 1999 (Adlaf et al., 2000). The difference between the genders was marginal. A parallel increase in "ecstasy" was noted. None of the drugs declined in use during this period. In total, 38\% of the students had used an illicit substance during the previous year.

In a more resent Canadian study on drug-using university students (mean age 21.7 years, 58.7\% female and $78.5 \%$ Caucasian), the investigators studied the simultaneous use of several drugs (Barrett et al., 2006). Of the 149 subjects interviewed, 65\% had used hallucinogenic mushrooms/psilocybin, starting on average at an age of 17 years. The drugs most often combined with mushrooms/psilocybin were tobacco (61.9\%), cannabis (59.8\%), and alcohol (41.2\%). When alcohol was combined with mushrooms, it was more common that the alcohol consumption occurred before than after the mushroom/psilocybin intake. The mushroom use did not influence the amount of alcohol consumed. However, tobacco smoking increased in combination with use of mushrooms/psilocybin.

Not unexpectedly, higher rates of using hallucinogenic mushrooms have been reported in subgroups. In a study, Schwartz and Smith (1988) reported that $26 \%$ of 174 young American drug-users had used hallucinogenic mushrooms. The use had been infrequent, but when it occurred, it did so in conjunction with alcohol or other drugs. Similar observations were done on young drug users from the great Los Angeles area (Siegel, 1985). Löhrer and co-workers asked 180 patients in a rehabilitation clinic for young addicts to fill out a questionnaire regarding their regularly consumed drugs (Löhrer and Kaiser, 1999) or plants (Löhrer and Albers, 1999). Of the 110 patients who answered the questionnaire, seventy-nine were under 30 years old. Forty-nine of them stated that they regularly $(n=23)$ or sometimes $(n=26)$ used Psilocybe mushrooms. Thus, hallucinogenic mushrooms were one of the most used drugs in youngsters of this age group on a rehabilitation clinic.

One of the earliest reports on the use of hallucinogenic mushrooms in Europe is a review of 297 psilocybin-related calls to the London National Poison Information Service between 1978 and 1981. The review revealed peak usage in the 15 to 19 years age group, with males comprising $83 \%$ or more of the cases (Francis and Murray, 1983).

In another study from the United Kingdom the extent of use of eight different types of drugs by 2610 15-16 year-olds in Wales were investigated (Smith and Nutbeam, 1992). Of the $86 \%$ of pupils returning the questionnairs, the most frequently reported drugs were marijuana, glue/solvents, and psilocybin (magic mushrooms). The current use of 
magic mushrooms was not exceptional - 97.8\% had not used it during the last month, $1.4 \%$ had tried it $1-2$ times and $0.9 \%$ at least 3 times. As many as slightly more than $10 \%$ had ever tried magic mushrooms but of these cases three quarters had only used it 1-2 times. The authors stated that drug use was likely under-reported due the higher likelihood that absentees used drugs and that some questions on drug use were not answered by between 3.8 and $7.4 \%$ of the students, figures that were somewhat higher than in other studies. Past research has indicated that absentees of school pupils will include a disproportionately large number of young people who use drugs. The prevalence of drug use was higher for pupils from single parent families, and more boys than girls reported using psilocybin.

Webb et al. (1998) studied whether the lifestyle of medicinal students in England was similar to those of students at other universities, and whether their life style had changed over time. In this study of 333 men and 417 women, $9.8 \%$ of the men and $4.6 \%$ of the women had used magic mushrooms as a hallucinogen.

In 1989 Lassen and co-workers (1992) investigated the extent of hallucinogenic mushroom consumption among students from a highschool in the county of Aarhus, Denmark, students at the University of Aarhus and students from the Danish school of journalism in Aarhus. Three percent of the high-school students had used psilocybin-containing mushrooms as a hallucinogen. Only $1 \%$ had experience with LSD. Most highschool students that had tried hallucinogenic psilocybin-containing mushrooms had tried it only a few times, often for the first time abroad. The use of psilocybin-containing mushrooms in the studied group seemed to be of a recreational nature, and did not seem to be addictive. Being a male and above 25 years of age was significantly correlated to an increased used of hallucinogenic mushrooms (Lassen et al., 1992). Of the students at the University of Aarhus, and the Danish school of journalism in Aarhus, 333 persons (83\%) returned the anonymous questionnaire concerning their use of mushrooms and other narcotics. Nine percent had experience with hallucinogenic psilocybin containing mushrooms, a surprisingly high fraction. Only $2 \%$ had experience with LSD. This suggests that mushrooms are the most commonly used hallucinogenic substance in Denmark and that the use exceeds that of LSD. Fourteen (42\%) of the 33 respondents that had used hallucinogenic mushrooms had used it only once, eleven (33\%) had used it two to four times, six (18\%) had used it five to ten times, and two (6\%) eleven to fifteen times. No one had tried it more than fifteen times. Of users, 35\% wanted to stop using mushrooms, and $60 \%$ wanted to continue or had not taken a decision on this question. Those who wanted to continue using the hallucinogenic mushrooms had significantly more friends who used mushrooms and were themselves more experience with marijuana than those who wanted to stop using mushrooms. The study also showed that the intention to use mushrooms 
is more common among persons who have friends with experience to use hallucinogenic psilocybin-containing mushrooms, and usually in small groups.

In February 1993, Ventegodt and Merrick (2003) investigated by questionnaire the connection between use of psychoactive drugs and quality of life in a representative sample of the Danish population. Among 2460 persons aged 18 to 88 years, randomly selected from the Danish Central Register, and 7222 person from the Copenhagen Perinatal Birth Cohort 1959-61 (31-33 years old), 61\% and 64\% respectively, reported their use of ten different psychotropic drugs and quality of life. The use of conscious-altering drugs was found to be widespread in Denmark. Over half the Danish population had used illegal psychotropic drugs, most commonly cannabis (marijuana). Although other hallucinogenic drugs were previously more common, the investigation showed that psilocybin is now the most frequently used hallucinogenic drug in Denmark. 5.1\% of the 31 to 33 years olds had used psilocybin compared with $1.2 \%$ of the population sample. The use was connected to a small but significant reduction in quality of life. The study did not address the question whether the drug use was the result of a non-optimal quality of life (most likely), or resulted in a reduced quality of life (less likely) (Ventegodt and Merrick, 2003).

A clear trend in drug use over the last ten to twenty years is the increased consumption of hallucinogenic drugs, including psilocybincontaining mushrooms, in the context of youth cultural and entertainment movements (Pierrot et al., 2000). Recently performed surveys show that close to 35\% of young adults in France aged 18 to 25 years had used illegal drugs. Among the participants of parties in the techno-scene the corresponding figure was no less than $80 \%$ (Vollenweider and Vollenweider-Scherpenhuyzen, 2003).

Gross et al. (2002) recruited 210 participants from three different rave parties in Montreal, a bilingual metropolitan Canadian city, to fill out a self-report questionnaire on the use of drugs during the last thirty days. The participants were between 16 and 32 years old. Average age at first use of psilocybin was 16.5 years, which was at a later age than when first using alcohol, nicotine, cannabis, and LSD. $70 \%$ of the participants had ever used psilocybin-containing drugs, and $22 \%$ during the last 30 days. On average the users had tried the mushrooms 1.7 times during the last month.

The relationship between participating in rave parties and drug use has been studied also in the United Kingdom. Riley et al. (2001) surveyed 122 drug-using attenders (57\% males, $43 \%$ females) at three dance events in Edinburgh to a questionnaire on recreational drug use. Ninety percent of the participants were in employment or education (mainly higher education), most being between 18 and 23 years old. The participants were selected by answering yes to the question: "Have you used drugs for 
dance events in the past year"? Fifteen participants (12.3\%) reported use of psilocybin. Eleven of these were men. Three of the fifteen reported using psilocybin monthly or more often. Psilocybin was often used in combination with ecstasy and/or amphetamine. The majority (85\%) of the rave party participants bought the drugs from friends (Riley et al., 2001).

More recently, McCambridge et al. (2007) in a cross-sectional survey investigated the trend in the use of hallucinogens and other adjunct drugs in the context of dancing parties in the UK 1999-2003. Whereas use of LSD decreased during the period, the prevalence in psilocybin use increased. However, the mean age at firt use and the number of days used per month were unchanged.

It should be stressed that it is far from easy to study the use of hallucinogenic mushrooms. The pattern of usage is known to vary within adolescent subcultures, and investigators attempting to describe these patterns have usually not used standardised survey techniques and datagathering instruments. Furthermore, they have not in depth evaluated the response consistency in self-reporting of young adolescents' drug use. An Irish study has recently shown that data on use/non-use of hallucinogenic mushrooms are particularly prone to be recanted a few years later (Percy et al., 2005).

\subsection{Legal aspects of hallucinogenic mushrooms and/or psilocybin and related compounds}

The natural tendency of human beings to use "mind-altering" substances is so well documented that one can easily perceive why arbitrary legislation and enforcement procedures are manifestly unsuccessful in preventing such social pharmacological behaviour in modern societies. The sanctioning of some modulators of "escape", such as ethanol, with the disapproval or legal taboo of other more efficacious substances is difficult to understand for some people.

Because the use of psilocybin-containing hallucinogenic mushrooms possibly may result in adverse effects, or at least induce uncontrolled action in the user, many countries have wished to restrict the use of these mushrooms. However, the legal frame-work to reach this goal is not easy to construct.

Three strategies of approach seem to be available to the authorities to restrict the illicit use of hallucinogenic mushrooms. These are (i) restrictions based on fungal types; (ii) restrictions based on the presence of specified chemical constituents of the fungi, or contained within extracts of preparations of the fungi; and (iii) restrictions based on hallucinogenic activity. All approaches have their specific merits and pitfalls. The merits and pitfalls of these legal approaches have been extensively discussed by 
Hall (1973) in relation to the problem of legislating against hallucinogenic mushrooms.

From a legal point of view, it might be useful to know at what stages of the life cycle of mushrooms psilocybin and psilocin can be detected. To test this question scientifically, Gross (2000) cultivated Psilocybe cyanescens mushrooms from their spores in a controlled setting, and analysed the various developmental stages of the mushroom for psilocybin and psilocin. No hallucinogenic compounds could be found in spores and in the early mycelium. The mycelium knot stage was the earliest point in time when the Psilocybe culture could be shown to contain psilocybin and psilocin. Subsequently, Gross (2002) confirmed that psilocybin and psilocin could be identified in material of Psilocybe mushrooms at later stages of development (mycelium, primordia, and mature fruit bodies). These materials were confiscated by the authorities from illicit mushroom growing operations. Although spores contain no psilocybin and psilocin, it is evident that these mushroom tissues may produce mycelium, primordial, and mature mushrooms with the hallucinogenic compounds when cultivated.

In general, the main problems associated with attempting to produce an effective legislation controlling the use of hallucinogenic fungi are related either to the necessity of making exact mycological identification, or the requirement of using chemical analytical techniques for the identification of the specific hallucinogenic compounds. Identification of mushrooms is very difficult, and is complicated by academic controversies on taxonomy. This severely complicates the situation as possession of fungal species producing hallucinogenic mushrooms or their precursors might be a criminal offence. During later years, DNA-based molecular techniques based on the polymerase chain reaction (PCR) have been developed to identify the various species at the nucleic acid level (Nugent and Saville, 2004; Maruyama et al., 2006). Lately, Linacre et al. (2002) discussed the use of DNA profiling to identify presence of 'magic mushrooms' in forensic material. Chemical analysis requires another type of expertise. A reasonable high degree of analytical skill is required to positively identify the presence of these compounds, particularly those present in small concentrations (Hall, 1973). In both these cases, the authorities have to consider the question of "possession" in great detail. Another question that has to be dealt with, if the legislation is dealing with compounds rather than mushrooms, is what to do with compounds capable of being converted into a substance with hallucinogenic properties.

The problems were exemplified with the more than 60 individual Australian drug abusers charged with offences concerning fungi containing psilocybin or psilocin in 1972. In Australia, the non-traditional use of psychoactive mushrooms became popular sometime between 1969 and 1975, whereas they became popular in New Zealand a few years later (Allen et al., 1991). This development stimulated a legislative develop- 
ment in the area, but the laws differ over the country as drug abuse legislation and enforcement systems are approved for each (nine) individual Australian State or Territory individually. The isolated compounds psilocybin and psilocin were declared drugs in Tasmania already in 1965. Only a single state in mainland Australia, Queensland, has declared a specific fungus as being a prohibited drug (on May 8, 1971). The species in question is Psilocybe cubensis (Hall, 1973). A few years later, Psilocybe mexicana and Psilocybe cubensis were declared prohibited plants in New Zealand by the Drug Act of 1975. Interestingly, none of these Psilocybe species can be found growing in New Zealand. When it was recognised that psilocybin-containing mushroom grows on the islands, an amendment to the drug Act declared all species of the genera Psilocybe and Panaeolus as prohibited fungi in 1988.

Although each country has a separate system for listing and classifying substances classified as controlled drugs, most European countries, including the Nordic countries, consider the isolated compounds psilocybine and psilocine as such controlled substances under Schedule 1 of the 1971 UN Convention on Psychotropic Substances (European legal database on drugs, 2008). At the national level, it should be noted that the classification can be conditional.

However, the control of the mushrooms themselves is interpreted in many different ways across Europe. In Denmark, cultivation, possession and sale of hallucinogenic mushrooms are specifically prohibited by Danish Executive Order BEK nr 698 of 31/8/93, "Bekendtgørelse om euforiserende stoffer". In Finland, cultivation, possession and sale of the hallucinogenic mushrooms is treated as narcotics offence according to Decree 1603/93, with severity according to the quantity. In Norway these mushrooms are prohibited according to the Regulation related to Narcotics ("Forskrift om narkotika m.v."). There is no separate, national categorisation of the substances, but Norway has adopted the categorisation used by the UN conventions. In Sweden the legal situation for hallucinogenic mushrooms is a bit more complicated. Sweden lists its controlled substances in the law "LVFS 1997:12 (Föreskrifter om ändring i Läkemedelsverkets föreskrifter om förteckningar över narkotika”). According to the Ordinance on the Control of Narcotic Drugs (1992:1554) those parts of the fungi Psilocybe semilanceata and Psilocybe cubensis growing above ground shall be considered to be narcotic drugs for the purposes of the Narcotic Drug Punishment Act (1968:64). The same shall be the case for other fungi containing psilocybin or psilocin, if the fungi have been cultivated or if they have been dried or prepared in other ways. It could also be noted that in Sweden, cultivation of narcotic drugs is punishable according to the Narcotic Drugs Punishments Act (1968:64). These legislations indicate that there is a potential for that some of the mushrooms shown by Table 4 and growing in the Nordic countries may be handled 
differently be the legal system in the Nordic countries, depending on how the mushroom has been handled.

\subsection{Market}

Of the mushrooms that have been identified to contain hallucinogenic compounds (Table 4) none is identified as a traditional edible mushroom. Although they might not be toxic, many do not have a pleasant taste, and others are small or rare. Hallucinogenic mushrooms might have a role in religious ceremonies. In his extensive systematic revision of the genus Psilocybe, Guzmán (1983) describes an episode when he in 1958 ate the hallucinogenic. Psilocybe cubensis in an Indian religious ceremony held in a very small town called Rancho El Cura, near Huautla de Jiménez. In his hallucinations he saw people, friends, and relatives who talked to him although he knew he was alone sitting on the ground in a corner of an Indian house. He also saw a "human castle" in the corner of the room, smiling and saying "come to me, do not be afraid". This castle was his mushroom dryer. The absolute majority of the hallucinogenic mushrooms available on the market are, however, intended to be used for recreational purposes.

According to Mace (1979) and Badham (1984), the quality of hallucinogenic mushrooms on the black market is highly unreliable and a gamble of the worst sort for the purchaser. Not only is the variation in psilocybin concentration greater (Bigwood and Beug, 1982), but the buyer takes the risk of purchasing adulterants. One American study from the 1970's reported that of 333 specimens, 25\% were inert, 53\% were Agaricus bisporus (J. Lange) Pilat adulterated with LSD, 1\% were Agaricus bisporus plus PCP, 4\% were Agaricus bisporus plus LSD and PCP, and $15 \%$ were hallucinogenic Psilocybe sp. (Ratcliffe, 1974). It is not known whether this type of fraud is equally common today and in the Nordic countries. Additionally, street "psilocybin" has frequently been found to be LSD or other, mostly unidentified compounds (Johnson and Gunn, 1972; Brown and Malone, 1973, 1976; Kok et al., 1973; Mattke and Steinigen, 1973).

Since mushroom-growing kits can be purchased over internet or on the black market, it should be kept in mind that many psychoactive mushrooms are grown in vitro and sold on the illicit market. Apart from fresh or dried mushrooms, other unconventional preparations of Psilocybe mushrooms on the market include crushed dried Psilocybe mushroom in honey, "blue mead" (honey with blue Psilocybe mexicana mushrooms) and pizza with Psilocybe mushrooms, to mention a few (Bogusz et al., 1998). More recent description of the local mushroom market is given in the review of Supprian et al. (2001). 



\section{Summary of biological effects of psilocybin and psilocin}

This section does not intend to review the extensive literature on the pharmacological and toxicological effects available on psilocybin and psilocin. It only aims at presenting the most characteristic properties of the compounds in relation to effects observed in humans. Animal data will only be mention as supporting information.

\subsection{Pharmacokinetic}

In the human body, psilocybin from hallucinogenic mushrooms is rapidly metabolised to the active compound psilocin, presumably via a first pass effect by hepatic metabolism, and then easily taken up by tissues and exert a multitude of pharmacological effects (Hasler et al., 1997). The absence of reliable chemical analytical methods for psilocybin in plasma have not made it possible to show the absence of psilocybin in the blood during the active phase of the hallucinogenic experiences, and confirm that psilocin is the active metabolite.

Psilocybin and psilocin are stoichiometrically equivalent in potency. Pharmacokinetic studies have shown that slightly more than 50 percent of orally supplied psilocin is absorbed, and its activity distributed uniformly in the body, including the brain (Kalberer et al., 1962; Hopf and Eckert, 1969). Serum levels $\left(C_{\max }\right.$ commonly in the region $\left.4-21 \mathrm{ng} / \mathrm{ml}\right)$ and pharmacological activity (from $4 \mathrm{ng} / \mathrm{ml}$ in serum) peak within 2 hours after the psilocybin intake, and then decline over the next 3 to 4 hours (Hasler et al., 1997; Lindenblatt et al., 1998; Halpern, 2004). As the average half-life of psilocin is reported to be about 2.5-3.0 hours, the psilocin concentration reaches the limit of quantification within around 6-7 hours (Hasler et al., 1997; Anastos et al., 2005). Psilocin is excreted in urine, mainly as glucuronide and unchanged psilocin (Sticht and Käferstein, 2000; Hasler et al., 2002; Kamata et al., 2003). Other metabolites found in lower quantities include 4-hydroxyindole-3-yl-acetaldehyde, 4hydroxyindole-3-yl-acetic acid, and 4-hydroxytryptophol (Holzmann, 1995; Hasler et al., 1997). A possible metabolic scheme for psilocybin in humans has been suggested by Passie et al. (2002).

Psilocin is an indoleamine that is structurally related to the neurotransmitter of the central nervous system serotonin (5-hydroxytryptamine; 5-HT) and the drug lysergide (LSD-25). The psychotomimetic effects observed after exposure to psilocybin/psilocin result from stimulation of 
5-hydroxytryptamine receptors, especially the $5-\mathrm{HT}^{2 \mathrm{a}}$ receptor (Strassman, 1992; Vollenweider et al., 1998). It is discussed in the scientific community whether also other receptors are influenced by psilocybin/psilocin. In contrast to LSD, psilocybin has no affinity for dopamine receptors (Creese et al., 1975).

Using PET methodology to study brain metabolism of psilocybin, Gouzoulis et al. (1999b) found no increase of global brain metabolism after per oral exposure to $0.2 \mathrm{mg} / \mathrm{kg}$ psilocybin, whereas Vollenweider et al. (1997) found a general increase of cortical metabolism in various parts of the brain after slightly higher exposure levels $(0.26 \mathrm{mg} / \mathrm{kg})$.

\subsection{Pharmacological effects in humans}

Psilocybin and psilocin are stoichiometrically equivalent in potency. Therefore, the symptoms induced by psilocybin-containing mushrooms, psilocybin or psilocin are more or less equivalent. It is believed that the former is dephosphorylated to psilocin in vivo. Psilocybin is an inhibitor of serotonin, the major indolic neurotransmitter of the central nervous system. It is also an autonomic stimulant, leading to characteristic mydriasis, piloerection and hyperthermia. The mono- and demethylated analogues baeocystin and norbaeocystin are much less explored pharmacologically.

Already in the first publication reporting the isolation of psilocybin from hallucinogenic mushrooms, it was stated that per oral application of the compound in man produce similar psychotropic effects to the mushroom Psilocybe mexicana (Hofmann et al., 1958a). Depending on the individual, an intake of 4-10 mg psilocybin/psilocin, or 1-2 $\mathrm{g}$ of the dried Psilocybe mushroom, results in effects searched for. These psychic effects include stimulation, enhanced ability for introspection and altered psychological functioning in the direction of Freudian primary processes, also known as hypnagogic experience and dreams (Passie et al., 2002). Especially noteworthy are generally pleasant sensation of intellectual and bodily relaxation and detachment from the environment (perceptual changes such as illusions, synaestesias, affective activation, and alterations of thought and time sense), without producing a setback. The central effects obtained become apparent in about 20-30 minutes and develop with a startling rapidity over the following 20 minutes. Higher doses, at least $6 \mathrm{mg}$, produce more profound changes associated with altered temporal and spatial perception, an introspective state, and a variety of visual effects. Illusions and hallucinations may be experienced (Cerletti and Hofmann, 1963).

A difficulty with the hallucinogenic compounds is that the subjective experiences produced vary considerably from person to person and within the same person on different occasions. These experiences are markedly 
influenced by the expectations of the user and the setting in which the drugs are taken, as well as by the personality structure and mental status of the user (Franz et al., 1996). There is frequently time distortion (subjective slowing) under influence of psilocybin/psilocin. The activity plateau rarely lasts much more than an hour and is characterized by alterations in spatial and temporal perception, often with distortions in awareness of body image. Positive expectations usually lead to pleasant experiences and, conversely, larger doses in users with anxiety or uncertainty may allow adverse experince. In the absence of visual and auditory input (as with night-time isolation) the experience can be largely fantasy and rich with hypnogogic imagery. Gradual recovery requires an additional two to three hours and there is a good recall of the phenomena experienced (Shulgin, 1980).

There are a number of general features which are characteristic of the psychedelic reaction. Perceptual changes include illusions, pseudohallucinations, and hallucinations. Vision seems most affected. Most common are illusions. Objects, pictures, or patterns seem to come alive, shift, ripple, or become wavy. Depth relationships are altered so that twodimensional objects appear three-dimensional.

More common than true hallucinations, are pseudo-hallucinations in which the user has a visual experience without any appropriate sensory cue, but he knows his visions are subjective, a result of the influence of the drug. He may se geometric figures, kaleidoscopic shapes, or flashes of light. He may see dream-like sequences of panoramic visions related to previous life experiences, tranquil scenes, or imagined horrors. True hallucinations are rare but may assume almost any form.

Colours appear more brilliant and intense. Nuances of colours are often experienced as emotionally meaningful and exceptionally beautiful. Changed perception in the other senses is not as dramtic, but taste, touch, smell, and hearing all seem to become more acute.

A remarkable feature of the hallucinogenic drug reaction concerns the translation of one type of sensory experience into another, or synesthesia. Sounds or music may be experienced visually or as bodily vibrations. The user may think he can feel or taste colours and images. Perception and mood become interwoven. Colour may come to represent a particular emotion and induce it.

When psilocybin was given to healthy volunteers, psychological symptoms reported were emotional alterations (100\%), disorders/alterations of consciousness (91\%), depersonalisation (84\%), perceptual alterations (75\%), disorders/alteration of volition and psychomotor behaviour (34\%), body image distortions (25\%), disorders/alteration of attention (22\%), disturbances in thought processes (22\%), and disorders of memory (19\%) (Parashos, 1976-1977; Spitzer et al., 1996; Vollenweider et al., 1999). Similar symptom picture was noted in schizophrenic patients consuming psilocybin, as illustrated by two case reports by 
Nielen et al. (2004). The cases illustrate that in schizophrenic patients hallucinogenic mushrooms may induce an acute psychotic state that necessitate hospitalisation (Nielen et al., 2004). The psychotic symptoms in volunteers appeared within 20 to 30 minutes after oral ingestion, lasted for about two hours and subsided completely within six hours. There are no epidemiological on long-lasting psychiatric complications (Supprian et al., 2001).

However, psilocybin is also an autonomic stimulant, leading to characteristic mydriasis, piloerection, irregularities in heart and breathing rate, and hyperthermia. Similar pharmacological effects have been documented in mice, rats, rabbits, cats, dogs and rhesus monkeys (Cerletti, 1958; Horibe, 1974). The mono- and demethylated analogues baeocystin and norbaeocystin are much less explored pharmacologically.

Emotional lability, extreme mood swings, and spontaneous emotional discharges are common. The user may become profoundly depressed, anxious, fearful, giggly, euphoric, serene, or ecstatic during a single drug experience. Occasionally, blunting of affect, suspiciousness, hostility, or suicidal urges may be felt. The user can usually converse rationally when pressed to do so and can subsequently recall much of his drug experince.

Importantly, it has not been established whether the potential benefits of the use of psychedelic drugs justify the risk of adverse reactions. From the users point of view, out of all mushroom users in a study $73 \%$ reported some positive effects of the use and approximately $45 \%$ reported only positive effects. Only 5\% reported predominantly negative effects (Thompson et al., 1985). In a double-blind study on hallucinogen-naïve subjects, Griffiths et al. (2006) recently showed that psilocybin under supportive conditions give rise to experiences similar to spontaneously occurring mystical experiences that were rated very positively by the volunteers. Negative effects were rare. Higher rates of adverse reactions have been reported in habitual drug users (Schwartz and Smith, 1988).

\subsection{Hallucinogenic experience and potential toxicity}

The magic mushrooms are inconspicuous and are not likely to attract the interest of anyone looking for food mushrooms. However, intoxications due to ingestion of hallucinogenic mushrooms thought to be edible mushrooms have been reported. Ancient or historic evidence of cerebral mycetisms induced by accidental ingestion of psychoactive mushrooms in various parts of the world has been reviewed by Allen et al. (1991). The authors of this review article points out that outside of a few intoxications caused by Psilocybe cubensis and Psilocybe semilanceata (Cullinan and Henry, 1945; Charters, 1957; Stein, 1958; Wasson, 1959; Stocks, 1963; Heim, 1971; Harries and Evans, 1981), the majority of all intoxications that occurred before the deliberate recreational use of hallucinogenic 
mushroom species was caused by various species of Panaeolus, with the exception of Japan where some of the inebriations were the result of ingesting Gymnopilus species and some that were attributed to the ingestion of Stropharia caerulescens. Because of some similarities with the edible mushroom Marasmius oreades (Bolt.:Fr.) Fr., Inocybe aeruginascens has subsequently caused accidental hallucinogenic poisonings in previous East-Germany and Hungary (Drewitz, 1983; Gartz and Drewitz, 1985, 1986; Gartz, 1986, 1989). Other cases of miss-identification of food mushrooms have been described by Bigwood and Beug (1982), Rold (1986), Raff et al. (1992) and Calvino et al. (1998).

Magic mushrooms are usually collected by persons solely interested in mushrooms containing hallucinogens. These mushroom collectors frequently rely on only two identifying characteristics: a habitat on or near dung in pastures, and stems that stain blue on handling. Since even professional mycologists have difficulties identifying many of these small brown mushrooms, it is no wonder that the uninformed mushroom hunter makes mistakes. Some of these mistakes may be of low risk, others may lead to poisoning, which sometimes may be severe.

Other risks to become intoxicated by hallucinogenic mushrooms are usually related to natural variation in psilocybin content of the mushrooms (see, Table 4; differences between flushes, differences between wild and cultivated mushrooms, etc.), miss-quantification of dose (mushroom weight and number) or exaggerated intake (e.g., Harries and Evans, 1981), and differences in individual tolerance to hallucinogenic mushrooms (Beug and Bigwood, 1982; Bigwood and Beug, 1982). Stamets (1996) has calculated the threshold for intoxication to approximately 40 $\mu \mathrm{g}$ psilocybin/kg body weight, which typically would correspond to about 1-2 g of dried mushroom, or approximately 4 to $20 \mathrm{mg}$ psilocybin. Allen et al. (1991) have drawn similar conclusions, whereas others have indicated that clinical doses usually require larger amounts (Stein, 1958; Lincoff and Mitchell, 1977; Weil, 1980).

It should be noted that several of the mushrooms mentioned in Table 4 and 5 contain other bioactive constituents in addition to the hallucinogenic compounds. These constituents can of course influence the intoxication syndromes described. For example, the most common hallucinogenic mushroom in the Nordic countries, Psilocybe semilanceata, contains the biogenic amine phenylethylamine (Beck et al., 1998).

In Mexico, where hallucinogenic mushrooms has a natural niche in everyday life, there are persons who have consumed hallucinogenic mushrooms since their youth until they die over 70 years of age, without apparent physical illness (Allen et al., 1991). The acute toxicity of psilocybin/psilocin is very low (Cerletti, 1959; Hofmann, 1960; Auert et al., 1980; Leuner, 1981; Flammer and Horak, 1983; Gartz and Drewitz, 1986; Holm et al., 1997). In a recent double-blind, placebo-controlled doseeffect study with psilocybin in healthy subjects, the investigators found 
no cause for concern that psilocybin is hazardous with respect to somatic health (Hasler et al., 2004). Damage to the body may, however, occur when the perception of reality of an individual is influenced in such a way by the hallucinogenic mushrooms that he or she behaves in a risky way. For instance, Asselborn et al. (2000) describe an incident where two girls ingested a handful of Psilocybe mushrooms (species undefined) together with soft drinks. One of the girls tried to fly from a window on the second floor, fell to the ground and fatally fractured the scull. Chemical analysis of the mushroom revealed around $11000 \mathrm{mg}$ psilocybin and $5000 \mathrm{mg}$ psilocin/kg mushroom. Post-mortem studies of heart blood revealed $0.09 \mathrm{mg}$ psilocin $/ \mathrm{mL}$, one third of which was free psilocin. The compound was also quantified in femoral venous blood, urine, bile, liver, kidney and lung. No psilocin, or other drugs, was found in the hair, indicating that the girl had no history of drug use. It should be mentioned, however, that there are two reports on severe toxicity, although the role of the hallucinogenic mushrooms for these cases is not totally clear. In one case rhabdomyolysis was reported in a hepatitis C-infected man with a history of heroin, opiate and cannabis abuse (Bickel et al., 2005). In the other case (Gerault and Picart, 1996), a 22-year old man used to alcohol consumption and cannabis smoking died after first having consumed 3050 raw mushrooms (most likely Psilocybe semilanceata) when picking them, another 10 raw mushrooms three hours later, and a cup of tea prepared on mushrooms another two hours later, although he at this time did not feel well. When he got unconscious and was taken to hospital, there was no care to get. Having been transported back to his home he died. A standard forensic analysis on body fluids and tissues were performed without identification of any drugs and foreign substances except psilocin. The level of psilocin in the blood was $4 \mu \mathrm{g} / \mathrm{mL}$. Four friends who joined the victim drinking tea prepared on the mushrooms collected by the victim showed different symptoms from only feeling drunk to having colour vision or getting cramp.

The minimum amount of mushrooms required to promote "therapeutic" doses is somewhere between two and six, assuming mushrooms of high content of psilocybin or psilocin. Agitation and hallucinations may be seen with 10 mushrooms in one case, whereas 200 may produce only gastritis in another. Prolonged sympathomimetic effects and psychosis have been seen with 50 to 60 mushrooms (Hyde et al., 1978). Hollister and co-workers have described both the time sequence of onset of clinical effects from psilocybin among 16 subjects exposed orally to doses between 60 and $209 \mu \mathrm{g} / \mathrm{kg}$, and the frequency of response among 19 subjects given an oral dose of $150 \mu \mathrm{g} / \mathrm{kg}$ (Hollister, 1961; Hollister and Hartman, 1962; Hollister et al., 1960). The following clinical effects were mentioned for psilocybin intoxication in humans: 
0-30 min Slight nausea, giddiness (light headed), abdominal discomfort, weakness, muscle aches and twitches, shivering, anxiety, restlessness, and a numbness of lips.

30-60 min Visual effects (blurring, brighter colour, sharper outlines, longer after-images, visual patterns with closed eyes). Increased hearing, yawning, sweating, facial flushing. Decreased concentration and attention, slow thinking, feelings of unreality, depersonalisation, dreamy state. Incoordination, tremulous speech.

60-120 min Increased visual effects (coloured patterns and shapes, mostly with eyes closed). Wave-motion of viewed surfaces. Impaired distant perception. Euphoria, increased perception, and slowed passage of time.

120-240 min Waning and nearly complete resolution of above effects. Returning to normal within 4-12 hours. Other effects often included decreased salivation and appetite; uncontrollable laughter, transient sexual feelings and synethesis.

Similar symptoms and absence of adverse toxic effects in humans have been observed by others (Isbell, 1959; Gouzoulis-Mayfrank et al., 1999b)

In cases of intoxication, it might be useful to distinguish between the primary toxic effects and the secondary effects resulting due to the exposed persons emotional reactions to the primary symptoms of intoxication. The primary toxicological actions of psilocybin and related compounds are sympaticomimetic adrenergic symptoms and mental effects. Sympaticomimetic adrenergic symptoms include mydriasis, flushing and hyperreflexia, and elevated blood preassure, heart rate, frequency of respiration and body temperature; also tremor, dizziness, nausea, dryness of the mouth and tiredness may occur. The mental effects include euphoria, experiences of unreality, altered conception of time, feeling of happiness and clearness of mind. As a consequence of the previous reactions, illusions, pseudohallucinations or real hallucinations may occur. Table 6 summarizes most of the case reports on acute psychiatric symptoms after consumption of psilocybin-containing mushrooms. It should be stressed that most cases described in Tables 6 and 7 themselfes chose to consume the hallucinogenic mushrooms, that is, it is a recreational activity. The five reported cases from Japan (Musha et al., 1986), where Psilocybe argentipes were consumed, were, however, accidental cases. None of these consumers expected to have the type of experience they had.

Although primarily psychological effects are associated with consumption of psilocybin-containing mushrooms, depressive or paranoid reactions, mood changes, disorientation, and an inability to distinguish between real- 
ity and fantasy may sometimes occur (Leary et al., 1963; Mills et al., 1979; Weil, 1980; Grinspoon and Bakalar, 1981). Understandably, other routes of exposure might be significantly more dangerous. There are case reports on persons that have extracted Psilocybe mushrooms and experienced severe toxic symptoms after having injected the extract intravenously (Sivyer and Dorrington, 1984; Curry and Rose, 1985).

Fatal intoxications from the exposure to hallucinogenic mushrooms are rare (McCawley et al., 1962; Gonmori and Yoshioka, 2003). The first case was a 6-year-old child who developed hyperthermia and status epilepticus following ingestion of Psilocybe baeocystis (McCawley et al., 1962). In the latter case a 27-year-old man was found in an irrigation canal. Cultivations of Psilocybe subcubensis was found in his home and psilocybin/psilocin were detected both in the mushroom, and in body fluids of the diseased man. It was suggested that the case had been influenced by the hallucinogenic substances and died of cold temperature in winter time.

A death of an 18-year-old male living in Hawaii, was in commercial media declared to have died due to consumption of ten hallucinogenic mushrooms. Later investigations into his death, however, showed that the youngster died of an overdose of heroine. Psilocybin or psilocin were not detected in the stomach content, nor was amatoxins (Allen, 1988).

An unexpected risk was highlighted by two young mushroom hunters being shot in Florida when looking for their afterthought treasure (Lincoff and Mitchel, 1977). 


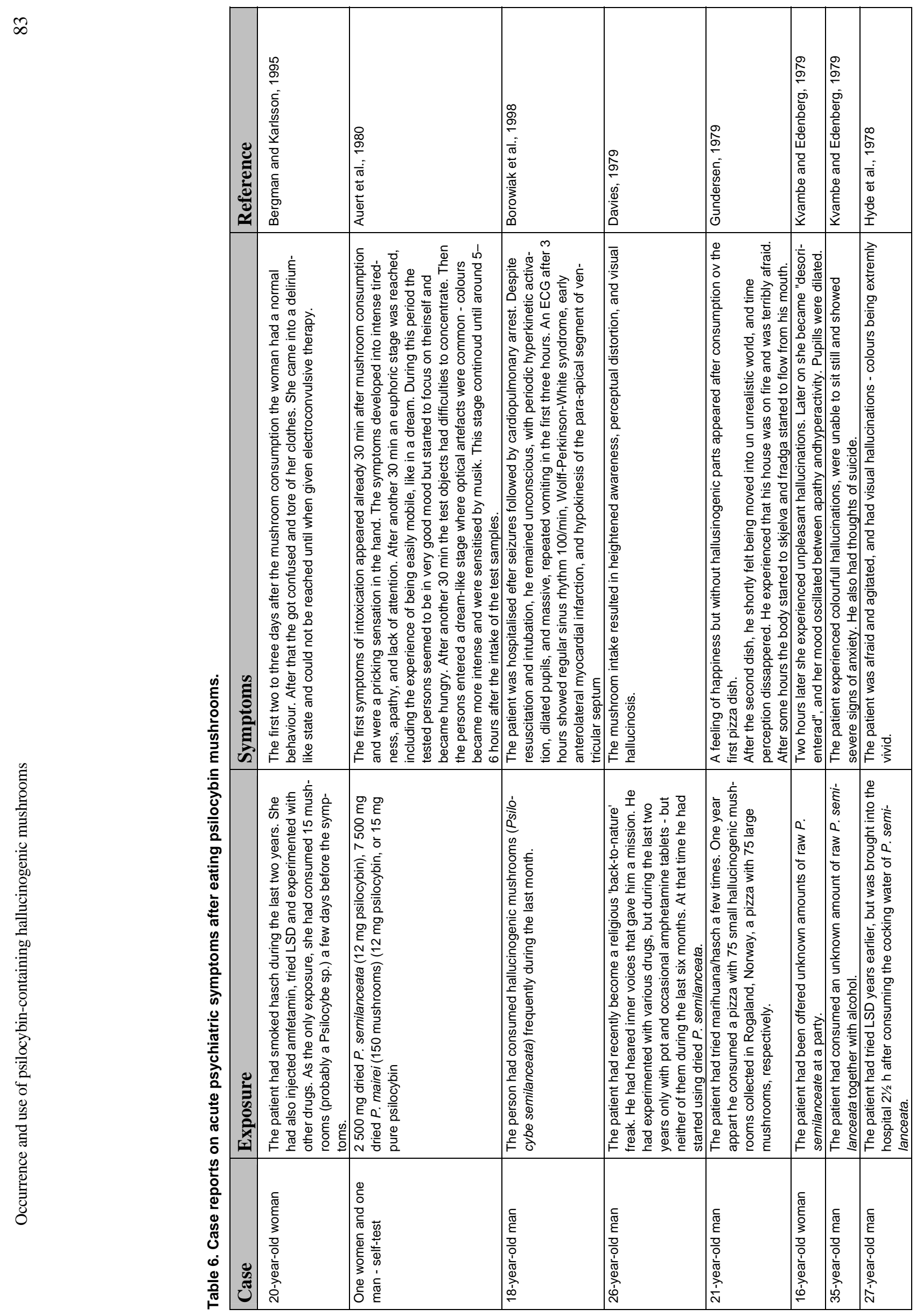




\begin{tabular}{|c|c|c|c|c|c|c|c|c|c|c|}
\hline 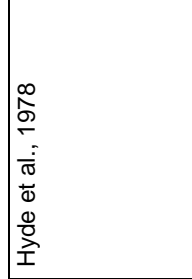 & 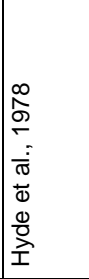 & 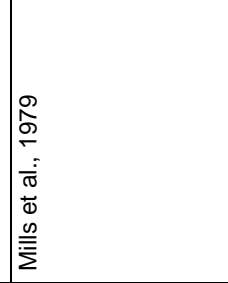 & 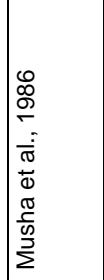 & 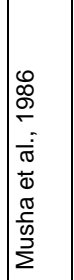 & 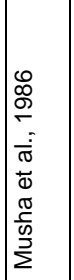 & $\mid$ & 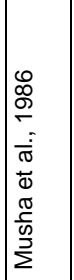 & 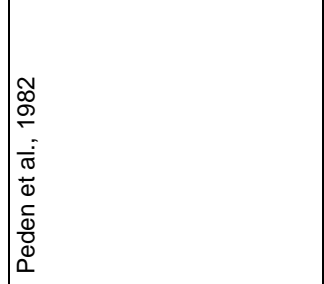 & 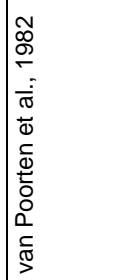 & 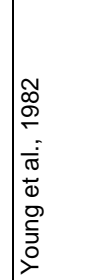 \\
\hline 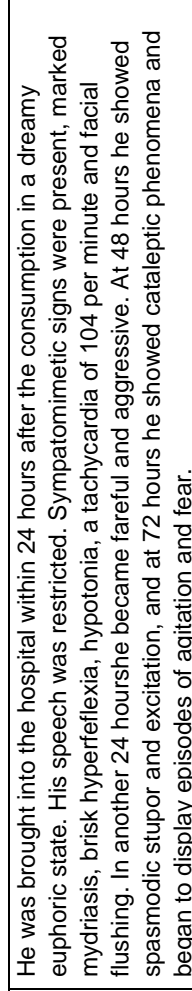 & 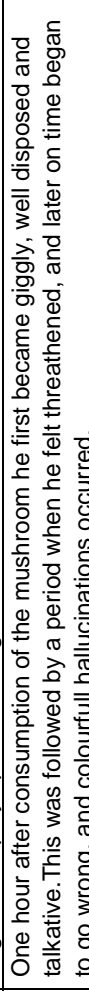 & 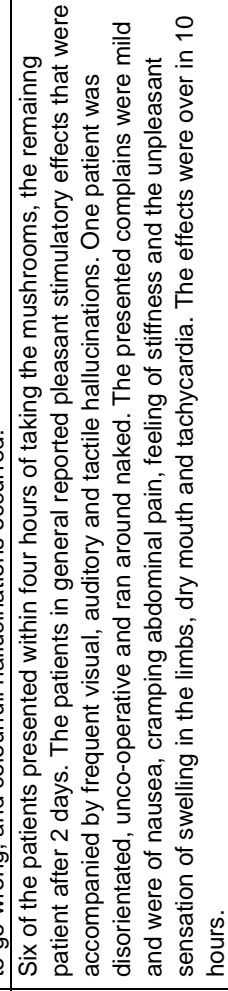 & 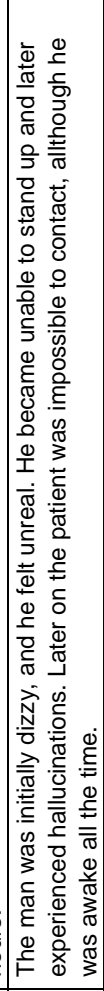 & 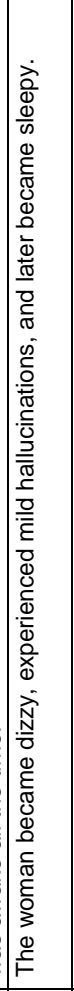 & 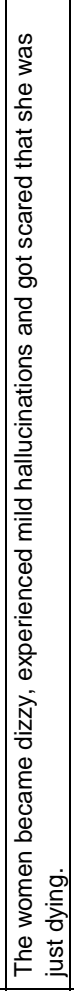 & 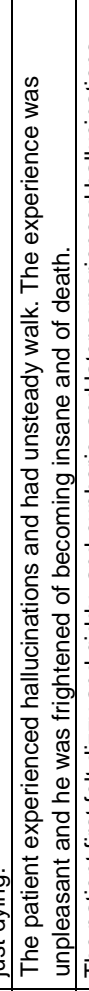 & 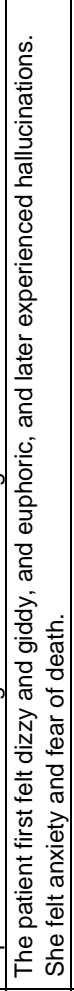 & 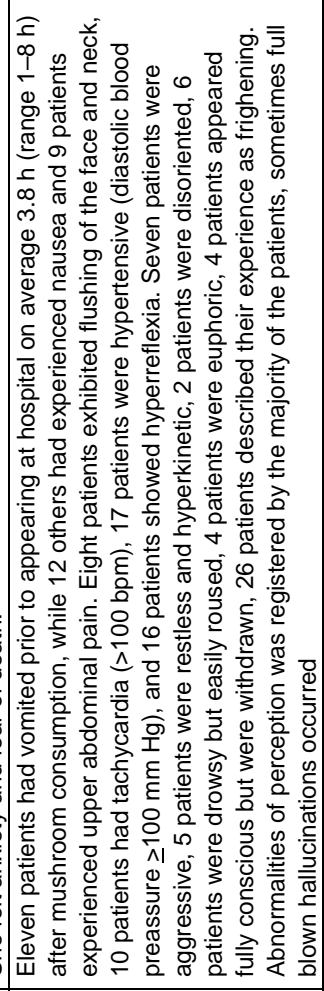 & 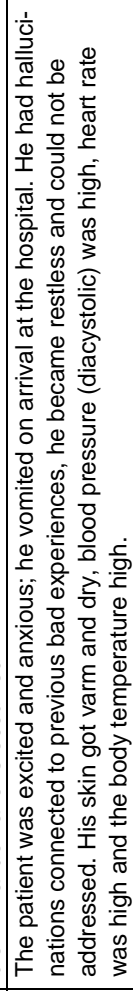 & 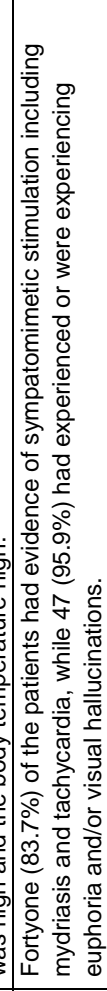 \\
\hline 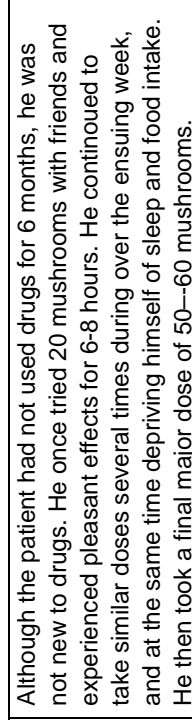 & 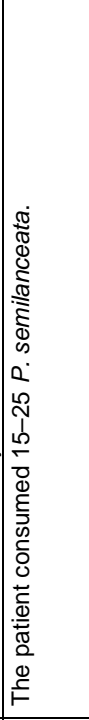 & 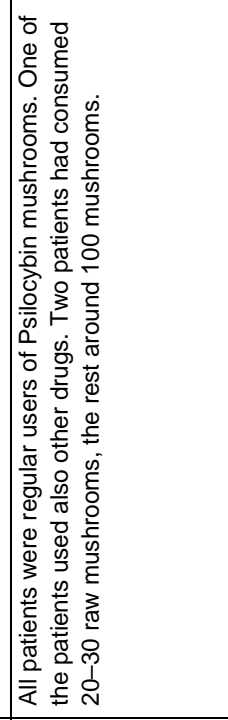 & 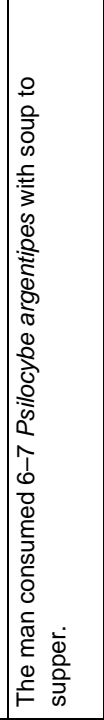 & 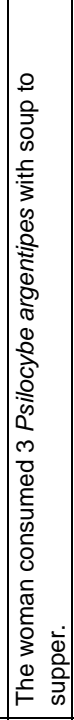 & 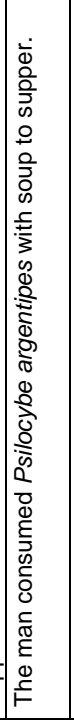 & 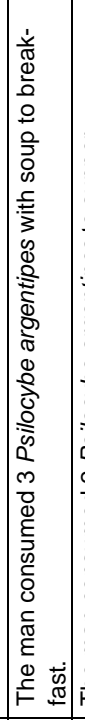 & 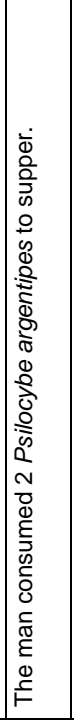 & 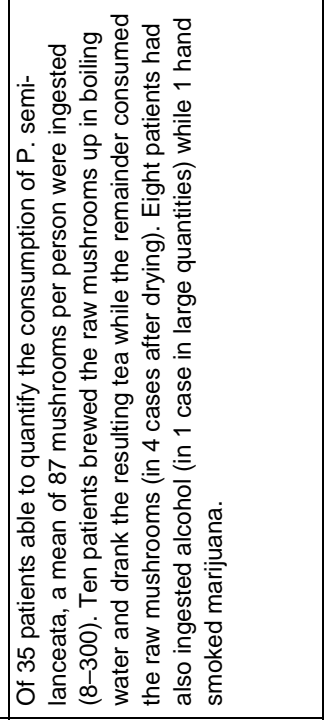 & 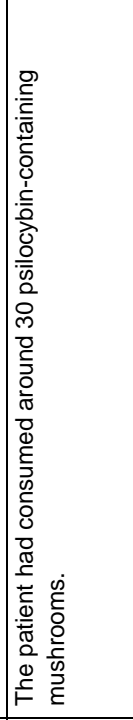 & 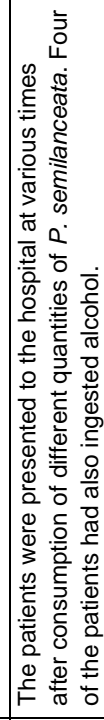 \\
\hline 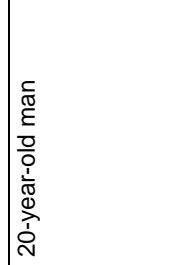 & 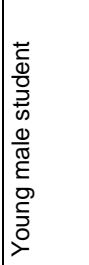 & 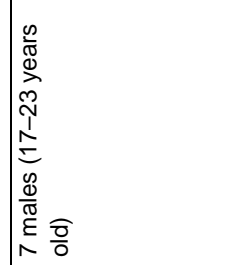 & 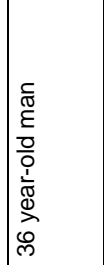 & 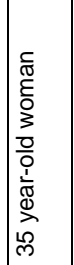 & 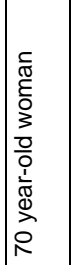 & 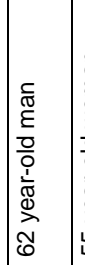 & 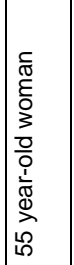 & 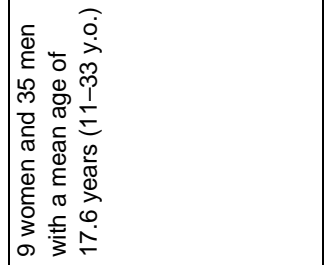 & 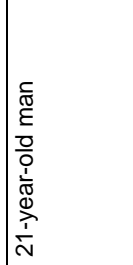 & 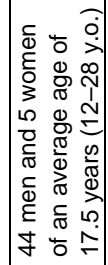 \\
\hline
\end{tabular}




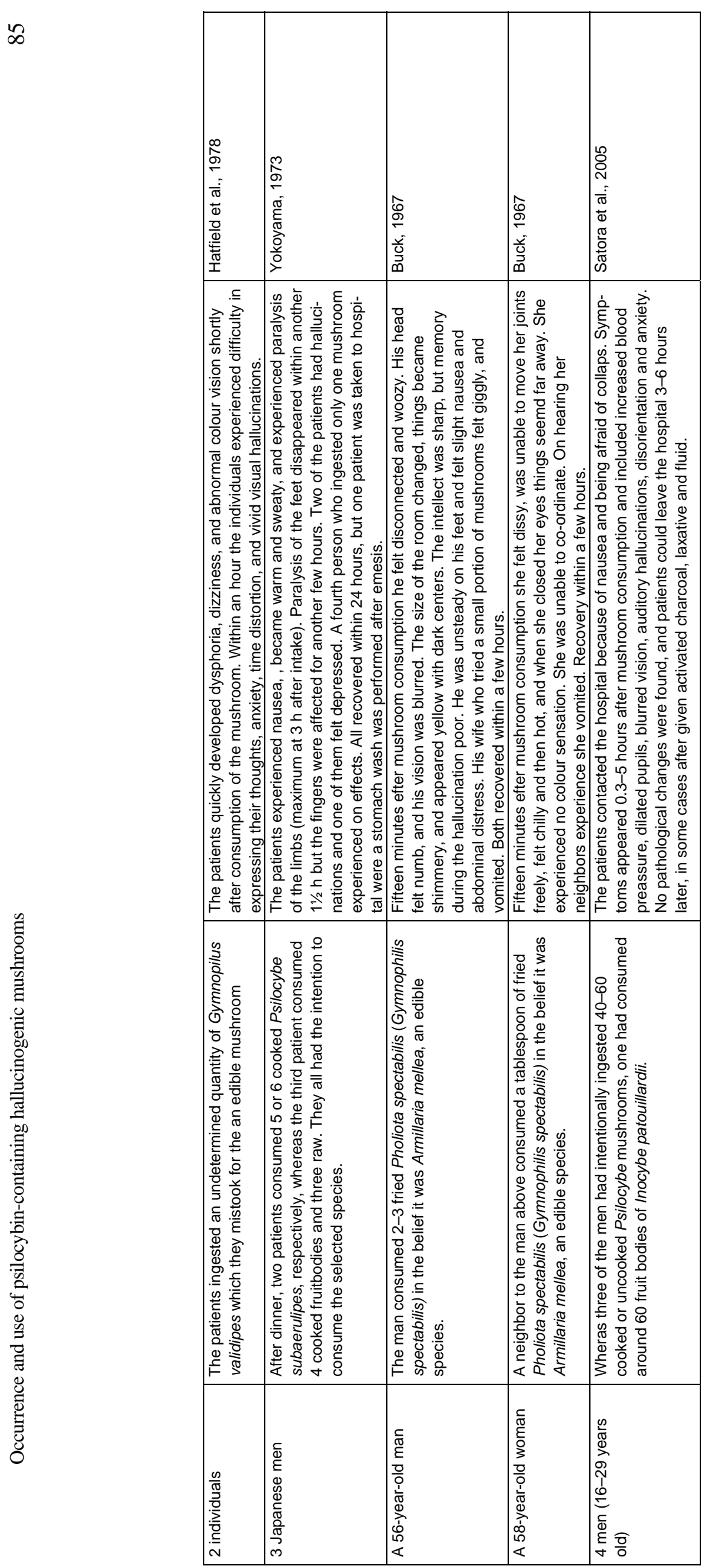


In summarising the 150 known cases of intoxication from psychoactive mushrooms in Australia and New Zealand between 1934 and 1989, Allen et al. (1991) pointed out that only one case required hospital care, and that was because he had fallen and cut his head. However, three of 150 persons (2\%) had suffered prolonged psychological difficulties following their mushroom experience, two of which were flashbacks. In these cases a predisposition was acknowledged for two of the people. Therefore, it could be argued that certain people are psychologically at serious risk from these substances and must be urged to avoid them (Allen et al., 1991).

There has been continuing concern as to the long-term effects of psilocybin and other hallucinogenic compounds on the human body. The most notable concerns have been the possibility or recurrent flashbacks. Flashbacks are spontaneous recurrences of a previous psilocybin experience after the immediate effect of the drug has worn off and without renewed intake of the compound. Table 7 summarizes cases of persistent psychiatric symptoms described in the literature. Espiard et al. (2005) described a 18-year old student that appeared at the clinic with perceptual impairments. These were lasting for 8 months. The patient had a history of social anxiety and a troubled family situation. He smoked moderate amounts of cannabis regularly. Perceptual distortions initially appeared after unique psilocybin consumption (40 mushrooms of the species Psilocybe semilanceata in infusion). During later use of cannabis he reexperienced the symptoms (objects' distortions, relief's modifications, auditory disturbances with resonance feeling, depersonalisation, derealization, body lightness or weightiness feeling, spatiotemporal disturbances, and inability to distinguish illusion from reality). The flashbacks started to weaken when the student stopped using cannabis. No somatic lesions were identified. The flashbacks disappeared six month later after several months on chemotherapeutica. The prevalence of flashbacks, and its requirement for expression is difficult to estimate.

Other long-term effects investigated include potential reproductive toxicity, teratogenicity and mutagenicity. The result of none of these has given rise to concern. Already in 1967 Rolsten evaluated the effect of oral administration of $25 \mathrm{mg}$ psilocin per $\mathrm{kg}$ body weight on pregnant C57BL/10 mice and their offspring. The psilocin treatment had no influence on fertility as determined by pregnancy rate, pregnancy length, and weight gain. It also did not influence maternal brain weight, liver glycogen, and serum cholesterol, and brain, liver, and heart organ to body weight ratios, or mean litter weight. Neither were any influences on serum and organ biochemistry of the offspring at birth found (Rolsten, 1967). An American population-based case-control study performed 1989-1991 found no increased risk for neural tube defects due to maternal and paternal periconceptional use of psilocybin/mushrooms/peyote or other recreational drugs (Shaw et al., 1996). 
$\infty$

\begin{tabular}{|c|c|c|c|c|}
\hline & 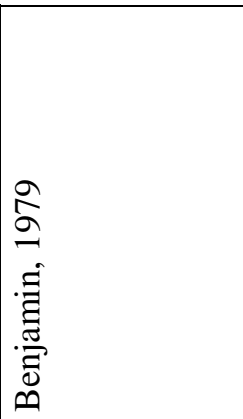 & 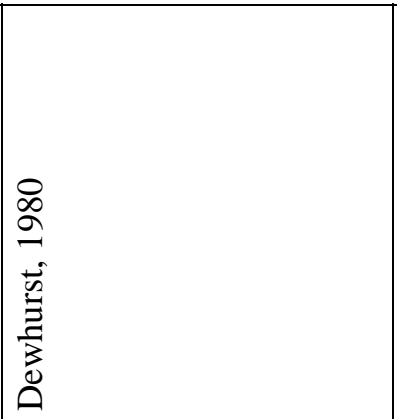 & 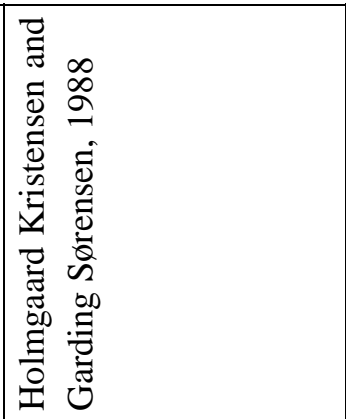 & 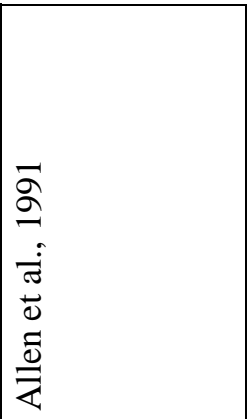 \\
\hline & 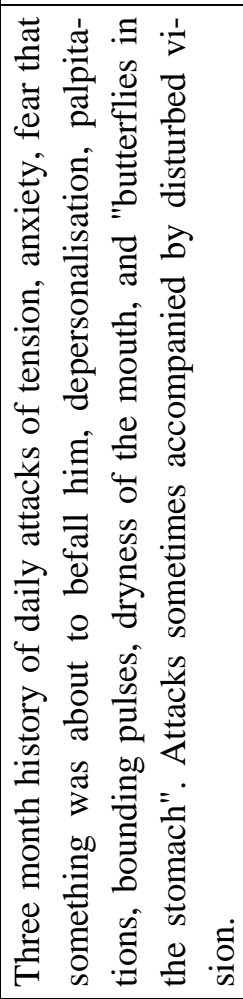 & 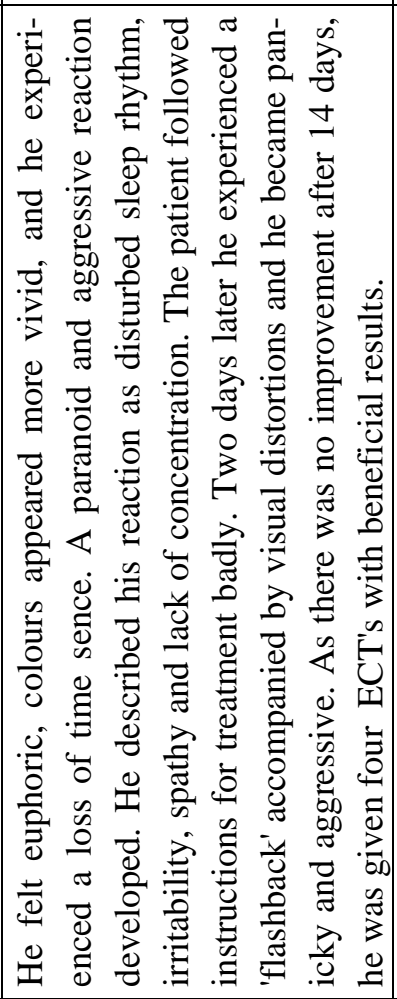 & 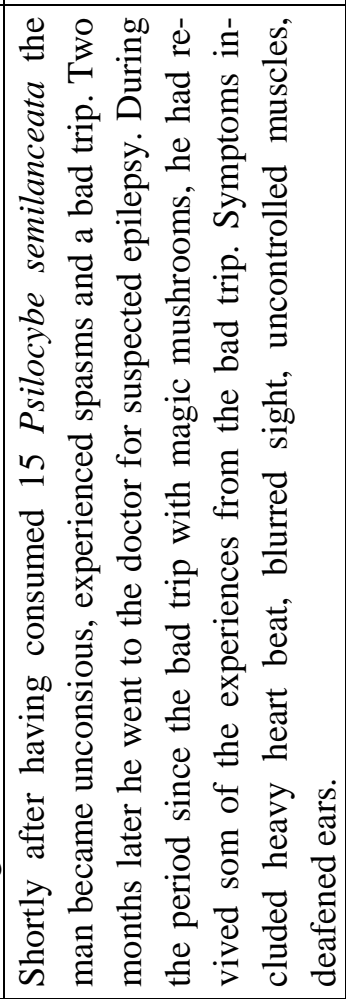 & 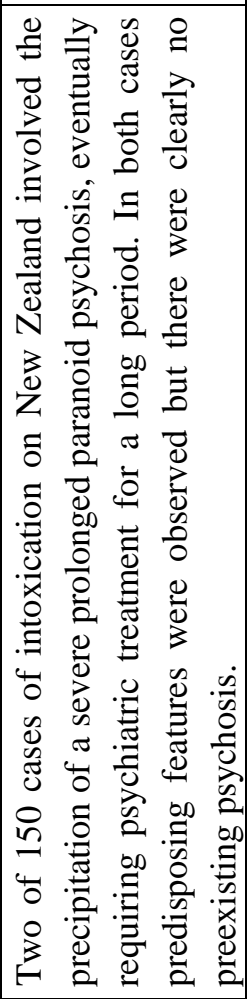 \\
\hline 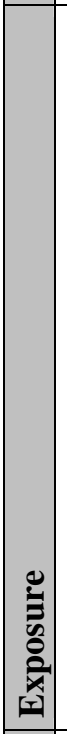 & 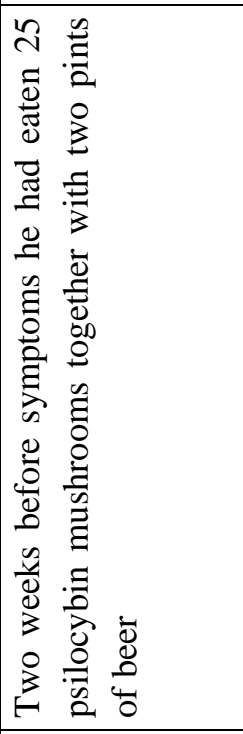 & 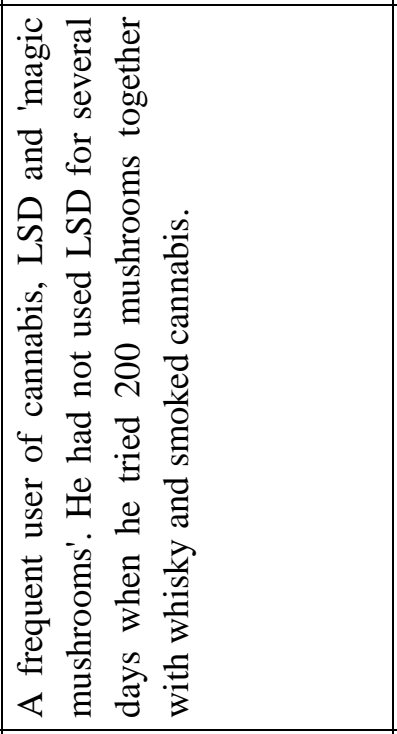 & 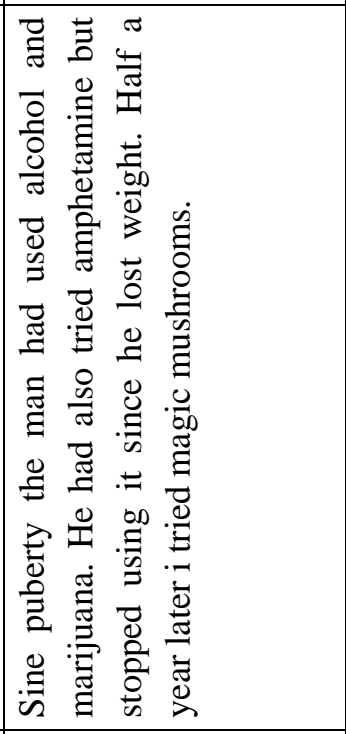 & 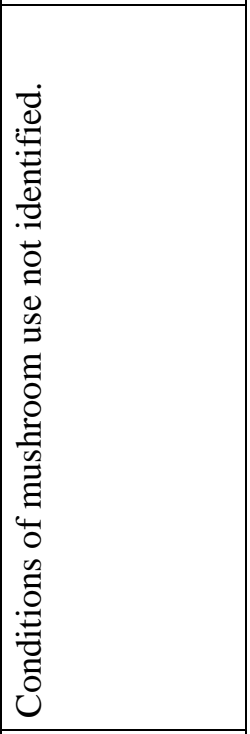 \\
\hline u & 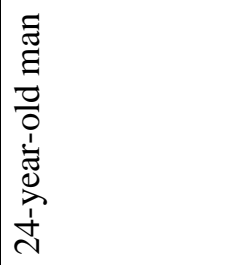 & 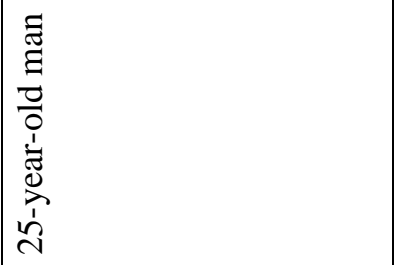 & 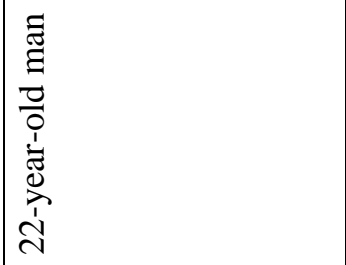 & 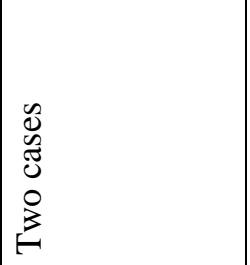 \\
\hline
\end{tabular}


No micronuclei were induced in mice exposed to 4, 8 or $16 \mathrm{mg}$ psilocybin per kg body weight (Van Went, 1978). Tolerance to psilocybin (or cross-tolerance with LSD) might develop, but physical dependence does not occur (Abramson et al., 1956; Isbel et al., 1961; Abramson and Rolo, 1965; Balestrieri, 1967).

\subsection{Hallucinogenic mushroom use in the Nordic countries}

In Norway the first report on the use of Psilocybe semilanceata as delivering a recreational drug appeared in 1977, and several others have appeared thereafter (Nordbø, 1979, Kvambe and Edenberg, 1979). These reports described hallucinogenic intoxications of consuming the mushroom and stimulated investigations into the content of psilocybin and psilocin in Norwegain mushrooms (Høiland, 1978; Høiland et al., 1984; Christiansen et al., 1984; also see Table 4). It was concluded that Psilocybe semilanceata is rich in hallucinogenic compounds, and that there is a marked difference in psilocybin content between samples (Christiansen et al., 1982). It was also concluded that it is a risk that mushroom pickers looking for $P$. semilanceata might by mistake collect several different toxic mushrooms with a similar structure.

Beck and his colleagues (1998) have discussed the clinical data that had been collected from hospital case records and sent to the Swedish Poison Information Centre concerning Psilocybe mushroom poisoning during the period 1980-1995. The total number of patients was 25, of which 21 were between 19 and 27 years of age. Five of the cases occurred in 1995. The recorded symptoms in these hospitalized patients included mydriasis (68\%), visual hallucinations (52\%), tachycardia (44\%), anxiety (40\%), euphoria (24\%), agitation (16\%), hypertention (16\%), , hyperflexia (12\%), flushing (12\%), nausea (12\%) and flashbacks (8\%). Thus, the symptoms in Swedish patients were the same as those observed in patients from other countries (Malitz et al., 1960; Peden et al., 1981, 1982).

Beck and colleagues (1998) also verified the presence of 1000-3 500 $\mathrm{mg} / \mathrm{kg}$ wet weight psilocybin in Psilocybe semilanceata mushrooms that had resulted in intoxications at three different locations in Sweden. However, these investigators also noted that these mushrooms contained the biogenic amine phenylethylamine (1-146 mg/kg wet weight). The sample with the highest level of phenylethylamine came from the clinical case of hospitalization after the ingestion of magic mushrooms. The pharmacological mode of action of phenylethylamine is not fully elucidated, but it has been reported to exert amphetamine-like activity and to have peripheral sympathomimetic effects (Schwarts and Smith, 1988; Shulgin, 1980; Mantegazza and Riva, 1963; Sabelli and Giardina, 1972). The neuro- 
physiological effects have been related to the enhancement of catecholaminergic activity (Sabelli and Javaid, 1995). Systemic administration of phenylethylamine produces behavioral effects in rats and mice (Saavedra et al., 1970). The serotonergic system is thought to mediate the neurophysiological responses to hallucinogens (Glennon et al., 1984; Strassman, 1992). It is therefore interesting to note that serotonin receptor blockade can potentiate the behavioral effect of phenylethylamine (Goudie and Buckland, 1982). The high amount of phenylethylamine in the case of mushroom intoxication mentioned above suggests that phenylethylamine may contribute to the adverese reactions. The much higher variability in phenylethylamine content as compared with psilocybin is intriguing because it could explain why adverse reactions occur only in certain cases.

Lassen and co-workers (Lassen et al., 1990, 1992, 1993b) and Holm et al. (1997) have summarised available information on Danish mushrooms containing psilocybin, and the use of these mushrooms in society. Up to 1996, the Danish Poison Information center had registered 22 contacts due to hallucinogenic mushrooms of the species $P$. semilanceata (Holm et al., 1997). The reason for contacting the Poison Information center was mainly negative secondary psychic reactions on the psychomimetic effects of psilocybin. In seven of these cases the patients experienced hallucinations, showed tremendously anxiety and could not stay calm. The other 15 cases were milder - dysfori and some anxiety - sometimes followed by moderate sympatomimetic or gastrointestinal symptoms. One of the cases was a young man that experienced flashback phenomena during three months in the form of diffuse anxiety after ingestion of "magic mushrooms" in Thailand (Holmgaard Kristensen and Harding Sørensen, 1988. In none of the cases severe somatic complications were registered.

Psilocybe semilanceata is also occacionally used as hallucinogenic mushroom in Finland, where is grows more or less over the whole country. Jokiranta et al. (1984) reported that the psilocybin content can be failry high, up to $23700 \mathrm{mg} / \mathrm{kg}$ dry weight.

\subsection{Treatment of psilocybin-intoxication}

The major dangers associated with psilocybin are primarily psychological in nature. Anxiety or panic states (bad trips), depressive or paranoid reactions, mood changes, disorientation, and inability to distinguish between reality and fantasy may occur (Allen et al., 1991). Recommended treatment for these types of adverse reactions to hallucinogenic mushrooms is mainly supportive and consists mostly of calming the patient's fears and preventing him from harming himself or others (Mitchel and Rumack, 1978), but may, when indicated by symptomatic. This report does not aim to cover the management of poisoning of psilocybin-containing mush- 
rooms. The readers interested in this area are referred to reviews available (e.g., Leikin et al., 1989; Köppel, 1993).

In severe poisoning, restraints must be used. Diazepam (Valium ${ }^{\circledR}$ ), up to $10 \mathrm{mg}$ in adults, will control seizures. Chlorpromazine (Thorazine ${ }^{\circledR}$ ) or equivalent phenothiazines can be used to control hallucinations (DiPalma, 1981). Mostly it is enough to follow the patients carefully during the progressive decline in psychic experience. If the patient arrives at the hospital within two hours after ingestion of the mushroom, active charcoal may be given to the patient. Ventricular aspiration would not be the preferred method of removing the toxins, since in this case the treatment could be a higher risk than the exposure to the toxin. However, measures could be taken to reduce the absorption of the toxins involved, either by gastric lavage or emesis when it is suspected that a very poisonous mushroom has been mistaken for a hallucinogenic mushroom (Francis and Murray, 1983; Allen et al., 1991).

\subsection{Medical uses of psilocybin and psilocin}

In April 1966, Sandoz decided to withdraw its sponsorship of investgations on hallucinogenic drugs such as psilocybin and LSD. The firm transferred all of its remaining stock of these compounds to the National Institute of Mental Health in the USA. Because the compounds are legally handled in Schedule I of the Controlled Substances Act in the United States, studies on their usefulness for society, for example, in relation to treatment of various mental illnesses, is severly restricted. Nontheless, psilocybin has been tested as a treatment for anxiety and post-traumatic stress disorder, and mediator of mystical experiences. Thus, Francisco Moreno of the University of Arizona at Tucson has treated patients to test anecdotal reports that the drug can help patients to manage symptoms of obsessive-compulsive disorder, and Charles Grub at the University of California, Los Angeles, treated patients to investigate whether psilocybin is able to relieve anxiety in terminally ill cancer patients (Check, 2004). Doctor Griffiths at John Hopkins University School of Medicine, Baltimore, have evaluated the acute and longer-term psychological effects of a high dose of psilocybin in hallucinogen-naïve adults regularly participating in religious or spiritual activities, and reported positive changes in attitudes and behaviour. 


\section{References}

Aaron, J.J., Sanders, L.B. and Winefordner, J.D. (1973) Analytical study of some important hallucinognes by a combined fluorimetric and phsophorimetric method. Clin. Chim. Acta., 45:375-386.

Aboul-Enein, H.Y. (1974) Psilocybin: a pharmacological profile. Am. J. Pharm., 146:91-95.

Abramson, H.A. and Rolo, A. (1965) Lysergic acid diethylamide (LSD-25): XXXVIII. Comparison with actions of methysergide and psilocybin on test subjects. J. Asthma Res., 3:81-96.

Abramson, H.A., Jarvik, M.E., Gorin, M.H. and Hirsch, M.W. (1956) Lysergic acid diethylamide (LSD 25): XVII. Tolerance development and its relationship to a theory of psychosis. J. Psychol., 41:81-86.

Adlaf, E. M. and Ivis, F. J. (1998) Recent findings from the Ontario student drug use survey. J. Can. Med. Assoc., 159:451-454.

Adalf, E. M., Paglia, A., Ivis, F. J. and Ialomiteanu, A. (2000) Nonmedical drug use among adolesecent students: highlights from the 1999 Ontario student drug use survey. J. Can. Med. Assoc., 162:1677-1680.

Aghajanian, G. K. (1977) Identifying indoleamine hallucinogens by their preferential action of serotonin autoreceptors. In: Animal Models in Psychiatry and Neurology, I. Hanin and E. Usdin (Eds.), pp. 83-90.

Aghajanian, G.K. and Haigler, H.J. (1975) Hallucinogenic indoleamines: Preferential action upon presynaptic serotonin receptors. Psychopharmacol. Commun., 1:619-629.

Agurell, S. and Nilsson, J.L.G. (1968a) A biosynthetic sequence from tryptophan to psilocybin. Tetrahedron Letters 9:1063-1064.

Agurell, S. and Nilsson, J.L.G. (1968b) Biosynthesis of psilocybin. II. Incorporation of labelled tryptamine derivatives. Acta Chim. Scand., 22:1210-1218.

Agurell, S., Blomkvist, S. and Caralfomo, P. (1966) Biosynthesis of psilocybin in submerged culture of Psilocybe cuben- sis. I. Incorporation of labelled tryptophan and tryptamine. Acta Pharm. Suecica., 3:37-44.

Albers, C., Lehr, M., Beike, J., Köhler, H. and Brinkmann, B. (2002) Synthesis of a psilocin hapten and a protein-hapten conjugate. j. Pharm. Pharmacol., 54:1265-1270.

Albers, C., Köhler, H., Lehr, M., Brinkmann, B. and Beike, J. (2004) Development of a psilocin immunoassay for serum and blood samples. Int. J. Legal Med., 118:326-331.

Allen, J. W. (1988) A private inquiry into the circumstances surrounding the 1972 death of John Gomilla, Jr., who died after allegedly consuming ten hallucinogenic mushrooms while residing in Hawaii. J. Psycoactive Drugs, 20:451-454.

Allen, J.W.(2001) List of 186 hallucinogenic mushrooms (http://www. erowid.org/plants/mushrooms/mushroom s_info12.shtml) 2008-01-04.

Allen, J.W. and Merlin, M.D. (1992) Psychoactive mushroom use in Koh Samui and Koh Pha-Ngan, Thailand. Journal of Ethnopharmacology., 35:205-228.

Allen, J.W., Merlin, M.D. and Jansen, K.L.R. (1991) An ethnomycological review of psychoactive Agarics in Australia and New Zealand. J. Psychoact. Drugs 23:39-69.

Almaula, N., Ebersole, B.J., Ballesteros, J.A., Weinstein, H. and Sealfon, S.C. (1996) Contribution of a helix 5 locus to selectivity of hallucinogenic and nonhallucinogenic ligands for the human 5hydroxytryptamine ${ }_{2 \mathrm{~A}}$ and 5hydroxytryptamine ${ }_{2 C}$ receptors: Direct and indirect effects on ligand affinity mediated by the same locus. The American Society for Pharmacology and Experimental Therapeutics., 50:34-42.

Ametamey, S., Vollenweider, F.X., Patt, J., Bourgquin, D., Hasler, F., Beer, H.-F. and Schubiger, P.A. (1998) ${ }^{11} \mathrm{C}$ -

Radiolabeling of hallucinogenic psilocin, a potential radioligand for studying the role of serotonin receptors in psychotic symptom formation. J. Labelled Comp. Radiopharmaceut., 41:585-594. 
Anastos, N., Barnett, N.W., Lewis, S.W., Gathergood, N., Scammells, P.J. and Sims, D.N. (2005) Determination of psilocin and psilocybin using flow injection analysis with acidic potassium permanganate and tris $\left(2,2^{\prime}-\right.$

bipyridyl)ruthenium(II) chemilumininescence detection respectively. Talanta 67:354-359.

Anastos, N., Lewis, S.W., Barnett, N.W. and Sims, D.N. (2006a) The determination of psilocin and psilocybin in hallucinogenic mushrooms by HPLC utilizing a dual reagent acidic potassium permanganate and tris( $2,2^{\prime}-$

bipyridyl)ruthenium(II) chemiluminescence detection system. J. Forensic. Sci., 51:45-51.

Anastos, N., Barnett, N.W,, Pfeffer, F.M. and Lewis, S.W. (2006b) Investigation into the temporal stability of aqueous standard solutions of psilocin and psilocybin using high performance liquid chromatography. Science \& Justice 46:91-96.

Andén, N.-E., Corrodi, H. and Fuxe., K. (1971) Hallucinogenic drugs of the indolealkylamine type and central monoamine neurons. The Journal of Pharmacology and Experimental Therapeutics., 179-236-249.

Andén N.-E. (1974) Effect of acute axotomy (spinal cord transection) on the turnover of 5-hydroxytryptamine. Advances in Biochemical Psychopharmacology., 10:35-43.

Anderberg, E.K., Nyström, C. and Artursson, P. (1992) Epithelial transport of drugs in cell culture. VII: Effects of pharmaceutical surfactant excipients and bile acids on transepithelial permeability in monolayers of human intestinal epithelial (Caco-2) cells. J. Pharmaceut. Sci., 81:879-887.

Angst. J. (1970) Halluzinogen-Abusus. Schweiz med. Wschr., 100:710-715.

Anonymus (1968) Hallucinogenic drugs. Anesthesia and Analgesia, 47:72-76.

Appel, J.B. and Callahan, P.M. (1989) Involvement of 5-HT receptor subtypes in the discriminative stimulus properties of mescaline. European Journal of Pharmacology., 159:41-46.

Appel, J.B. and Freedman D.X. (1968) Tolerance and cross-tolerance among psychotomimetic drugs. Psychopharmacologyia., 13:267-274.
Appel, J.B, Joseph, J.A. Utsey, E., Hernandez, L.L. and Boggan, W. (1977) Sensitivtyto psychoactive drugs and the sertonergic neuronal system. Communications in Psychopharmacology 1:541-551.

Van Asperen de Boer, S.R., Barkema, P.R. and Kappers, J. (1966) Is it possible to induce esp with psilocybine? An exploratory investigation. Int. J. Neuropsychiatry 2:447-473.

Asselborn, G., Wennig, R. and Yegles, M. (2000) Tragic flying attempts under the influence of "magic mushrooms". Problems of Forensic Science 42:41-46.

Auert. G, Dolezal, V., Hausner, M. and Semerdzieva, M. (1980) Halluzinogene Wirkungen zweier Hutpilze der Gattung Psilocybe tschechoslowakisher Herkunft. Z ärtzl. Fortbild. 74:833-835.

Babakhanian, R.V., Busshuev, E.S., Zenkevich, I.G., Kazankov, S.P., Kostyrko, T.A. and Kuz'minykh, K.S. (1998) The forensic chemical study of psilocybincontaining fungi. Sud. Med. Ekspert., 41:24-26.

Babakhanian, R.V., Ivanova, G.V., Kostyrko, T.A., Safrai, A.E. and Iagmurov, O.D. (1999) The morphofunctional changes in the internal organs in the modelling of poisonings by psilocybine-containing mushrooms. Sud. Med. Ekspert., 42:6-9.

Badham, E.R. (1984) Ethnobotany of psilcybin mushrooms, especially Psilocybe cubensis. Journal of Ethnopharmacology., 10:249-254.

Baker, R.W., Chothia, C., Pauling, P. and Weber, H.P. (1973) Molecular structures of hallucinogenic substances: lyseric acid diethylamide, psilocybin, and 2,4,5trimetoxyampetamine. Molecular Pharmacology., 9:23-32.

Balestrieri, C. (1967) On the action mechanisms of LSD 25. In: The use of LSD in psychotherapy and alcoholism, Abramson, H.A: (Ed.), Bobbs Merrill, Indianapolis, New York, Kansas City, pp. 653-660.

Barnes, D.T. (1970) The uses and abuses of LSD and other hallucinogenic drugs. Aust. N.Z. J. Psychiat., 4:170-173.

Barrett, S.P., Archamboult, J., Engelberg, M.J. and Pihl, R.O. (2000) Hallucinogenic drugs attenuate the subjective response to alcohol in humans. Human Psychopharm., 15:559-565.

Barrett, S.P., Darredeau, C. and Pihl, R.O. (2006) Patterns of simultaneous poly- 
substance use in drug using university students. Human Psychopharmacol., 21:255-263.

Beck, O., Helander, A., Karlsson-Stiber, C. and Stephansson, N. (1998) Presence of phenylethylamine in hallucinogenic Psilocybe mushroom: Possible role in adverse reactions. Journal of Analytical Toxicology., 22:45-49.

Bellman, S.W. (1968) Mass spectral identification of some hallucinogenic drugs. J. A.O.A.C. 51:164-175.

Benedict, R.G., Brady, L.R., Smith, A.H. and Tyler, V.E. (1962a) Occurrence of psilocybin and psilocin in certain Conocybe and Psilocybe species. Lloydia 25:156-159.

Benedict, R.G., Brady, L.R. and Tyler, V.E. (1962b) Occurrence of psilocin in Psilocybe baeocystis. J. Pharmaceut. Sci., 51:393-394.

Benedict, R.G., Tyler, V.E. and Watling, R. (1967) Blueing in Conocybe, Psilocybe and a Stropharia species and the detection of psilocybin. Lloydia 30:150157.

Benjamin, C. (1979) Psychiatric symptoms and hallucinogenic compounds. British Medical Journal., 6188:500.

Benjamin, C. (1979) Persistent psychiatric symptoms after eating psilocybin mushrooms. British Medical Journal., 6174:1319-1320.

ten Berge, J.(2002) Jekyll and Hyde revisited: paradoxes in the appreciation of drug experiences and their effects on creativity. J. Psychoact. Drugs 34:249-262.

Bergman, B. and Karlsson, A.-C. (1995) Varning för psilocybin i ängssvamp: Ung missbrukare fick akut delerium. Läkartidningen., 92:3779-3780.

Berkenbaum, C. (1969) Líntoxication psilocybinbique auto-observation. Evolution Psychiatrique 34:817-848.

Bermond, F. and Bert, J. (1968) Étude des effets électrophysiologiques de la psilocybine chez un cercopithecinae, Papio papio. Electroencephalography and Clinical Neurophysiology., 27:48-56.

Bermond, F. and Bert, J. (1969) Action de la psilocybine sur le comportement d'un cercopithecinae papio-papio. Psychopharmacologia., 15:109-115.

Bermond, F., Bert, J. and Ayats, H. (1967) Etude comparative de láction de la psilocybine sur les potentiels évoqués au niveau du cortex occipital et dúne aire corticale spécifique chez un Cercopithe- cinae Papio papio. Comptes rendus des Seances de la Societe de biologie et de ses filial 161:147-150.

Besl, H. (1993) Galerina steglichii spec. Nov., eom jaööizompgener Häubling. Z. Mykologie 59:215-218.

Beug, M.W. and Bigwood, J. (1981) Quantitative analysis of psilocybin and psilocin in Psilocybe baeocystis (Singer and Smith) by high-performance liquid chromatography and by thin-layer chromatography. Journal of chromatography., 207:379-385.

Beug, M.W. and Bigwood, J. (1982) Psilocybin and psilocin levels in the twenty species from seven genera of wild mushrooms in the pacific northwest, U.S.A. Journal of Ethnophamacology, 5:271-285.

Bickel, M., Ditting, T., Watz, H., Roesler, A., Weidauer, S., Jacobi, V., Vueller, S., Betz, C., Fichtlscherer, S. and Dtein, J. (2005) Severe rhabdomyolysis, acute renal failure and posterior encephalopathy after ,magic mushroom' abuse. European Journal of Emergency Medicine 12:306-308.

Bigwood, J. and Beug, M.W. (1982) Variation of psilocybin and psilocin levels with repeated flushes (harvest) of mature sporocarps of Psilocybe cubensis (Earle) Singer. Journal of Ethnophamacology, 5:287-291.

Blackman, J.R.. (1993) Clinical approach to toxic mushroom ingestion. J. Am. Board Fam. Pract., 7:31-37.

Blair, J.B., Kurrasch-Orbaugh, D., MaronaLewicka, D., Cumbay, M.G., Watts, V.J., Barker, E.L. and Nichols, D-E. (2000) Effect of ring fluorination on the pharmacology of hallucinogenic tryptamines. J. Med. Chem., 43:4701-4710.

Blaschko, H. and Levine, W. G. (1958) Enzymic oxidation of psilocine and other hydroxyindoles. Biochem. Pharmacol., 3:168-169.

Blaschko, H. and Levine, W. G. (1960) A comparative study of hydroxyindole oxidases. Brit. J. Pharmacol., 15:625-633.

Bocks, S.M. (1967) Fungal metabolism IV. The oxidation of psilocin by pdiphenol oxidase (laccase). Phytochem., 6:1629-1631.

Bogusz, M.J. (2000) Liquid chromatography-mass spectrometry as a routine method in forensic sciences: a proof of maturity. J. Chromatogr., 748:3-19.

Bogusz, M.J., Maier, R.-D., Schäfer, A.Th. and Erkens, M. (1995) Honey with Psi- 
locybe mushrooms: a revival of a very old preparation on the drug market? Int Legal Med., 111:147-150.

Bogusz, M. J., Maier, R.-D., Schäfer. A. T. and Erkens, M. (1998) Honey with psilocybe mushrooms: a revival of a very old preparation on the drug market? Int. J. Legal Med.. 11:147-150.

Bogusz, M.J. (2000) Liquid chromatography-mass spectrometry as a routine method in forensic sciences: a proof of maturity. J. Chrom., 748:3-19.

Borner, S. and Brenneisen, R. (1987) Determination of tryptamine derivatives in hallucinogenic mushrooms using high-performance liquid chromatography with photodiode array detection. J. Chromatog. 408: 402-408.

Borowiak,K.S.,Ciechanowski, K. and Waloszczyk, P. (1998) Psilocybin mushroom (Psilocybe semilanceata) Intoxication with myocardial infarction. Clinical Toxicology, 36:47-49.

Bourn, W.M., Keller, W.J. and Bonfiglio, J.F. (1978) Psychoactivity of normacromerine in animals. Life Sciences, 23:1175-1184.

Brack, A., Hofmann, A., Kalberer, F., Kobel, H. and Rutschmann, J. (1961) Tryptophan als biogenetische Vorstufe des Psilocybins. Arch. Pharm., 294:230-234.

Brawley, P. and Duffield, J.C. (1972) The pharmacology of hallucinogens. Pharmacological Reviews, 24:31-66.

Bressloff, P. D., Cowan, J. D., Golubisky, M., Thomas, P. J., and Wiener, M. C. ( 2002) Neural Computation, 14: 473-491.

Brimblecombe, R.W. (1973) Psychotomimetic drugs: Biochemistry and pharmacology. Advnces in Drug Research, 7:165-206.

Brown, R. (1968) Psychedelic Guide to Preparation of the Eucharist in a Few of its Many Guises. Linga Sharira Incense Co., Austin, Texas.

Brown, R.T. and Braden, N.J. (1987)

Hallucinogens. The Pediatrics Clinics of North America 34/2:341-347.

Brown, J.K. and Malone, M.H. (1973)

Some US street drug identification programs. J. Am. Pharmaceut. Assoc., NS13:670-674.

Brown, J.K. and Malone, M.H. (1976) Status of drug quality in the street-drugmarket-An update. Clinical Toxicology, 9:145-168.

Brown, J.K., Shapazian, L. and Griffin, G.D. (1972) A rapid screening procedure for some "street drugs" by thin-layer chromatography. J. Chromatogr., 64:129-133.

Buck, R. W. (1967) Psycedelic effect of Philiota spectabilis. New England J. Med.. 276:391-393.

Buck, R.W. (1978) Acute encephalopathy in children after eating wild mushrooms. In: Mushroom Poisoning: Diagnosis and Treatment, B.H. Rumack and E. Salzman (Eds.), CRC Press Inc., West Palm Beach, p. 191-197.

Buckholtz, N.S., Zhou, D., Freedman, D.X. and Potter W.Z. (1990) Lysergic acid diethylamid (LSD) administration selectively downregulates serotonin $n_{2}$ receptors in rat brain. Neuropsychopharmacology, 3:137-148.

Buckman, J. (1971) Social and medical aspects of illicit use of LSD. Int. J. Social Psychiatry 17:163-176.

Callahan, P.M. and Appel, J.B. (1988) Differences in the stimulus properties of 3,4-methylenedioxyamphetamine and 3,4- methylenedioxymethamphetamine in animals trained to discriminate hallucinogens from saline. The Journal of Pharmacology and Experimental Therapeutics, 246:866-870.

Calvino, J., Romero, R., Pintos, E., Novoa, D., Güimil, D., Cordal, T., Mardaras, J., Arcocha, V., Lens, X.M. and SanchezGuisande, D. (1998) Voluntary ingestion of Cortinarius mushrooms leading to chronic interstitial nephritis. Am. J. Nephrol., 18:565-569.

Cameron, O.G. and Appel, J.B. (1973) A behavioral and pharmacological analysis of some discriminable properties of dLSD in rats. Psychopharmacologia, 33:117-134.

Cameron, O.G. and Appel, J.B. (1976) Drug-induced conditioned supression: Specificity due to drug employed as UCS. Pharmacology Biochemistry and Behaviour, 4:221-224.

Carter, M. (1976) Will the legal liberty cap cause home official hallucinations? New Scientist 71:599.

Casale, J.F. (1985) An aqueous-organic extraction method for the isolation and identification of psilocin from hallucinogenic mushrooms. J. Forens. Sci., 30:247-250.

Castellano, C. (1978) Effects of mescaline and psilocin on acquisition, consolidation, and performance of light-dark discrimina- 
tion in two inbread strains of mice. Psychopharmacology, 59:129-137.

Catalfomo, P. and Tyler, V.E. (1964) The production of psilocybin in submerged culture by Psilocybe cubensis. Lloydia 27:53-63.

Cerletti, A. (1958) Étude pharmacologique de la psilocybine. In : Les Champignons Hallucinogenes du Mexique, R. Heim and R.G. Wasson (Eds.), Museum de historie naturelle, Paris, p. 268-271.

Cerletti, A. (1959) Pharmacology of psilocybine. In : Neuro-psychopharmacology, Bradley, P., Deniker, P., RadoucoThomas, C. (Eds.), Elsevier, Amsterdam, pp. 291-294.

Cerletti, A. and Hoffman, A. (1963) Mushrooms and toadstools. The Lancet i:58-59.

Ceröetto, A., Taeschler, M. and Weidmann, H. (1968) Pharmacologic studies on the structure-activity relationship of hydroxyindole alkylamines. Adv. Pharmacol., 6B:233-246.

Ceruti Scurti, J., Fiussello, N. and Jodice, R. (1972) Idrossi-indol derivati in basidiomiceti. III. Influenza del substrato sui metaboliti del micelio e del carpofori de "Panaeolus subbalteatus” Berk. Et Br. Allionia 18:91-96.

Charters. A.D. (1957) Mushroom poisoning in Kenya. Transactions of the Royal Society of Tropical Medicine and Gygiene 51:265-270.

Check, E. (2004) The ups and downs of ecstasy. Nature 429:126-128.

Cheek, F.E., Newell, S. and Joffe, M. (1970) Deceptions in the illicit drug market. Science 167:1276.

Chilton, W.S. (1978) Chemistry and mode of action of mushroom toxins. In: Mushroom Poisoning: Diagnosis and Treatment, B.H. Rumack and E. Salzman (Eds.), CRC Press Inc., West Palm Beach, Florida, p. 87-124.

Chilton, W. S., Bigwood, J. and Jensen, R. E. (1979) Psilocin, bufotenin and serotnin: Historical and biosynthetic observations. J. Psychedelic Drugs, 11:61-69.

Christiansen, A.L. and Rasmussen, K.E. (1982) Analysis of indole alakaloids in Norwegican Psilocybe semilanceata using high-performance liquid chromatography and mass spectrometry. J. Chromatog. 244:357-364.

Christiansen, A.L. and Rasmussen, K.E. (1983) Screening of hallucinogenic mushrooms with high-performance liq- uid chromatography and detection. Journal of Chromatography, 270:293-299.

Christiansen, A.L., Rasmussen, K.E. and Tønnesen, F. (1981a) Determination of psilocybin in Psilocybe semilanceata using high-performance liquid chromatography on a silica column. J. Chromatogr., 210:163-167.

Christiansen, A.L., Rasmussen, K.E. and Høiland, K. (1981b) The content of psilocybin in Norwegian Psilocybe semilanceata. Planta Medica 42:229-235.

Christiansen, A. L., Rasmussen, K. E. and Höjland, K. (1982) Spiss fleinsopp som narkotikum. Tidskr. Nor. Laegeforen., 102:17-18.

Christiansen, A. L., Rasmussen, K. E. and Höjland, K. (1984) Detection of psilocybin and psilocin in norwegian species of Pluteus and Conocybe. Planta Medica, 45:341-343.

Cohen, S. (1984) The hallucinogens and the inhalants. In: The Psychiatric Clinics of North America, P. Sanders (Ed.), pp. 681-688.

Collins, R.L., Ordy, J.M. and Samorajski, T. (1966) Psilocin: effects on behaviour and brain serotonin in mice. Nature 209:785-787.

Consroe, P.F. (1972) Specific pharmacological management of acute toxicity due to "psychedelic"drugs. Arizona Med., 29:920-925.

Cooles, P. (1980) Abuse of the mushroom Panaeolus foenisecii. Br. Med. J., 280:446-447.

Corne, S.J. and Pickering, R.W. (1967) A possible correlation between druginduced hallucinations in man and a behavioural response in mice. Psychopharmacologia 11:65-78.

Corrigan, D. (1982) 'Magic' mushrooms. Irish Pharmaceut. J., 60:351-352.

Cullinan, E.R. and Henry, D. (1945) Fungus poisoning in the Nairobi district. East African Med. J., 22:252-254.

Cuomo, M.J., Dyment, P.G. and Gammino, V.M. (1994) Increasing use of "ecstasy " (MDMA) and other hallucinogens on a college campus. Journal of American Colege Health, 42:271-274.

Cox, P.A. (1981) Use of a hallucinogenic mushroom, Copelandia cyanescens, in Samoa. J. Ethnopharmacol., 4:115-116.

Creese, I., Burt, D.R. and Snyder, S.H. (1975) The dopamine receptor: Differential binding of $d$-LSD and related agents 
to agonist and antagonist states. Life Science 17:1715-1720.

Curry, S. C. and Rose, M. C. (1985) Intravenous mushroom poisoning. Annals of Emergency Medicine, 14: 900/125902/127.

Davis,M. and Walters, J.K. (1976) Psilocybin: Biphasic dose-response effects on the acoustic startle reflex in the rat. Pharmacology Biochemistry and Behavior, 6:427-431

Davies, N.S. (1979) Psychiatric symptoms and hallucinogenic compounds. British Medical Journal, 6193:797.

Dewhurst, K. (1980) Psilocybin intoxication. 137:303-304.

DiPalma, J.R. (1981) Pushroom poisoning. Clin. Pharmacol., 23:169-172.

DiSclafani, A., Hall, R.C.W. and Gardner, E.R. (1981) Drug-induced psychosis: Emergency diagnosis and management. Psychosomatics 22:845-850.

Drewitz, G. (1983) Eine halluziogene Risspilzart Grünlichfärbender Risspilz (Inocybe aeruginascens). Mykol. Mitt. Bl., 26:11-17.

Drummer, O.H. (1999) Chromatographic screening techniques in systematic toxicological analysis. J. Chromatogr., 733:27-45.

Dubanský, B. And Vyhánková, M. (1967) Unterschiede in der Reaktionsweise von Psilocybin bei hirngeschädigten Versuchspersonen bezogen auf die Lokalisation der Läsion. Activates Nervosa Superior 9:418-420.

Dubanský, B., Vyhnánková, M. and Setlik, L. (1968) Soucasny výskyt neurologických príznaku a zmeneneho proprioceptivního vnímání po psilocyninu u nemocných s organickým poskozením mozku. Ceskoslovenská neurologie 31:394-399.

Duke, R.B. and Keeler, M.H. (1968) The effect of psilocybin, dextroamphetamine and placebo on performance of the trial making test. J. Clin. Psycol., 24:316-317.

Dyer, D.C. and Gant, D.W. (1973) Vasoconstriction produced by hallucinogens on isolated human and sheep umbilical vasculature. The Journal of Pharmacology and Experimental Therapeutics184:366-375.

Eberle, P. And Leuner, H. (1970) Chromosomendefekte bei Psilocybin-Patienten. Humangenetik 9:281-285.
Eberle, P. (1973) Verursachen Hallucinogene Chromosomendefekte und Missbildungen? Nervenarzt, 44:281-284.

Edwards, J. N. and Henry, J. A. (1989) Medical problems of mushroom ingestion. The Mycologist, 3:13-15.

Eivindvik, K. and Rasmussen, K.E. (1989) Handling of psilocybin and psilocin by everted sacs of eat jejenum and colon. Acta. Pharm. Nord., 1:295-302.

Enos, L. (1970) A Key to the American Psilocybin Mushroom. Youniverse, Lemon Grove, California.

Erspamer, V., Ferrini, R. and Glässer, A. (1960) A note on the oxidative deamination of isomers of 5-hydroxytryptamine and other indolealkylamines. J Pharm. Pharmacol., 12:761-764.

Espiard, M.-L., Lecardeur, L., Abadie, P., Halbecq, I. and Dollfus, S. (2005) Hallucinogen persisting perception disorder after psilocybin consumption: a case study. European Psychiatry 20:458-460.

European legal database on drugs (2008). (http://eldd.emcdda.europa.eu/html.cfm/i ndex5036EN.html).

Faniciullacci, M., Franchi, G. and Sicuteri, F. (1974) Hypersensitivity to lyseric acid diethylamide (LSD-25) and psilocybin in essential headache. Experentia, 30:14411442.

Fairchild, M.D., Jenden, D.J., Mickey, M.R. and Yale, C. (1980) EEG effects of hallucinogens and cannabinoids using sleep-waking behavior as baseline. Pharmacology Biochemistry and Behavior, 12:99-105.

Farnsworth, N.R. (1968) Hallucinogenic plants: Various chemical substances are known to be the active hallucinogenic principle in many plants. Science, 162:1086-1092.

Fellner, C.H. (1968) Pst-traumatic neurosis - theme and variations. Industrial Med. Surg., 37:347-350.

Fischer, R. (1966) Sympathetic excitation and biological chronometry. Int. J. Neuropsychiatry 2:116-121.

Fischer, R. (1969) The perceptionhalllucination continuum. Diseases of the Nervous System 30:161-171.

Fischer, R. (1970) The psycholytic treatment of a childhood schizophrenic girl. Int. J. Social Psychiatry 16:112-130.

Fischer, R. and Goldman, H. (1975) Therapeutic usefulness of hallucinogenic drugs as a function of their chemical structure. Phamakopsych., 8:176-184. 
Fischer, R. and Hill, R.M. (1971) Psychotropic drug-induced transformation of visual space. Int. Pharmacopsychiat., 6:28-37.

Fischer, R. and Landon, G.M. (1972) On the arousal state-dependent recall of "subconscious" experience: Stateboundness. Brit. J. Psychiat., 120:159-172.

Fischer, R. and Mead, E.L. (1966) Time contraction and psychomotor performance produced by "psilocybin". Nature, 209:433-434.

Fischer, R. and Rockey, M.A. (1967) A heuristic model of creativity. Experentia 23:150-151.

Fischer, R. and Rockey, M.A. (1968) Psychophysics of excitation and tranquilization from steady-state perspective. Neuroscience Research I, pp. 263-314.

Fischer, R. and Scheib, J. (1971) Creative performance and the hallucinogenic drug-induced creative experience. or One man's brin-damage is another's creativity. Confin. Psychiat., 14:174202.

Fischer, R., England, S.M., Archer, R.C. and Dean, R.K. (1966) Psilocybin reactivity and time contraction as measured by psychomotor performance. Arzneimittel-Forschung 16:180-185.

Fischer, R., Marks, P.A., Hill, R.M. and Rockey, M.A. (1968) Personality structure as the main determinant of drug induced (model) psychoses. Nature 218:296-298.

Fischer, R., Hill, R.M. and Warshay, D. (1969) Effects of the psychodysleptic drug psilocybin on visual perception. Changes in brightness preference. Experientia 25:166-169.

Fischer, R., Thatcher, K., Kappeler, T. and Wisecup, P. (1969) Unity and covariance of perception and behavior. Perceptual variability: a predictor of psychotomimetic drug-induced behavior. Arzneimittel-Forschung 19:1941-1945.

Fischer, R., Kappeler, T., Wisecup, P. And Thatcher, K. (1970) Personality trait dependent performance under psilocybin. Dis. Nerv. System 31:91-101.

Fischer, R., Hill, R., Thatcher, K. And Scheib, J. (1970) Psilocybin-induced contraction of nearby visual space. Agents Actions 1:190-197.

Fischer, R., Kappeler, T., Wisecup, P. And Thatcher, K. (1969?) Measurement of handwriting area to pressure ratios during psilocybin-induced hallucinations. ?????
Fiussello, N. and Ceruti Scurti, J. (1972a) Idrossi-indol derivati in basidiomiceti. I.Presenza di Psilocibina e di 5-idrossiindol derivati in Panaeolus retirugis Fr. Atti Accad. Sci. Torino, 106:725-735.

Fiussello, N. and Ceruti Scurti, J. (1972b) Idrossi-indol derivati in basidiomiceti. II. Psilocibina, psilocina e 5-idrossi-indol derivati in carpofori di "Panaeolus" e generi affini. Allionia 18:85-90.

Flammer, R. (1985) Neurotoxische und psychoakive Pilze. Schweiz Rundschau Med., 74:988-991.

Flammer, R. and Horak, E. (1983) Giftpilze - Pilzgifte. Kosmos, Stuttgart.

Francis, J. and Murray, V.S. (1983) Review of enquiries made to the NPIS concerning Psilocybe mushroom ingestion, 1978--1981. Hum. Toxicol., 2:349-352.

Franz, M., Regele, H., Kirchmair, M., Kletzmayr, J., Sunder-Plassmann, G., Hörl, W.H. and Pohanka, E. (1996) Nephrol. Dial. Transplant., 11:23242327.

Fukuda, K. (2002) Possible mechanisms of panic attack and schizophrenia via APUD system. Med. Hypotheses 58:123-126.

Fuxe, K., Everitt, B.J., Agnati, L., Fredholm, B. And Jonsson, G. (1976) On the biochemistry and pharmacology of hallucinogens. In: Schizophrenia Today, D. Kemali (Ed.), Oxford Pergamon Press, pp. 135-157.

Gable, R.S: (1993) Towards a comparative overview of dependence potential and acute toxicity of psychoactive substances used nonmedically. Am. J. Drug Alcohol Abuse 19:263-281.

Garcia Fernandez, J.C. (1984) Role played by narcotics laboratories in the campaign against drug abuse and drug trafficking. A view from a developing country. Bulletin on Narcotics.36:3-13.

Gartz, J. (1985a) Zur Untersuchung von Psilocybe semilanceata (Fr.) Kumm. Die Pharmazie 40:506.

Gartz, J. (1985b) Zur Isolierung des Baeocystins aus den Fruchtkörpern einer Psilocybeart. Die Pharmazie 40:274.

Gartz, J. (1985c) Zur Extraktion und Chromatografie des blauen Farbstoffes einer Psilocybeart. Die Pharmazie 40:274-275.

Gartz, J. (1985d) Vergleichende dünnschichtschromatografische undersuchungen zweier Psilocybe- und einer halluzinogenen Inocybeart. Pharmazie 40:134. 
Gartz, J. (1985e) Dünnschichtchromatografische Analyse der Inhaltsstoffe von Pilzen der Gattung Stropharia. Pharmazie 40:134-135.

Gartz, J. (1985f) Zum Nachweis der Inhaltstoffe einer Pilzart der Gattung Panaeolus. Die Pharmazie 40:431.

Gartz, J. (1986a) Quantitative Bestimmung der Indolderivate von Psilocybe semilanceata (Fr.) Kumm. Biochem. Physiol. Pflanzen 181:117-124.

Gartz, J. (1986b) Psilocybin in mycelkulturen von Inocybe aeruginascens. Biochem. Physiol. Pflanzen 181:511-517.

Gartz, J. (1986c) Ethnopharmakologie und Entdeckungsgeschichte der halluzinogenen Wirkstoffe von europäischen Pilzen der Gattung Psilocybe. Z. Ärztl. Fortbild., 80:803-805.

Gartz, J. (1986d) Nachweis von Tryptaminderivaten in Pilzen der Gattung Gerronema, Hygrocybe, Psathyrella und Inocybe. Biochem. Physiol. Pflanzen 181:275-278.

Gartz, J. (1987a) Variation der Indolalkaloide von Psilocybe cubensis durch unterschiedliche Kultivierungsbedingungen. Beiträge zur Kenntnis der Pilze Mitteleuropas/Arbeitsgemeinschaft Mykologie Ostwürttemberg der Deutschen Gesellschaft für Mykologie Schwäbisch Gmün Dietenberger 1984-, 3:275-281.

Gartz, J. (1987b) Vorkommen von Psilocybin und Baeocystin in Fruchtkörpern von Pluteus salicinus. Planta Medica 48:290-291.

Gartz, J. (1987c) Variation der Alkaloidmengen in Fruchtkörpern von Inocybe aeruginascens. Planta Medica 48:539-541.

Gartz, J. (1989a) Analysis of aeruginascin in fruit bodies of the mushroom Inocybe aeruginascens. Int. J. Crude Drug Res., 27:141-144.

Gartz, J. (1989b) Biotransformation of tryptamine derivatives in mycelial cultures of Psilocybe. J. Badic Microbiol., 29:347-352.

Gartz, J. (1989c) Biotransformation of tryptamine in fruiting mycelia of Psilocybe cubensis. Planta Medica 55:249-250.

Gartz, J. (1989d) Bildung und Verteilung der Indolalkaloide in Fruchtkörpern, Mycelien und Sklerotien vonPsilocybe cubensis. Beiträge zur Kenntnis der Pilze Mitteleuropas 5:167-174.

Gartz, J. (1991) Einfluss von Phosphat auf Fruktifikation und Sekundärmetabolis- men der Myzelien von Psilocybe cubensis, Psilocybe semilanceata und Gymnophilus purpuratus. Z. Mykologie 57:149-154.

Gartz, J. (1994) Extraction and analysis of indole derivatives from fungal biomass. J. Badic Microbiol., 34:17-22.

Gartz J. and Drewitz, G. (1985) Der erste Nachweis des Vorkommens von Psilocybin in Rißpilen. Zeitschrift für Mykologie 51:199-203.

Gartz, J. and Drewitz, G. (1986) Der Grünlichverfärbende Rissbilz - eine Inocybeart mit halluzinogener Wirkung. Z . Ärztl. Fortbild., 80:551-553.

Gartz, J. and Müller, G.K. (1989) Analysis and cultivation of fruit bodies and mycelia of Psilocybe bohemica. Biochem. Physiol. Pflanzen 184:337-341.

Gartz, J., Allen, J.W. and Merlin, M.D. (1994) Ethnomycology, biochemistry, and cultivation of Psilocybe samuiensis Guzmán, Bandala, and Allen, a new psychoactive fungus from Koh Samui, Thailand. J. Ethnopharmacol., 43:73-80.

Gathergood, N. and Scammelis, P.J. (2003) Preparation of the 4hydroxytryptamine scaffold via palladium-catalyzed cyclization: a practical and versatile synthesis of psilocin. Organic Letters 5:921-923.

Gebhart, E. (1979) Zur Frage der erbutschädigenden Nebenwirkung von psychotropen Substanzen. II. Rauschund Suchtdrogen. Fortschr. Med., 97:103-106.

Genest, K. And Lowry, L.J. (1970) Microcrystalloptic test for lysergic acid diethylamide and other hallucinogens. J. Pharm. Pharmac., 22:839-844.

Geert-Jörgensen, E. (1968) Further observations regarding hallucinogenic treatment. Acta Psychiatr. Scand. Suppl., 203:195-200.

Gelpke, R. (1981) On travels in the universe of the soul: Reports on selfexperiments with delysid (LSD) and psilocybin (CY). J. Psychoactive Drugs 13:81-89.

Gerault, A. and Picart, D. (1996) Fatal poisoning after a group of people voluntarily consumed hallucinogenic mushrooms. Bull. Soc. Mycol., 112:1-14.

Gessner, P. K., Khairallah, P. A., McIsaac, W. M. and Page, I., H. (1960) The relationships between the metabolic fate and pharmacological actions of serotonin, 
bufotenine and psilocybin. J. Pharmacol. Exp. Therapeut., 130:126-133.

Gessner, P.K., Godse, D.D., Krull, A.H. and McMullan, J.M. (1968) Structureactivity relationships among 5-methoxy$\mathrm{N}$ :N-dimethyltryptamine, 4-hydroxy$\mathrm{N}: \mathrm{N}$-dimethyltryptamine (psilocin) and other substituted tryptamines. Life Sci., 7:267-277.

Geyer, M.A., Petersen, L.R., Rose, G.J., Horwitt, D.D., Light, R.K., Adams, L.M., Zook, J.A., Hawkins, R.L. and Mandell, A.J. (1978) The effects of lysergic acid diethylamide and mescalinederived hallucinogens on sensoryintegrative function: Tactile startle. J. Pharmacol. Exp. Ther., 207:837-847.

Geyer, M.A., Light, R.K., Rose, G.J., Petersen, L.R., Horwitt, D.D., Adams, L.M. and Hawkins, R.L. (1979) A characteristic effect of hallucinogens on investigatory responding in rats. Psychopharmacol., 65:35-40.

Ghuran, A. and Nolan J. (2000) Recreational drug misuse: issues for the cardiologist. Heart, 83:627-633.

Gill, R. (1986) High pressure liquid chromatography. In: Moffat, A.C., Jackson, J.V., Moss, M.S. and Widdop, B., eds. Clarke's Isolation and Identification of Drugs. The Pharmaceutical Press, London 1986, pp. 208.

Gillespie, A.M. (1969) A spectrofluorometric study of selected hallucinogens. Analyt. Letters 2:609-622.

Gilmour, L.P. and O’Brien, R.D. (1967) Psilocybin: Reaction with a fraction of rat brain. Science 155:207-208

Ginestet, D. (1967) Les substances hallucigonènes. Maroc Medical 47:429433.

Glennon, R.A., Titeler, M. And McKenney, J.D. (1984) Evidence for 5$\mathrm{HT}_{2}$ involvement in the mechanism of action of hallucinogenic drugs. Life Sci., 35:2505-2511.

Gonmori, K. and Yoshioka, N. (2003) The examination of mushroom poisonings at Akita University. Legal Med., 5:S83-S86. Gonzalez-Lima, F., Stiehl, W.L. and Medina, R. (1984) Long-lasting behavioral effects of bromocriptine in cats. E. J. Pharmacol., 102:279-287.

Goudie, A.J. and Buckland, C. (1982) Serotonin receptor blockade potentiates behavioural effects of betaphenylehtylamine. Neuropharmacology 21:1267-1272.
Gouzoulis, E., Hermle, L. and Sass, H. (1994) Psychedelische Erlebnisse zu Beginn produktiver Episoden endogener Pychosen. Nervenartz 65:198-201.

Gouzoulis-Mayfrank, E., Schreckenberger, M., Sabri, O., Arning, C., Thelen, B., Spitzer, M., Kovar, K.-A., Hermle, L., Büll, U. and Sass, H. (1999a) Neurometabolic effects of psilocybin, 3,4methylenedioxyethylamphetamine (MDE) and d-methamphetamine in healthy volunteers. A double-blind, placebo-controlled PET study with $\left[{ }^{18} \mathrm{~F}\right]$ FDG. Neuropsychopharmacology 20:565-581.

Gouzoulis-Mayfrank, E., Thelen, B., Habermeyer, E., Kunert, H.J., Kovar, K.A., Lindenblatt, H., Hermle, L., Spitzer, M., and Sass, H. (1999b) Psychopathological neuroendocrine and autonomic effects of 3,4-methylenedioxyethylamphetamine (MDE), psilocybin and d-methamphetamine in healthy volunteers. Psychopharmacology 142:41-50.

Gouzoulis-Mayfrank, E., Thelen, B., Maier, S., Heekeren, K., Kovar, K.-A., Sass, H. and Spitzer, M. (2002) Effects of the hallucinogen psilocybin on covert orienting of visual attention in humans. Neuropsychobiol., 45:205-212.

Graham, K., Feigenbaum, A., Pastuszak, A., Nulman, I., Weksberg, R., Einarson, T.R., Ashby, S., Koren, G. and Goldberg, S. (1992) Pregnancy outcome and infant development following gestational cocaine use by social cocaine users in Toronto, Canada. Clin. Invest. Med., 15:384-394.

Grant, I. and Hohns, L. (1975) Chronic cerebral effects of alcohol and drug abuse. Int. J. Addict., 10:883-920.

Green, J.P., Weinstein, H. and Maayani, S. (1978) Defining the histamine H2-receptor in brain: The interaction with LSD. In: Quantitative structure activity relationships of analgesics, narcotics, antagonists, and hallucinogens, G. Bernett, M. Trsic and R. Willette (Eds.), National Intstitute on Drug Abuse, pp. 38-59.

Greenberg, I., Kuhn, D. and Appel, J.B. (1975) Comparison of the discriminative stimulus properties of $\Delta^{9}$-THC and psilocynin in rats. Pharmacol. Biochem. \& Behav., 3:931-934.

Grieshaber, A.F., Moore, K.A. and Levine, B. (2001) The detection of psilocin in human urine. J. Forensic Sci., 46:627-630. 
Griffiths, R.R., Richards, W.A., McCann, U. and Jesse, R. (2006) Psilocybin can occasion mystical-type experiences having substantial and sustained personal meaning and spiritual significance. Psychopharmacology 187:268-283.

Grinspoon, L. and Bakalar, J.B. (1981) The psychedelic drug therapies. Current Psychiatric Therapies 20:275-283.

Gross, L.J. (1975) Drug-induced handwritting changes: An empirical review. Texas Rep. Biol. Med., 33:371-390.

Gross, S. T. (2000) Detecting psychoactive drugs in the developmental stages of mushrooms. J. forensic sciences, 45:527-537.

Gross, S.T. (2002) Psychotropic drugs in developmental mushrooms: a case study review. J. Forensic Sci., 47:1298-1302.

Gross, S.R., Barrett, S.P., Shestowsky, J.S. and Pihl, R.O. (2002) Ecstasy and frug consumption patterns: a Canadian rave population study. Can. J. Psychiatry 47:546-551.

Gundersen, T. (1979) Pizza med fleinsopp. Tidsskr. Nor. Lægeforen 99:424.

Gurevich, L.S. (1993) Indole derivatives in certain Panaeolus species from East Europe and Siberia. Mycol. Res., 97:251-254.

Guzmán, G. (1978) Variation, distribution, ethnomycological data and relationships of Psilocybe aztecorum, a Mexican hallucinogenic mushroom. Mycologia 70:385-396.

Guzmàn, G. (1983) The genus Psilocybe. Beihefte zur Nova Hedwigia 74, 435 p.

Guzmán, G. and Ott, J. (1976) Description and chemical analysis of a new species of hallucinogenic Psilocybe from the pacific northwest. Mycologia 68:1261-1267.

Guzmán, G. and Vergeer, P.P. (1978) Index of taxa in the genus Psilocybe. Mycotaxon 6:464-476.

Guzmán, G., Ott, J., Boydston, J. and Pollock, S.H. (1976) Psychotropic mycoflora of Washington, Idaho, Oregon, California and British Columbia. Mycologia 68:1267-1272.

Guzmán, G., Bandala, V.M. and Allen, J.W. (1993) A new Psilocybe from Thailand. Mycotaxon 46:155-160.

Guzmán, G., Tapia, F. and Stamets, P. (1997) A new bluing Psilocybe from USA. Mycotaxon 65:191-195.

Haan, J. (1981) Drogenabhängigkeit. Eine Übersicht über betäubende und halluzinogen wirkende Drogen. Med. Mo. Pharm., 4:129-137.
Hadfield, P. (2001) Freaky fungi in Japan. US News \& World Report 131:27.

Haddad, L.M. (1976) Management of hallucinogen abuse. Am. Fam. Physician 14:82-87.

Haefely, W. (1974) The effects of 5hydroxytryptamine and some related compounds on the cat superior cervical ganglion in situ. NaunynSchmiedeberg's Arch. Pharmacol., 281:145-165.

Halaris, A.E. (1982) Nerve terminal effects of indoleamine psychotomimetics on 5-hydroxytryptamine. Neurosci. Biobehav. Rev., 6:483-487.

Hall, M.C. (1973) Problems in legislating against abuse of hallucinogenic fungi in Australia. Bull. Narcotics 25:27-36.

Halpern, J.H. (2004) Hallucinogens and dissociative agents naturally growing in the United States. Pharmacology \& Therapeut., 102:131-138.

Hanes, K.R. (1996) Serotonin, Psilocybin, and body dysmorphic disorder: A case report. J. Clin. Psychopharmacol., 16:188-189.

Hanrahan, J.P. and Gordon, M.A. (1984) Mushroom poisoning. Case reports and review of therapy. J. Am. Med. Assoc., 251:1057-1061.

Hanus, H.-, Preiningerová, O. and Fryntová, H. (1968) Nekteré méne obvyklé psychopatologické príznaky intoxikace psilocyninem. Activitas Nervos Superior 10:279-280.

Hanus, H.-, Preiningerová, O. and Fryntová, H. (1970) Vliv spánkové deprivace na psilocyninovou experimentální psychozu. Karlovy v Hradei Kroalove (Suppl.) 13:319-331.

Harries, A. D. and Evans, V. (1981) Sequele of a "magig mushroom banquet". Postgraduate Med. J., 57:571-572.

Haselbarth G., Michaelis, H. and Salnikow, J. (1985) Nachweis von Psilocybin in Inosybe aeruginascens Babos. Myk. Mitteilungsblatt, 28:59-62.

Hasler, F., Bourquin, D., Brenneisen, R., Bär, T. and Vollenweider, F.X. (1997) Determination of psilocin and 4hydroxyinodole-3-acetic acid in plasma by HPLC-ECD and pharmacokinetic profiles of oral and intravenous psilocybin in man. Pharmaceutica Acta Helv., 72:175-184.

Hasler, F., Bourquin, D., Brenneisen, R., and Vollenweider. R. X. (2002) Renal excretion profiles of psilocin following 
oral administration of psilocybin: a controlled study in man. J pharmaceutical and Biomedical Analysis, 30:331-339.

Hasler, F., Grimberg, U., Benz, M.A., Huber, T. and Vollenweider. R. X. (2004) Acute psychological and physiological effects of psilocybin in healthy humans: a double-blind, placebocontrolled dose-effect study. Psychopharmacol., 172:145-156.

Hatfield, G.M., Valdes, L.J. and Smith, A.H. (1978) The occurrence of psilocybin in Gymnopilus species. Lloydia 41:140-144.

Hayden Pollock, S. (1975/1976) Liberty caps: recreational hallucinogenic mushrooms. Drug Alcohol Dep., 1:445-447.

Heim, R. (1971) A propos des proprietes hallucinogens du Psilocybe semilanceata. Naturaliste Can., 98 :415-424.

Heim, R. and Hofmann, A. (1958a) Isolement de la psilocybine à partir du Stropharia cubensis Earle et d'autres espèces de champignons hallucinogens mexicains apartenant au genre Psilocybe. Compt. Rend. Hebd. Séances Acad. Sci., 247:557-561.

Heim, R and Hofmann, A. (1958b) La psilocybine et la psilocine chez les psilocybes et Strophaires hallucinogènes. In : Les champignons hallucinogenes du Mexico. Paris : Editions du Museum National d'Histoire Naturelle 6 :258-262.

Heim, R. and Wasson, R.G. (1958) Les Champignons Hallucinogènes du Mexique. Editions du Muséums National d'Historie Naturelle, Paris.

Heim, R., Hofmann, A. and Tscherter, H. (1966a) Sur une intoxication collective à syndrome psilocynien causée en France par un Copelandia. C.R.Acad. Sc. Paris. 262:519-523.

Heim, R., Genest, K., Hughes, D.W. and Belec, G. (1966b) Botanical and chemical characterization of a forensic mushroom specimen of the genus Psilocybe. J. Forensic Sci. Soc. 6: 192-201.

Heim, E., Heimann, H. and Lukács, G. (1968) Die psychische Wirkung der mexikanischen Droge "Ololiuqui” am Menschen. Psychopharmacologia 13:35-48.

Heimann, H. (1969) Effects of psychotropic drugs on normal man. Confin. Psychiat., 12:205-221.

Heimann, H. (1974) Prüfung psychotroper Substanzen am Menschen. Arzneim.Forsch., 24:1341-1346.
Herblin, W.F. and O’Brien, R.D. (1968) Interactions of norepinephrine with subcellular fractions of rat brain. I. Characteristics of norepinephrine utptake. Brain Res., 8:298-309.

Hermle, L., Gauzoulis, E., Oepen, G., Spitzer, M., Kovar, K.A., Borchardt, D., Fünfgeld, M. and Berger, M. (1993) Zur Bedeutung der historischen und aktuellen Halluzinogenforschung in der Psychiatrie. Nervenartz 64:562-571.

Hill, R.M. and Fischer, R. (1971) Interpretation of visual space under druginduced ergotropic and trophotropic arousal. Agents Act., 2/3:122-130.

Hill, R.M. and Fischer, R. (1973) Induction and extinction of psilocybin induced tranformations of visual space. Pharmacopsychiat., 6:258-263.

Hill, R.M., Fischer, R. and Warshay, D. (1968) Effects of excitatory and tranquilizing drutgs on visual perception. Am. J. Optomet. Arch. Am. Acad. Optomet., 45:454-457.

Hill, R.M., Fischer, R. and Warshay, D. (1969) Effects of excitatory and tranquilizing drugs on visual perception, spatial distortion thresholds. Experientia 25:171-172.

Ho, E., Karimi-Tabeshi, L. and Koren, G. (2001a) Characteristics of pregnant women who use Ecstasy (3,4methylenedioxymethamphetamine). Teratology 63:280.

Ho, E., Karimi-Tabesh, L. and Koren, G. (2001b) Characteristics of pregnant women who use Ecstasy (3,4methylenedioxymethamphetamine). Neurotox. Teratol., 23:561-567.

Hofmann, A. (1960) Psychotomimetica. Chemische, Pharmakologisches und Medizinische Aspekte. Svensk Kemisk Tidskrift 72:723-747.

Hofmann, A., Heim, R., Brack, A. and Kobel, H. (1958a) Psilocybin, ein psychotroper Wirkstoff aus dem mexikanishen Rauschpilz Psilocybe mexicana Heim. Experientia 14: 107-109.

Hofmann, A., Frey, A., Ott, H., Petrzilka, Th. and Troxler, F. (1958b) Konstitutionsaufklärung und Synthese von Psilocybin. Experientia 15:397-399.

Hofmann, A., Frey, A., Ott, H., Petrzilka, Th. and Troxler, F. (1958c) Détermination de la structure et synthèse de la psilocybine. In : Les champignons hallucinogenes du Mexico. Paris : Editions du 
Museum National d'Histoire Naturelle $6: 263-267$.

Hofmann, A., Heim, R., Brack, A., Kobel, H., Frey, A., Ott, H., Petrzilka, T. and Troxier, F. (1959) 168. Psilocybin und Psilocin, zwei psychotrope Wirkstoffe aus mexikanischen Rauschpilsen. Helvetica Chimica Acta 42:1557-1572.

Hofmann, A., Heim, R. and Tscherter, H. (1963) Présence de la psilocybine dans une espèce euroéenne. Comptes Rendus Hebdomadaires des Seances 257:10-12.

Hohmeyer, H. (1984) Inocybe aeruginascens Babos in Berlin gefunden. Z. Mykologie 50:211-214.

Høiland, K. (1978) The genus Psilocybe in Norway. Nore. J. Bot., 24:111-122.

Høiland, K., Christiansen, A.L. and Rasmussen, K.E. (1984) Nye norske hallusinogene sopper. Tidsskr. Nor. Laegeforen., 104:1665-1666.

Holden, M. 1965. A Possible Case of Poisoning by Panaeolina foenisecii. Bull. Brit. Mvcol. Soc., 25:9-10.

Hole, G. (1967) Uber die Kulturgeschichte der halluzinogenen Drogen. Med. Mschr., 21:550-555.

Hole, G. (1967) LSD und verwandte Halluzinogene. Geschichte - Wirkung - Gebrauch und Gefahren. Münchener Med. Wochenschr., 109:1389-1397.

Hollister, L.E. (1961) Clinical, biochemical and psychological effects of psilocybin. Arch. Int. Pharmacodyn., 80:42-52.

Hollister, L.E. and Hartman, A.M. (1962) Mescaline, lysergic acid diethylamide and psilocybin: Comparison of clinical syndromes, effects on color perception and biochemical measures. Comprehens. Psychiat., 3:235-241.

Hollister, L.E., Prusmack, J.J., Paulsen, J.A. and Rosenquist, N. (1960) Comparison of three psychotropic drugs (psilocybin, JB329, and IT-290) in volunteer subjects.J. Nerv. Ment. Dis., 131:428-434.

Holm, J.W., Ebbehøj, N.E. and Fjeldberg, A. (1997) Hallucinogene svampe i Danmark. Ugeskr. Laeger. 159:5116-5118.

Holmgaarad Kristiansen, L. and Harding Sörensen, B. (1988) Vedvarende symptomer efter indtagelse af hallucinogene svampe. Ugeskr Laeger, 150:1224-1225

Holmstedt, B., Vandenheuvel, W.J.A., Gardiner, W.L. and Horning, E.C. (1964) Separation and identification of tryptamine-related indole bases by gas chromatographic methods. Anal. Biochem., 8:151-157.
Holt-Hansen, K. (1976) Extraordinary experiences during cross-modal perception. Perceptual Motor Skills 43:10231027.

Holzmann, P.P. (1995) Bestimmung von Psilocybin-Metaboliten im Humanplasma und -urin. Ph:D. Thesis, EberhardKarls-Universität, Tübingen, Germany.

Hopf, A. and Eckert, H. (1968) Verteilungsmuster markierter Psychopharmaka im Ratengehirn. Acta histochemica (Suppl.) 8:343-348.

Hopf, A. and Eckert, H. (1974) Distribution patterns of ${ }^{14} \mathrm{C}$-Psilocin in the brains of various animals. Activ. Nerv. Sup. (Praha) 16:64-66.

Hopf, A. and Eckert, H. (1969) Autoradiographic studies on the distribution of psychoactive drugs in the rat brain. Psychopharmacologia 16:201-222.

Horibe, M. (1974) The effects of psilocybin on EEG and behaviour in monkeys. Activ. Nerv. Sup. (Praha) 16:40-42.

Horita, A. (1963) Some biochemical studies on psilocybin and psilocin. J. Neuropsych., 4:270-273.

Horita, A. and Weber, L.J. (1961) Dephosphorylation of psilocybin to psilocin by alkaline phosphatase. Proc. Soc. Exp. Biol. Med., 106:32-34.

Horita, A. and Weber, L.J. (1961b) The enzymatic dephosphorylation and oxidation of psilocybin and pscilocin by mammalian tissue homogenates. Biochem. Pharmacol., 7:47-54.

Horita, A. and Weber, L.J. (1962) Dephosphorylation of psilocybin in the intact mouse. Toxicol. Appl. Pharmacol., 4:730-737.

Hughes, J.R. (1996) A review of the usefulness of the standard EEG in psychiatry. Clin. Electroencephalography 27:35-39.

Huikko, K., Kotaho, T., and Kostainen, R. (2002) Effects of nebulizing and drying gas flow on capillary electrophoresis/mass spectrometry. Rapid Commun. Mass Spectrom., 16:1562-1568.

Hyde, C., Glancy, G., Omerod, P., Hall, D. and Taylor, G.S. (1978) Abuse of indigenous psilocybin mushrooms: A new fashion and some psychiatric complications. Brit. J. Psychiat., 132:602-604.

Isbell, H. (1959) Comparison of the reactions induced by psilocybin and LSD-25 in man. Psychopharmacologia 1:29-38.

Isbel, H., Wolbach, A.B., Wikler, A. and Miner, E.J. (1961) Cross tolerance be- 
tween LSD and psilocybin. Psychopharmacologia 2:147-159.

Jacobs, K.W. (1975) Hallucinogenic mushrooms in Mississippi. J. Miss. St. Med. Assoc., 16:35-37.

Jacobs, B.L., Trulson, M.E. and Stern, W.E. (1976) An animal behavior model for studying the actions of LSD and related hallucinogens. Science 194:741-743.

Jacobs, B.L., Trulson, M.E., Stark, A.D. and Christoph, G.R. (1977) Comparative effects of hallucinogenic drugs on behavior of the cat. Commun. Psychopharmacol., 1:243-254.

Jacobs, B.L., Trulson, M.E. and Stern, W.E. (1977) Behavioral effects of LSD in the cat: Proposal of an animal behavior model for studying the actions of hallucinogenic drugs. Brain Res., 132:301-314.

Janoszka, J., Rymkiewicz, A. and Dobosz, T. (2005) Hallucinogenic fungi (Psilocybe). Part I. Characteristics, results of consumption, recognition. Arch. Med. Sadowej. Kryminol., 55:215-219.

Jenny, E. and Solberg, R. (1968) Pharmakologische eigenschaften partiell gereinigter glutaminsäuredecarboxylase (Lglutamate-1-carboxylase, E.C.4.1.1.15) aus kalbshirnrinde. Helv. Physiol. Acta 26:305-314.

Jensen, N., Gartz, J. and Laatsch, H. (2006) Aeruginascin, a trrimethylammonium analogue of psilocybin from the hallucinogenic mushroom Inocybe aeruginascens. Planta Med., 72:665666.

Jokiranta, J., Mustola, S., Ohenoja, E. and Airaksinen, M.M. (1984) Psilocybin in Finnish Psilocybe semilanceata. Planta Medica 50:277-278.

Johnson, D.W. and Gunn, J.W. (1972)

Dangerous drugs: adulterants, diluents and deception in street samples. J. Forensic Sci., 17:629-639.

Järbe, T.U.C. (1980) LSD-25 as a discriminative stimulus for response selection by pigeons. Pharmacol. Biochem. Behav., 13:549-554.

Järbe, T.U.C. and Henriksson, B.G. (1974) Discriminative response control produced with hashish, tetrahydrocannabinols ( $\Delta^{8}$-THC and $\Delta^{9}$-THC), and other drugs. Psychopharmacol., 40:1-6.

Jork, H., Funk, W. Fischer, W. and Wimmer, H. (1994) Thin-layer chromatography: Reagents and detection methods. VCH Verlagsgesellschaft mbH, Veinheim, 1b: 243-247.
Jörgensen, F. (1968) Abuse of psychotomimetics. Acta Psychiatr. Scand. (Suppl.) 203:205-216.

Kaij, L. (1969) Hallucinogener. Läkartidningen 66:4989-4991.

Kalberer, F., Kreis, W. and Rutschmann, J. (1962) The fate of psilocin in the rat. Biochem. Pharmacol., 11:261-269.

Kamata, T., Nishikawa, M., Katagi, M., and Tsuchihashi, H. (2003) Optimized glucuronide hydrolysis for the detection of psilocin in human urine samples. $\mathrm{J}$ cromotography B, 796:421-427.

Kamata, T., Nishikawa, M., Katagi, M., and Tsuchihashi, H. (2005) Liquid chromatography-tandem mass spectrometric determination of hallucinogenic indoles psilocin and psilocybin in "magic mushroom" samples. J. Forensic Sci., 50:336-340.

van Kampen, J. and Katz, M. (2001) Persistent psychosis after a single ingestion of 'ecstasy'. Psychosomatics 42:525-527.

Kang, S., Johnson, C.L. and Green, J.P. (1973) Theoretical studies on the conformations of psilocin and mescalin. Mol. Pharmacol., 9:640-648.

Katp, L., Gözsy, B., Ban, T.A. and Sterlin, C. (1971) Effects of psychoactive agents on the conditioning of the microcirculation in the rat. Cond. Reflex 6:67-77.

Kaul, B. And Davidow, B. (1980) Application of a radioimmunoassay screening test for detection and management of phencyclidine intoxication. J. Clin. Phamacol., 20:500-505.

Keller, T., Schneider, A., Regenscheit, P., Dirnhofer, R., Rücker, T., Jaspers, J. and Kisser, W. (1998) Analysis of psilocybin and psilocin in Psilocyne subcubensis GUZMÁN by ion mobility spectrometry and gas chromatography - mass spectrometry. Forenc. Sci. Internat., 99:93-105. Keller, T., Schneider, A., Regenscheit, P., Dirnhofer, R., Rücker, T., Jaspers, J. and Kisser, W. (1999a) Analysis of psilocybin and psilocin in Psilocybe subcubensis GUZMÁN by ion mobility spectrometry and gas chromatography-mass spectrometry. Forensic Sci. Int. 99:93-105.

Keller, T., Schneider, A., Tutsch-Bauer, E., Skopp, G. and Aderjan, R. (1999b) Ion mobility spectrometry fort he detection of drugs in confiscates and on body surfaces. Beiträge zum XI Symposion der GTFCh, Mosbach, 22-24 April 1999, p. 129-145. 
Keller, T., Keller, A., Tutsch-Bauer, E. and Monticelli, F. (2006) Application of ion mibility spectrometry in cases of forensic interest. Forensic Sci. Internat., 161:130-140.

Kemper, F. (1969) Hemmung der Entwicklung durch Psychotica. NaunynSchmiedebergs Arch. Pharmakol. Exp. Pathol., 263:271-272.

Kieffer, S.N. and Moritz, T.B. (1968) Psychedelic drugs. Pennsylvania Medicine 71:57-67.

Kikura-Hanajiri, R., Hayashi, M., Saisho, K. and Goda, Y. (2005) Simultaneous determination of nineteen hallucinogenic tryptamines/ $\beta$-calbolines and phenethylamines using gas chromatography-mass spectrometry and liquid chromatography-electrospray ionisation-mass spectrometry. J. Chromatogr., B825:29-37.

Kleinman, J.E., Gillin, J.C. and Wyatt, R.J. (1977) A comparison of the phenomenology of hallucinogens and schizophrenia from some autobiographical accounts. Schizophrenia Bull., 3:560-586.

Klug, E. (1971) Zur Kenntnis des Rauschmittelnachweises. Z. Rechtsmedizin 68:171-179.

Knoll, J., Vizi, E.S. and Knoll, B. (1970) Pharmacological studies on parabromomehamphetamine (V-111) and LSD. Acta Physiologica Academiae Scientiarum Hungaricae, Tomus 37:151-170.

Knudsen, H. and Vesterholt, J. (2008) Funga Nordica. Agaricoid, boletoid and cyphelloid genera. Nordsvamp, Copenhagen, $968 \mathrm{p}$.

Koerner, J. and Appel, J.B. (1982) Psilocybin as a discriminative stimulus: Lack of specificity in an animal behavior model for 'hallucinogens'. Psychopharmacol., 76:130-135.

Koike, Y., Wada, K., Kusano, G. and Nozoe, S. (1981) Isolation of psilocybin from Psilocybe argentipes and its determination in specimens of some mushrooms. J. Natural Prod., 44:362-365.

Kok, J.C.P., Kamp, P.E. and van Welsum, R.A: (1973) The results of a street drug identification program in Amsterdam. Pacific Information Service on Street Drugs 2:35-40.

Kolarik, J. (1971) EEG changes after psilocybin in organic brain lesions. Activitas Nervosa Superior 13:316-317.

Kolarik, J. (19??) Different reaction of local and diffuse epileptic EEG activity to psilocybin. ???
Kolarik, J. and Penicková, V. (1975) A contribution to the electrogenesis of distant rhythms in EEG. Activitas Nervosa Superior 17:29-30.

Kostowski, W., Rewerski, W. and Piechocki, T. (1972) II. The effects of some hallucinogens on aggressiveness of mice and rats. Pharmacol., 7:259-263.

Kreisel, H. and Lindequist, U. (1988) Gymnopilus purpuratus, ein psilocybinhaltiger Pilz adventiv im Bezirk Rostock. Z. Mykologie 54:73-76.

Kresanek, J., Plackova, S., Caganova, B. And Klobusicka, Z. (2005) Drug abuse in Slovak Republic. Przeglad Lekarski 62:357-360.

Krieglsteiner, G.J. (1986) Studien zum Psilocybe cyanescens-callosasemilanceata-Komplex in Europa. Beiträge zur Kenntnis der Pilze Mitteleuropas 2:57-72.

Krippner, S. (1985) Psychedelic drugs and creativity. J. Psychoactive Drugs 17:235245.

Kugler, J. (1973) EEG bei Rauschgiftsüchtigen. Deutch. Med. Wochenschr., 98:1047-1048

Kuhn, D.M., White, F.J. and Appel, J.B. (1976) Discriminable stimuli produced by hallucinogens. Psychopharmacol. Commun., 2:345-348.

Kuhn, D.M., Appel, J.B. and Greenberg, I. (1974) An analysis of some discriminative properties of $d$-amphetamine. Psychopharmacol., 39:57-66.

Kuhnert-Brandstätter, M. and Heindl, W. (1976) Polymorhe Medifikationen und Solvate von Psilocin und Psilocybin. Arch. Pharm. (Weinheim) 309:625-631.

Kvambe, V. and Edenberg, J. (1979) Sopp med hallusinogen effekt. Tidsskr. Nor. Lægeforen., 99:1453-1454.

Kysilka, R. (1990) Determination of psilocin in rat urine by high-performance liquid chromatography with electrochemical detection. J. Chromatogr., 534:287-290.

Kysilka, R. and Wurst, M. (1989) Highperformance liquid chromatographic determination of some psychotropic indole derivatives. J. Chromatogr., 464:434-437. Kysilka, R. and Wurst, M. (1990) A novel extraction procedure for psilocybin and psilocin determination in mushroom samples. Planta Medica 56:327-328.

Kysilka, R., Wurst, M., Pacáková, V., Stulík, K. And Haskovec, L. (1985) High-performance liquid chroma- 
tographic determination of hallucinogenic indoleamines with simultaneous UV photometric and voltammetric detection. J. Chromatogr., 320:414-420.

Sticht, G. and Käferstein, H (2000) Detection of psilocin in body. fluids. Forensic Sci Int 113:403-407.

Köppel, C. (1993) Clinical symptomatology and management of mushroom poisoning. Toxicon 31:1513-1540.

La Barre, W. (1979) Peyotl and mescaline. J. Psychedelic Drugs 11:33-39.

Ladefoged, O. (1973) Ehe effects of LSD, psilocybin, harmaline and amphetamine on the body temperature of parachlorophenylalanine pretreated rats. Arch. Int. Pharmacodyn., 204:326-332.

Laffont, F. and Lelord, G. (1971) Modifications du conditionnement des activit"es évoquées par couplage du son et de la lumière chez l'homme, sous l'action de la psilocynine. Comptes rendus des seances de la Societe de biologie et de ses lilial Paris 165:2391-2397.

Lampe, K. F. (1978) Pharmacology and therapy of mushroom intoxication. In: Mushroom Poisoning: Diagnosis and Treatment, B.H. Rumack and E. Salzman (Eds.), CRC Press, Inc., West Palm Beach, p. 125-169.

Lampe, K.F. (1979) Toxic fungi. Ann. Rev. Pharmacol. Toxicol., 19:85-104.

Landon, M. and Fischer, R. (1970) On similar linguistic structures in creative performance and psilocybin-induced experience. Confin. Psychiat., 13:115-138.

Lassen, J.F., Ravn, H.B. and Lassen, S.F. (1990) Hallucinogene psilocybinholdige svampe. Ugeskr. Læger 152:314-317.

Lassen, J.F., Lassen, N.F. and Skov, J. (1992) Unges brug af hallucinogene psilocybinholdige svampe. Ugeskr. Læger 154:2678-2681.

Lassen, J.F., Lassen, N.F. and Skov, J. (1993a) Hallucinogene psilocyninholdige svampe. Ugeskr. Læger 155:1368-1370.

Lassen, J. F., Lasen, N. F. and Skov, J. (1993b) Hallucinogenic mushroom use by Danich students: pattern of consumption. J Internal Medicine, 233:111-112

Lavenhar, M.A. and Sheffet, A. (1973) Recent trends in nonmedical use of drugs reported by students in two suburban New Jersey communities. Prev. Med., 2:490-509.

Leary, T., Litwin, G.H. and Metzner, R. (1963) Reactions to psilocybin adminis- tered in a supportive environment. $\mathrm{J}$. Nerv. Ment. Dis., 137:561-573.

Lee, R.E. (1985) A technique for the rapid isolation and identification of psilocin from psilocin/psilocybin-containing mushrooms. J. Forensic Sci., 30:931-941.

Lee, J. C.-I., Cole, M. and Linacre, A. (2000a) Identification of members of the genera Panaeolus and Psilocybe by DNA test a preliminary test for hallucinogenic fungi. Forensic Sci. Int., 112:123-133.

Lee, J. C.-i., Cole, M. and Linacre, A. (2000b) Identification of hallucinogenic fungi from the genera Psilocybe and Panaeolus by amplified fragment length polymorphism. Electrophoresis, 21:1484-1487.

Leikin, J.B., Krantz, A.J., Zell-Kanter, M., Barkin, R.L. and Hryhorczuk, D.O. (1989) Clinical features and management of intoxication due to hallucinogenic drugs. Med. Toxicol. Adverse Drug Exp., 4:324-350.

Leonard, H.L. and Rapoport, J.L. (1987) Relief of obsessive-compulsive symptoms by LSD and psilocin. Am. J. Psychiatry 144:1239-1240.

Leuner, H. (1968) Die toxische Ekstase. Bibl. Psychiat. Neurol., 134:73-114.

Leuner, H. (1968) Ist die Verwendung von LSD-25 für die experimentelle Psychiatrie und in der Psychotherapie heute noch vertretbar. Nervenarzt 39:356-360.

Leuner, H. (1971) Ûber den Rauschmittelmissbrauch Jugendlicher. Nervenarzt 42:281-291.

Leuner, H. (1971) Verhaltensforschung und experimentelle Psychose. Akt. Fragen Psychiat. Neurol., 11:164-176.

Leuner, H. (1981) Halluzinogene. Bern, Stuttgart, Wien: Huber.

Leung, A.Y. and Paul, A.G. (1967) Baeocystin, a mono-methyl analog of psilocybin from Psilocybe baeocystis saphrophytic culture. J. Pharmaceut. Sci., 56:146.

Leung, A.Y. and Paul, A.G. (1968) Baeocystin and norbaeocystin: New analogs of psilocybin from Psilocybe baeocystis. J. Pharmaceut. Sci., 57:1667-1671.

Leung, A.Y. and Paul, A.G. (1969) The relationship of carbon and nitrogen nutrition of Psilocybe baeocystis to the production of psilocybin and its analogs. Lloydia 32:66-71.

Leung, A.Y., Smith, A.H. and Paul, A.G. (1965) Production of psilocybin in Psi- 
locybe baeocystis saprophytic culture. J. Pharmaceut. Sci., 54:1576-1579.

Levine, W.G. (1967) Formation of blue oxidation product from psilocybin. Nature 215:1292-1293.

Li, C. and Oberlies, N.H. (2005) The most widely recognized mushroom: Chemistry of the genus Amanita. Life Sciences 78:532-538.

Linacre, A., Cole, M. amd Öee, J. C.-I. (2002) Identifying the presence of 'magic mushrooms' by DNA profiling. Sci. Justice 42:50-54.

Lincoff, G. and Mitchel, D.H. (1977) Toxic and Hallucinogenic Mushroom Poisoning. A Handbook for Physicians and Mushroom Hunters. W.K. Williams (Ed.), Van Nostrand Reinhold Comp., New York, 259 p.

Lindenblatt, H., Krämer, E., HolzmannErens, P., Gouzoulis-Mayfrank, E. and Kovar, K.-A. (1998) Quantitation of psilocin in human plasma by highperformance liquid chromatography and electrochemical detection: Comparison of liquid-liquid extraction with automated on-line sold-phase extraction. J. Chromatogr., 709:255-263.

Lindsay, S. (1987) High performance liquid chromatography. John Wiley \& Sons, Chichester, New York, Brisbane, Toronto, Singapore. pp. 83-102.

Litovicz, T., Klein-Schwarz, W., Rodgers, G.C., Cobaugh, D.J., Youniss, J. Omslaer, J.C. et al. (2002) Annual report of the American Association of Poison Control Centers Toxic Exposure Surveillance System. Am. J. Emerg. Med., 20:400.

Little, B.B., Snell, L.M. and Gilstrap, L.C. (1992) Use of hallucinogens during pregnancy. In: Drugs in Pregnancy, L.C. Gilstrap and B.B. Little (Eds.), Chapman and Hall, pp. 409-411.

Logan, W.J. (1975) Neurological aspects of hallucinogenic drugs. Adv. Neurol., 13:47-78.

Louria, D.B. (1968) Some aspects of the current drug scene. With emphasis on drugs in use by adolescents. Pediatrics 42:904-911.

Lovenberg, W. (1973) Toxic amines in human food substances. Am. Chem. Soc., 165:AGFD:abstract 30.

Löhrer, F. and Albers, M. (1999) Biologische suchtmittel - Gibt es ein neues Konsumverhalten bei jungen Abhängigen? Psychiatrische Praxis, 26:199-201.
Löhrer, F. and Kaiser, R. (1999) Biogene Suchtmittel. Neue Konsumgewohnheiten bei jungen Abhängigen? Nervenarzt 70:1029-1033.

Mace, S. (1979) LSD. Clin. Toxicol., 15:219-224.

Mack, R.B. (1983) Phenomenally phunny phungi - psilocybin toxicity. North Carolina Med. J., 44:639-640.

Malitz, S. and Kanzler, M. (1970) Effects of drugs on perception in man. In: Association for Research in nervous and Mental Disease, Effects of drugs, Malitz et al. (Eds.), pp. 35-53.

Malitz, S., Esecover, H., Wilkens, B. And Hoch, P.H. (1960) Some observations on psilocybin, a new hallucinogen, in volunteer subjects. Comprehen. Psychiat., 1:8-17.

Mantegazza, P. and Riva, M. (1963) Amphetamine-like activity of $\beta$ phenethylamine after a monoamine oxidase inhibitor in vivo. J. Pharm. Pharmacol., 15:472-478.

Mantle, P.G. and Wright, E.S. (1969) Occurrence of psilocybin in the sporophores of Psilocybe semilanceata. Trans. Br. Mycol. Soc., 53:302-304.

Marcano, V., Morales méndez, A., Castellano, F., Salazar, F.J. and Martinez, L. (1994) Occurrence of psilocybin and psilocin in Psilocybe pseudobullacea (Petch) Pegler from the Venezuelan Andes. J. Ethnopharmacol., 43:157-159.

Marchbanks, R.M. (1967) Inhibitory effects of lysergic acid derivatives and reserpine on 5-HT binding to nerve ending particles. Biochem. Pharmacol., 16:1971-1979.

Margot, P. and Watling, R. (1981) Studies in Australian agarics and boletes. 2. Further studies in Psilocybes. Transactions of the British Mycological Society 76:485-489.

Martin, R.J. and Alexander, T.G. (1968) Analytical procedures used in FDA laboratories for the Analysis of hallucinogenic drugs. J. A.O.A.C., 51:159-163. Martin, W.R. and Eades, C.G. (1970) The action of tryptamine on the dog spinal cord and its relationship to the agonistic actions of LSD-like psychotogens. Psychopharmacol., 17:242-257.

Martin, W.R. and Sloan, J.W. (1974) The possible role of tryptamine in brain function and its relationship to the action of LSD-like hallucinogens. Mount Sinai J. Med., 41:276-283. 
Martin, W.R. and Sloan, J.W. (1986) Relationship of CNS tryptaminergic processes and the action of LSD-like hallucinogens. Pharmacol. Biochem. Behav., 24:393-399.

Martin, W.R., Vaupel, D.B., Nozaki, M. and Bright, L.D. (1978) The identification of LSD-like hallucinogens using the chronic spinal dog. Drug Alcohol Dep., 3:113-123.

Martindale, C. and Fischer, R. (1977) The effects of psilocybin on primary process content in language. Confinia Psychiat., 20:195-202.

Maruyama, T., Yokoyama, K., Makino, Y., and Goda, Y. (2003a) Phylogenetic relationship of psychoactive fungi based on the rRNA gene for a large subunit and their identification using the TagMan assay. Chem. Pharm. Bull, 51: 710-714.

Maruyama, T., Shirota, O., Kawahara, N., Yokoyama, K., Makino, Y. and Goda, Y. (2003b) Discrimination of psychoactive fungi (commonly called "magic mushrooms") based on the DNA sequence of the internal transcribed spacer region. Shokuin Eiseigaku Zasshi 44:44-48.

Maruyama, T., Kawahara, N., Yokoyama, K., Makino, Y., Fukiharu, T. and Goda, Y. (2006) Phylogenetic relationship of psychoactive fungi based on rRNA gene for a large subunit and their identification using the TaqMan assay (II). Forensic Sci. Internati., 163:51-58.

Mason, H.S. (1955) Comparative biochemistry of the phenolase complex. Adv. enzymol. rel. subj., 16:105-184.

Mattke, D.J. and Steinigen, M. (1973) The chemical composition of illicit street drugs in Munich. Pacific Information Service on Street Drugs 3:10-16.

McCall, R.B. (1982) Neurophysiological effects of hallucinogens on serotonergic neuronal systems. Neurosci. Biobehav. Rev., 6:509-514.

McCall, R.B., and Aghajanian, G.K. (1980) Hallucinogens potentiate responses to serotonin and norepinephrine in the facial motor nucleus. Life Sciences 26:1149-1156.

McCambridge, J., Winstock, A., Hunt, N. and Mitcheson, L. (2007) 5-Year trends in use of hallucinogens and other adjunct drugs among UK dance drug users. Eur. Addict. Res., 13:57-64.

McCarthy, J.P. (1971) Some less familiar drugs of abuse. Med. J. Aust., 2:10781081.
McCawley, E.L., Brummett, R.E. and Dana, G.W. (1962) Convulsions from Psilocybe mushroom poisoning. Proc. West. Pharmacol. Soc., 5:27-33.

McCormick, D. J., Avbel, A, J. and Gibbons, R. B. (1979) Nonlethal moshroom poisoning. Annals Internal Medicine, 90:332-335.

McDonald, A. (1980) Mushrooms and madness. Hallucinogenic mushrooms and some phychopharmacological implications. Can. J. Psychiatry 25:586-594.

McElhatton, P.R. (2000) Fetal effects of substances of abuse. J. Toxicol. Clin. Toxicol., 38:194-195.

McGennis A. (1979) Psychiatric symptoms and hallucinogenic compounds. British Medical Journal, 6193:797.

McGuire, T.H. (1982) Ancient Maya mushroom connections: A transcendental interaction model. J. Psychoactive Drugs 14:221-238.

Meek, J.L. and Fuxe, K. (1971) Serotonin accumulation after monoamine oxidase inhibition. Biochem. Pharmacol., 20:693-706.

Meldrum, B.S. and Naquet, R. (1971) Effects of psilocybin, dimethylryptamine, mescaline and various lysergic acid derivatives on the EEG and on photically induced epilepsy in the baboon. Electroenceph. Clin. Neurophysiol., 31:563-572.

Meldrum, B.S. and Naquet, R. (19??) Effects of psilocybin, dimethyltryptamine and various lysergic acid derivatives on photically-induced epilepsly in the baboon (Papio papio). Proc. Br. Pharmacol. Soc., x:144P-145P.

Meltzer, H.Y., Fessler, R.G., Simonovic, M. and Fang, V.S. (1978) Stimulation of rat prolactin secretion by indolealkylamine hallucinogens. Psychopharmacol., 56:255-259.

Menon, M.K., Clark, W.G. and Masuoka, D.T. (1977) Pissible involvement of the central dopaminergic system in the antireserpine effect of LSD. Psychopharmacol., 52:291-297.

Merlin, M.D. and Allen, J.W. (1993) Species identification and chemical analysis of psychoactive fungi in the Hawaiian islands. J. Ethnopharmacol., 40:21-40.

Michaelis, H. (1977) Psilocybe semilanceata (Fr.) Quel. (Spitzkegliger Kahlkopf). Nachweis von Psilocybin in 
deutschen Funden. Z. Pilszkunde 43:305-310.

Migliaccio, G.P., Shieh, T.-L. N., Byrn, S.R., Hathaway, B.A. and Nichols, D.E. (1981) Comparison of solution conformational preferences for the hallucinogens bufotenin and psilocin using 360Hz proton NMR spectroscopy. J. Med. Chem., 24:206-209.

Mills, P.R., Lesinskas, D. and Watkinson, G. (1979) The danger of hallucinogenic mushrooms. Scot. Med. J., 24:316-317.

Michel, D. H. and Rumack, B. H. (1978) Symtomatic diagnosis and treatment od mushroom poisoning. In Mushroom poisoning: Diagnosis and treatment (ed. Rumack, B. H. and Salzman, E.) pp.171-179.

Moeller, M.R. and Kraemer, T. (2002) Drugs of abuse monitoring in blood for control of driving under the influence of drugs. Therapeutic Drug Monitoring 24:210-221.

Moldavan, M.G., Grodzinskaya, A.A., Solomko, E.F., Lomberh, M.L., Wasser, S.P. and Storozhuk, V.M. (2001) The effect of Psilosybe cubensis extract on hippocampal neurons in vitro. Fiziol. Zh., 47:15-23.

Monti, A. (1971) Sistema limbico ed ipotalamo sotto accusa. Umore, comportamento e medicamenti. Minerva Medica 62:33-34.

Moreno, F.A. and Delgado, P.L. (1997) Hallucinogen-induced relief of obsessions and compulsions. Am. J. Psychiatry 154:1037-1038.

Moser, M. and Horak, E. (1968) Psilocybe serbica spec. Nov., eine neue Psilocybin und Psilocin bildende Art aus Serbien. Z. Piltzkunde 34:137-144.

Mulkey, D. (1972) Psilocybin. Texas Med., 68:87-91.

Muller, A.A. (2003) Mushrooms: toxins right in your own backyard. K. Emerg. Nursing 29:483-485.

Murrill, W.A. (1923) Dark-spored Agarics. V. Psilocybe. Mycologia 15:1-22.

Musha, H., Ishii, A., Tanaka, F. and Kusano, G. (1986) Poisoning by hallucinogenic mushroom Hikageshibiretake (Psilocybe argentipes $\mathrm{K}$. Yokoyama) indigenous to Japan. Tohoku J. Exp. Med., 148:73-78.

Musshoff, F., Madea, B. and Beike, J. (2000) Hallucinogenic mushrooms on the German market - simple instructions for examination and identification. Forensic Sci. Int., 113:389-395.

Nair, X. (1974) Contractile responses of guinea pig umbilical arteries to various hallucinogenic agents. Res. Commun. Chem. Pathol. Pharmacol., 9:535-542.

Neal, J.M., Benedict, R.G. and Brady, L.R. (1968) Interrelationship of phosphate nutrition, nitrogen metabolism, and accumulation of key secondary metabolites in saprophytic cultures of Psilocybe cubensis, Psilocybe cyanescens, and Panaeolus campanulatus. J. Pharmaceut. Sci., 57:1661-1667.

Nichols, D.E. (1986) Studies of the relationship between molecular structure and hallucinogenic activity. Pharmacol. Biochem. Behav., 24:335-340.

Nichols, D.E. and Frescas, S. (1999) Improvements to the synthesis of psilocybin and a facile method for preparing the $O$-acetyl prodrug of psilocin. Synthesis 6:935-938.

Nielen, R.J., van der Heijden, F.M.M.A., Tuinier, S. and Verhoeven, W.M.A. (2004) Khat and mushrooms associated with psychosis. World J. Biol. Psychiatry 5:49-53.

Nordbø, K. (1979) Sopp som rusmiddel. Tidsskr. Nor. Lægeforen., 99:14761477.

Nugent, K.G. and Saville, B.J. (2004) Forensic analysis of hallucinogenic fungi: a DNA-based approach. Forensic Science International 140:147-157.

Ohenoja, E., Jokiranta, J., Mäkinen, T., Kaikkonen, A. and Airaksinen, M.M. (1987) The occurrence of psilocybin and psilocin in Finnish fungi. J. Nat. Prod., 50:741-744.

Oláh, G.M. (1968) Etude chimiotaxinomique sur les Panaeolus. Reserches sur la présence des corps indoliques psychotropes dans ces champignons. C.R. Acad. Sc. Paris 267:1369-1372.

Oláh, G.-M. (1969) A taxinomical and physiological study of the genus Panaeolus with the latin descriptions of the new species. Revue de Mycologie 33:284-290.

Oláh, G.-M. (1973) The fine structure of psilocybe quebecensis. Mycopathologia et Mycologia Applicata 49:321-338.

Oláh, G.-M. and Heim, R. (1967) Une nouvelle espèce nord-américaine de Psilocybe hallucinogène: Psilocybe quebecensis. C.R. Acad. Sc. Paris 264:16011604. 
Olsen, E. and Knudsen, L. (1983) De generelle svamptoksikologiske aspekter på Færøerne after et tilfælde af tilstræbt forgiftning med spids nøgenhat (Psilocybe semilanceata). Ugeskr. Læger 145:1154-1155.

Ondra, P., Zedníková, K. And Válka, I. (2006) Detection and determination of abused hallucinogens in biological material. Neuro Endocrinol. Lett., 27(Suppl. 2):125-129.

Ono, M., Shimamine, M. and Takahashi, K. (1973) Studies on Hallucinogens III. Bull. Nat. Inst. Hygienic Sci., 91:39-41. Ortman, E. and Steen, G. (1973) Fenyletylamin - ett riskabelt substitut för amfetamin på narkotiamarknaden. Läkartidningen 70: 118-119.

Oss, O.T. and Oeric, O.N. (1986) Psilocybin. Magic Mushroom Grower's Guide. Revised edition., Quick American Publishing, First printing November 1991, pp. 81.

Ott, J. (1978) Recreational use of hallucinogenic mushrooms in the United States. In: Mushroom Poisoning: Diagnosis and Treatment, B.H. Rumack and E. Salzman (Eds.), CRC Press Inc., West Palm Beach, Florida, p. 231-243.

Ott, J. and Guzmán, G. (1976) Detection of psilocybin in species of Psilocybe, Panaeolus and Psathyrella. Lloydia 39:258-260.

Oughourlian, J.-M., Rougeul, A. and Verdeaux, J. (1971) Action des hallucinogènes sur

l'électroencéphalogramme. Thérapie 26:953-968.

Pahnke, W.N. (1969) Psychedelic drugs and mystical experience. Int. Psychiat. Clin., 5:149-162.

Panton, Y. And Fischer, R. (1973) Hallucinogenic drug-induced behavior under sensory attenuation. Arch. Gen. Psychiatry 28:434-438.

Parashos, A.J. (1976) The psilocybininduced "state of drunkenness" in normal volunteers and schizophrenics. Behav. Neuropsychiatry 8:83-86.

Passie, T., Seifert, J., Schneider, U. and Emrich, H.K. (2002) The pharmacology of psilocybin. Addiction Biol., 7:357364.

Peden, N.R. and Pringle, S.D. (1982) Hallucinogenic fungi. Lancet i:396-397. Peden, N.R., Bissett, A.F., Macaulay, K.E.C., Crooks, J. and Pelosi, A.J. (1981) Clinical toxicology of 'magic mushroom' ingestion. Postgrad. Med. J., 57:543-545.

Peden, N.R., Pringle, S.D. and Crooks, J. (1982) The problem of psilocybin mushroom abuse. Human Toxicol., 1:417424.

Pedersen-Bjergaard, S., Sannes, E., Rasmussen, K.E. and Tønnesen, F. (1997) Determination of psilocybin in Psilocybe semilanceata by capillary zone electrophoresis. J. Chromatogr., 694:375-381.

Pedersen-Bjergaard, S., Rasmussen, K.E. and Sannes, E. (1998) Strategies for the capillary electrophoretic separation of indole alkaloids in Psilocybe semilanceata. Electrophoresis 19:27-30.

Percy, A., McAlister, S., Higgins, K., McCrystal, P. and Thornton, M. (2005) Response consistency in young adolescents' drug use self-reports: a recanting rate analysis. Addiction 100:189-196.

Pérez-Moreno, J. and Ferrera.Cerrato, R. (1995) A review of mushroom poisoning in Mexico. Food Additives and Contaminants, 12:355-360

Perkal, M., Blackman, G.L., Ottrey, A.L. and Turner, L.K. (1980) Determination of hallucinogenic components of Psilocybe mushrooms using highperformance liquid chromatography. J. Chromatogr., 196:180-184.

Perrine, D.M. (1999) Hallucinogens and obsessive-compulsive disorder. Am. J. Psychiatry 156:1123.

Peterson, G.C. and Wilson, M.R. (1971) A perspective on drug abuse. Mayo Clin. Proc., 46:468-476.

Parashos, A.J. (1976) The psilocybininduced "state of drunkenness" in normal volunteers and schizophrenics. Behav. Neuropsychiatry 8:83-86.

Picker, J. and Rickards, R.W. (1970) The occurrence of the psychotomimetic agent psilocybin in an Australian agaric, Psilocybe subaeruginosa. Aust. J. Chem., 23:853-855.

Pierrot, M., Josse, P., Raspiller, M.-F., Goulmy, M., Rambourg, M.-O., Manel, J. and Lambert, H. (2000) Intoxication par champignons hallucinogènes. Annn. Med. Interne, 151:B16-B19.

Polettini, A. (1999) Systematic toxicological analysis of drugs and poisons in biosamples by hyphenated chromatographic and spectroscopic techniques. J. Chromatogr., 733:47-63. 
Pollock, S.H. (1974) A novel experince with Panaeolus: a case study from Hawaii. J. Psychedelic Drugs 6:85-89.

Pollock, S.H. (1975) The psilocybin mushroom pandemic. J. Psychedelic Drugs 7:73-84.

Pollock, S.H. (1976a) Psilocybin mycetismus with special reference to Panaeolus. J. Psychedelic Drugs 8:43-57.

Pollock, S. H. (1976b) Liberty Chaps: recreational hallucinogenic mushrooms. Drug and Alcohol Dependence, 1:445447.

van Poorten, J.F., Stienstra, R., Dworacek, B., Moleman, P. And Rupreht, J. (1982) Physostigmine reversal of psilocybin intoxication. Anesthesiol., 56:313.

Pullman, B., Courrière, P. And Berthod, H. (1974) Molecular orbital studies on the conformation of hallucinogenic indolealkylamines and related compounds. The isolated molecules and the solvent effect. J. Med. Chem., 17:439-447.

Rabin, R.A., Regina, M., Doat, M. and Winter, J.C. (2002) 5- $\mathrm{HT}_{2 \mathrm{~A}}$ receptorstimulated phosphoinositide hydrolysis in the stimulus effects of hallucinogens. Pharmacol. Biochem. Behav., 72:29-37.

Raff, E., Halloran, P.F., Kjellstrand and C.M. (1992) Renal failure after eating "magic" mushrooms. Can. Med. Assoc. J., 147:1339-1341.

Ramirez Fernandez, M., Laloup, M., Wood, M., De Boeck, G., LopezRivadulla, M., Wallemacq, P. and Samyn, N. (2007) Liquid chromatographytandem mass spectrometry method for the simultaneous analysis of multiple hallucinogens, chlorpheniramine, ketamine, ritalinic acid, and metabolites, in urine. J. Anal. Toxicol., 31:497-504.

Rao, K.R. and Fingerman, M. (1975) Color changes induced by certain indole alkaloids in the fiddler brab, UCA. Comp. Biochem. Physiol., 51C:59-62.

Ratcliffe, B. (1974) Summary of street drug results- 1973. PharmChem Newsletter 3: 1-3.

Rech, R.H., Tilson, H.A. and Marquis, W.J. (1975) Adaptive changes in behavior after repeated administration of various psychoactive drugs. In: Neurobiological Mechanisms of Adaptation and Behavior, J. Mandell (Ed.), Raven Press, New York, pp. 263-286.

Reingardiene, D., Vilcinskaite, J. and Lazauskas, R. (2005) Hallucinogenic mushrooms. Medicina (Kaunas)

41:1067-1070.

Repke, D.B. and Leslie, D.T. (1977)

Baeocystin in Psilocybe semilanceata. J. Pharmaceut. Sci., 66:113-114.

Repke, D.B., Leslie, D.T., Mandell, D.M. and Kish, N.G. (1977a) GLC-Mass spectral analysis of psilocin and psilocybin. J. Pharmaceut. Sci., 66:743-744.

Repke, D.B., Leslie, D.H. and Guzmán, G (1977b) Baeocystin in Psilocybe, Conocybe and Panaeolus. Lloydia 40:566578.

Repke, D.B., Ferguson, W.J. and Bates, D.K. (1981) Psilocin analogs II. Synthesis of 3-[2-(Dialkylamino)ethyl]-, 3-[2( $N$-Methyl- $N$-alkylamino)ethyl]-, and 3[2-(Cycloalkylamino)ethyl]indol-4-ols. J. Heterocyclic Chem., 18:175-179.

Rella, J. G., Nelson, L. S. and Hoffman, R. S. (1999) 5 years of 3,4-methylenedioxymethamphetamine (MDMA) toxicity. J Toxicol. Clin. Toxicol., 37:648.

Riba, J., Rodríguez-Fornells, A., and Barbanoj, M. J. (2002) Effects of ayahusca on snsor and sensormotor gatin in human as measured by P50 suppression and prepulse inhibition of the startle reflex, respectively. Psycopharacology, 165:18-28.

Riedlinger, T.J. (1993) Wasson's alternative candidates for soma. J. Psychoactive Drugs 25:149-156.

Riley, S.C.E., James, C., Gregory, D., Dingle, H. and Cadger, M. (2001) Patterns of recreational durg use at dance events in Edinburgh, Scotland. Addiciton 96:1035-1047.

Rimsza, M.E. and Moses, K.S. (2005) Substance abuse on the collage campus. Pediatr. Clin. N. Am., 52:307-319.

Robbers, J.E., Tyler, V.E. and Oláh, G.M. (1969) Additional evidence supporting the occurrence of psilocybin in Panaeolus foenisecii. Lloydia 32:399-400.

Robbers, J.E., Brady, L.R. and Tyler, V.E. (1964) Chemical and chemotaxonomic evaluation of Inocybe species. Lloydia 27:192-202.

Rold, J. F. (1986) Mushroom madness Psychactive fungi and the risk of fatal poisoning. Postgraduate Medicine, 79:217-218.

Rolsten, C. (1967) Effects of chlorpromazine and psilocin on pregnancy of C57BL/10 mice and their offspring at birth. Anatomical Rec., 157:311. 
Romagnesi, M.H. (1964) Champignons toxiques au Japon. Bull. Soc. Mycol. France 80:IV-V.

Rougeul, A., Verdeaux, J. and Buser, P. (1966) Signification des tracés corticaux "de sommeil" induits chez le chat vigile par trois hallucinogènes. Revue neurologique 115:181-184.

Rougeul, A., Verdeaux, J. and Letalle, A. (1969) Effects électrographiques et comportementaux de divers hallucinogènes chez le chat libre. Revue neurologieque 120:391-394.

Rougeul, A. and Verdeaux, J. (1972) Substances hallucinogenes et mecanismes du sommeil. Rev. Can. Biol., 31 (Suppl.):49-58.

Ruzickova, R., Bílý, D., Vyhnánková, M., Dubanský, B., Konias, V. and Soucek, Z. (1967) Ucinek psilocybinu u chronických schizofrenií. I. Cast klinické poznatky. Ceskoslovenska Psychiatrie 63:158-165.

Rydzy'nski, Z. And Gruszczy'nski, W. (1978) Treatment of alcoholism with psychotomimetic drugs. A follow-up study. Activitas Nervosa Superiori (Praha) 20:81-82.

Rydzýnski, Z., Cwynar, S., Grzelak, L. and Jagiello, W. (1968) Preliminary report on the experience with psychosomimetic drugs in the treatment of alcoholism. Activitas Nervosa Superior 10:273.

Rynearson, R.R., Wilson, M.R. Jr and Bickford, R.G. (1968) Psilocybininduced changes in psychologic function, electroencephalogram, and lightevoked potential in human subjects. Mayo Clin. Proc., 43:191-204.

Rysánek, K. (1970) Vztah monoaminu k psychickým poruchám. Avicenum Zdravotnické nakladatelstvi 12:97-108.

Saavedra, J.M., Heller, B. and Fischer, E. (1970) Antagonistic effects of tryptamine and $\beta$-phenylethylamine on the behaviour of rodents. Nature 226:868.

Sabelli, H.C. and Giardina, W.J. (1972) Amine modulationof affective behaviour. In: Chemical Modulation of Brain Function, H.C. Sabelli (Ed.), Raven, New York, pp. 225-259.

Sabelli, H.C. and Javaid, J.I. (1995) Phenylethylamine modulation of affect: therapeutic and diagnostic implications. J. Neuropsychiatry Clin. Neurosci., 7:614.
Saito, K., Toyo’ka, T., Fukushima, T., Kato, M., Shirota, O. and Goda, Y. (2004) Determination of psilocin in magic mushrooms and rat plasma by liquid chromatography with fluorimetry and electrospray ionization mass spectrometry. Analytica Chimica Acta 527:149-156.

Saito, K., Toyo'ka, T., Fukushima, T., Kato, M., Fukushima, T., Shirota, O. and Goda, Y. (2005) Determination of psilocybin in hallucinogenic mushrooms by reversed-phase liquid chromatography with fluorescence detection. Talanta 66:562-568.

Sakagami, H. and Ogasawara, K. (1999) A new synthesis of psilocin. Heterocycles 51:1131-1135.

Salomé, F., Boyer, P. and Fayol, M. (2000) The effects of psychoactive drugs and neuroleptics on language in normal subjects and schizophrenic patients: a review. Eur. Psychiatry 15:461-469.

Salzman, C., Lieff, J., Kochansky, G.E. and Shader, R.I. (1972) The psychology of hallucinogenic drug discontinuers. Am. J. Psychiat., 129:755-761.

Sanford, J.H. (1972) Japan’s “Laughing Mushroom”. Economic Botany 26:174181.

Sarwar, M. and McDonald, J.L. (2003) A rapid extraction and GC/MS methodology for the identification of psilocyn in mushroom/chocolate concoctions. Microgram J., 1:177-183.

Satora, L., Goszcz, H. and Ciszowski, K. (2005) Poisonings resulting from the ingestion of magic mushrooms in Kraków. Przeglad Lekarski 62:394-396.

Saupe, S.G. (1881) Occurrence of psilocybin/psilocin in Pluteus salicinus (Pluteaceae). Mycologia 73:781-784.

Schardein, J.L. (1993) Personal and social drugs. In: Chemically Induced Birth Defects. Marcel Dekker Inc., New York, pp. 598-641.

Schechter, M.D. and Rosecrans, J.A. (1972) Lysergic acid diethylamide (LSD) as a discriminative cue: Drugs with similar stimulus properties. Psychopharmacologia 26:313-316.

Schneider, C. (1968) Behavioural effects of some morphine antagonists and hallucinogens in the rat. Nature 220:586-587.

Scholes, N.W. and Gutnick, M.J. (1970) Relative activity of psychotoxic drugs on the avian optic lobe. Eur. J. Pharmacol., 12:289-296. 
Scholey, A.B., Parrott, A.C., Buchanan, T., Heffernan, T.M., Ling, J. and Rodgers, J. (2004) Increased intensity of ecstasy and polydrug usage in the more experienced recreational ecstasy/MDMA users: a WWW study. Addictive Behaviours 29:743-752.

Schultes, R.E. (1939) Plantae Mexicanae II. The identification of teonanacatl, a narcotic basidiomycete of the Aztecs. Bot. Museum Leaflets Harv. Univ., 7:37-54.

Schumacher, T. (1976) Hallusinogene sopper. Våre nyttevekster, 71:110-115.

Schwartz, R.H. and Smith, D.E. (1988) Hallucinogenic mushrooms. Clinic. Pediatr., 27:70-73.

Schäfer, A.T. (2000) Mikroskopische Untersuchung von Pulvern halluzinogener Pilze - Psilocybe sp. Institut $\mathrm{f} r$ Rechtsmedizin der RWTH Aachen, p. 30-36.

Scurti, J.C. and Bianco, M.A. (1973) Caratteristiche colturali di miceli di "Panaeolus”. Allionia 19:5-12.

Seal, R.E. (1970) The current status of the hallucinogenic drugs. Aust. N. Z. Psychiatry 4:64-67.

Seeger, R. (1995) Vergiftungen durch höhere pilze. Chech Mycol., 48:97-138.

Semerdzieva, M. and Neruá, F. (1973) Halluzinogene Pilze in der Tschechoslowakei. Ceská Mykologie 27:42-47.

Semerdzieva, M., Wurst, M., Koza, T. and Gartz, J. (1986) Psilocybin in Fruchtkörpern von Inocybe aeruginascens. Planta Medica 47:83-85.

Shaffer, J.H., Hill, R.M. and Fischer, R. (1973) Psychophysics of psilocybin and $\Delta^{9}$-tetrahydrocannabiol. Agents Actions 3:48-51.

Shaw, G.M., Velie, E.M. and Morland, K.B. (1996) Parental recreational drug use and risk for neural tube defects. Am. J. Epidemiol., 144:1155-1160.

Shein, H.M., Wilson, S., Larin, F. and Wurtman, R.J. (1971) Stimulation of $\left[{ }^{14} \mathrm{C}\right]$ serotonin synthesis from $\left[{ }^{14} \mathrm{C}\right]$ tryptophan by mescaline in rat pineal organ culture. Life Sci., 10:273-282.

Shirota, O., Hakamata, W. and Hoda, Y. (2003) Concise large-scale synthesis of psilocin and psilocybin, principal hallucinogenic constitutents of "magic mushroom”. J. Nat. Prod., 66:885-887.

Shein, H.M., Wilson, S., Larin, F. and Wurtman, R.J. (1971) Stimulation of $\left[{ }^{14} \mathrm{C}\right]$ serotonin synthesis from $\left[{ }^{14} \mathrm{C}\right]$ tryp- tophan by mescaline in rat pineal organ culture. Life Sci., 10:273-282.

Shirota, O., Hakamata, W. and Hoda, Y. (2003) Concise large-scale synthesis of psilocin and psilocybin, principal hallucinogenic constitutents of "magic mushroom”. J. Nat. Prod., 66:885-887.

Shulgin, A.T. (1980) Profiles of psychedelic drugs. 8. Psilocybin. J. Psycedelic Drugs 12:79.

Sicuteri, F. (1976) Migraine, a central biochemical dysnociception. Headache 16:145-159.

Sicuteri, F., Anselmi, B. And Del Bianco, P.L. (1973) 5-Hydroxytryptamine supersensitivity as a new theory of headache and central pain: A clinical pharmacological approach with $\mathrm{p}-$ chlorophenylalanine. Psychopharmacologia 29:347-356.

Siegel, R.K. (1981) Inside Castaneda's pharmacy. J. Psychoactive Drugs 13:325-332.

Siegel, R.K. (1985) New trrends in drug use among youth in California. Bull. Narcotics 37:7-17.

Singer, R. (1958a) Mycological investigations on teonanácatl, the mecixan hallucinogenic mushroom. Part I. The history of teonanácatl, field work and culture work. Mycologia 50:239-261.

Singer, R. (1958b) Observations on agarics causing cerebral mycetisms. Mycopahtologia et mycologia applicata 9:261284.

Singer, R. (1978) Hallucinogenic mushrooms. In: Mushroom Poisoning: Diagnosis and Treatment, B.H. Rumack and E. Salzman (Eds.), CRC Press Inc., West Palm Beach, Florida, p. 201-214.

Singer, R. and Smith, A.H. (1958) Mycological investigations on teonanácatl, the Mexican hallucinogenic mushroom. II. A taxonomic monograph of Psilocybe, section Caerulescentes. Mycologia 50:262-303.

Sivyer, G and Dorrinton, L. (1984) Intravenous injection of mushrooms. Medical J. Australia. ???:182.

Smolinske, S C. (1994) Psilocybincontaining mushrooms. In Handbook of mushroom poisoning diagnosis and treatment. (ed Spoerke, D. G. and Rumck, B. H.) pp. 310-324.

Smith, C. and Nutbeam, D. (1992) Adolescent drug use in Wales. Br. J. Addiction 87:227-233. 
Smolinske, S.C. (1994) Psilocybincontaining mushrooms. In: Handbook of Mushroom Poisoning. Diagnosis and Treatment. D.G. Spoerke and B.H. Rumack (Eds.), CRC Press, Boca Raton, p. 309-324.

Snyder, S.H., Faillao, L. and Hollister, L. (1967) 2,5-Dimethoxy-4-methylamphetamine (STP): A new hallucinogenic drug. Science 15?:669-670.

Sottolano, S.M. and Lurie, I.S. (1983) The quantitation of psilocybin in hallucinogenic mushrooms using high performance liquid chromatography. J. Forensic Sci., 28:929-935.

Southcott, R. V. (1974). Notes on Some Poisonings and other Clinical. Effects Following Ingestion of Australian Fungi. South Australian Clinics 6:442-478.

Spengos, K., Schwartz, A. and Hennerici, M. (2000) Multifocal cerebral demyelination after magic mushroom abuse. J. Neurol., 247:224-225.

Sperling, A. (1972) Analysis of hallucinogenic drugs. J. Chromatogr. Sci., 10:268-274.

Speeter, M.E. and Anthony, W.C. (1954) The action of oxalyl chloride on indoles. A new approach to tryptamines. J. Amer. Chem. Soc., 76:6209.

Spitzer, M., Thimm, M., Hermle, L., Holzmann, P., Kovar, K.-A., Heimann, H., Gouzoulis-Mayfrank, U. and Schneider, F. (1996) Increased activation of indirect semantic associations under psilocybin. Biol. Psychiatry 39:1055-1057.

Spoerke, D.G. and Hall, A.H. (1990)

Plants and mushrooms of abuse. Emerg. Aspects Drug Use 8:579-593.

Stahl, E., Brombeer, J. and Eskes, D. (1978) Rauschgiftpilze mit LSD? Arch. Kriminologie 162:23-33.

Stamets, P. (1978) Psilocybe Mushrooms and their Allies. Homestead Book Co., Seattle.

Stamets, P. (1996) Psilocybin Mushrooms of the World. Ten Sped Press, Berkeley, , California, pp. 243.

Stamets, P.E., Beug, N.W. and Bigwood, J.E. (1980) A new species and a new variety of Psilocybe from North America. Mycotaxon 11:476-484.

Stein, S.I. (1958) An unusual effect from a species of Mexican mushroom, Psilocybe cubensis. Mycopathologia et Micologia Applicata. Vol. 9:263-267.
Sticht, G. and Käferstein, H. (2000) Detection of psilocin in body fluids. Forensic Sci. Int., 113:403-407.

Stienstra, R., van Poorten, J.F., Vermaas, F.A. and Rupreht, J. (1981) Psilocybinevergiftiging door het eten van paddestoelen. Ned. T. Geneesk., 125:833-835.

Stijve, T. (1984) Psilocybe seimilanceata als Hallucinogene Paddestoel. Coolia 27:36-43.

Stijve, T. (1987) Vorkommen von Serotonin, Psilocybin und Harnstoff in Panaeoloideae. Beiträge zur Kenntnis der Pilze Mitteleuropas 3:229-234.

Stijve, T. and Bonnard, J. (1986) Psilocybine et urée dans le genre Pluteus. Mycologia Helvetica $2: 123-130$.

Stijve, T. and Kuyper, Th. W. (1985) Occurrence of psilocybin in various higher fungi from several European countries. Planta Medica, 51:385-387.

Siijve, T. and de Meijer, A.A.R. (1993) Macromycetes from the state of Paraná, Brazil. 4. The psychoactive species. Arq. Biol. Tecnol., 36:313-329.

Stijve, T., Hischenhuber, C. and Ashley, D. (1984) Occurrenec of 5-hydroxylated indole derivatives in Paneolina foenisecii (Fries) Kuehner from various origin. Zeitschrift für Mykologie 50:361368.

Stijve, T., Klán, J. and Kuyper, T. W. (1985) Occurrence of psilocybin and baeocystin on the genus Inocybe (Fr.) Fr. Persoonia, 12:469-473.

Stolk, J.M., Barchas, J.D., Goldstein, M., Boggan, W. and Freedman, D.X. (1974) A comparison of psychotomimetic drug effects on rat brain norepinephrine metabolism. J. Pharmacol. Exp. Ther., 189:42-50.

Stocks, A.E. (1963) Mushroom poisoning in Brisbane. Journal of the Princess Alexandra Hospital 1:21-24.

Strassman, R.J. (1992) Human hallucinogen interaction with drugs affecting serotonergic neurotransmission. Neurophsychopharmacol., 7:241-243.

Stříbrný, J., Borovička, J. and Sokol, M. (2003) Levels of psilocybin and psilocin in various types of mushrooms. Soud Lek., 48:45-49.

Subramanian, C.V. (1995) Mushrooms: Beauty, diversity, relevance. Current Sci., 69:986-998.

Sugrue, M.F. (1969) A study of the role of noradrenaline in behavioural changes 
produced in the rat by spychotomimetic drugs. Br. J. Pharmac., 35:243-252.

Supprian, T., Frey, U., Supprian, R., Rösler, M. and Wanke, K. (2001) Über den Gebrauch psychoaktiver Pilze als Rauschmittel. Fortschr. Neurol. Psucjoat., 69:597-602.

Taber, W.A. (1969) Microbial production of lysergic acid and psilocybin. Psychopharmacol. Bull., 5:32-33.

Tanimukai, H. (1967) Modifications of paper and thin layer chromatographic methods to increase sensitivity for detecting $\mathrm{N}$-methylated indoleamines in urine. J. Chromatog., 30:155-163.

Teeguarden, J. g., Dragan, Y., and Pitot, H. C. (1998) Impications of hormesis on the bioassay and hazard assessment of chemical carcinogenes. Human and Experimental Toxicology 17:254-258.

Thatcher, K., Wiederholt, W.C. and Fischer, R. (1971) An electroencephalographic analysis of personalitydependent performance under psilocybin. Agents Actions 2:21-26.

Thatcher, K., Kappeler, T., Wisecup, P. and Fisher, R. (1970) Personality trait dependent performance under psilocybin. Diseases of the Nervous System 21:181-192.

Thomson, B.M. (1980) Analysis of psilocybin and psilocin in mushroom extracts by reversed-phase high performance liquid chromatography. J. Forensic Sci., 25:779-785.

Thompson, J.P., Anglin, M.D., Emboden, W. and Fisher, D.G. (1985) Mushroom use by college students. J. Drug Educat., 15:111-124.

Thuillier, J. and Nakajima, H. (1966) Analogies et différences neuropharmacologiques entre les hallucinogènes et les intidépresseurs. Arzneimittelforsch., $16: 222-226$

Tiscione, N.B. and Miller, M.I. (2006) Psilocin identified in a DUID investigation. J. Anal. Toxicol., 30:342-345.

Tosi, O., Rockey, M.A. and Fischer, R. (1968) Quantitative measurement of time constraction induced by psilocybin. Arzneimittelforsch., 18:535-537.

Troxler, F., Seeman, F. and Hofmann, A. (1959) Abwandlungsprodukte von Psilocybin and Psilocin. Helv. Chim. Acta 42:2073-2103.

Trulson, M.E., Stark, A. D. and Jacobs, B.L. (1977) Comparative effects of hallucinogenic drugs on rotational behavior in rats with unilateral 6hydroxydopamine lesions. Eur. J. Pharmacol., 44:113-119.

Trulson, M.E., Heym, J. and Jacobs, B.L. (1981) Dissociations between the effects of hallucinogenic drugs on behavior and raphe unit activity in freely moving cats. Brain Res., 215:275-293

Trulson, M.E., Preussler, D.W. and Trulson, V.M. (1984) Differential effects of hallucinogenic drugs on the activity of serotonin-containing neurons in the nucleus centralis superior and nucleus raphe pallidus in freely moving cats. $\mathrm{J}$. Pharmacol. Exp. Ther., 228:94-102.

Tsujikawa, K., Kanamori, T., Uwata, Y., Ohmae, Y., Sugita, R., Inoue, H. and Kishi, T. (2003) Morphological and chemical analysis of magic mushrooms in Japan. For. Sci. Internat., 138:85-90.

Tyler, V.E. (1961) Indole derivatives in certain North American mushrooms. Lloydia 24:71-74.

Tyler, V.E. Jr. and Groger, D. (1964a) Occurrence of 5-hydroxytryptamine and 5-hydroxytryptophan in Panaeoulus sphinctrinus. J. Pharmaceut. Sci., 53:462-463.

Tyler, V.E. Jr. and Gröger, D. (1964b) Investigation of the alkaloids of Amanita species. II. Amanita citrina and Amanita porphyria. Planta Medica 12:397-402.

Umbricht, D., Vollenweider, F.X., Schimid, L., Frübel, C., Skrabo, A., Huber, T. and Koller, R. (2003) Effects of the $5-\mathrm{HT}_{2 \mathrm{~A}}$ agonist psilocybin on mismatch negativity generation and $\mathrm{AX}$ continuous performance task: implications for the neuropharmacology of cognitive deficits in schizophrenia. Neuropsychopharmacol., 28:170-181.

Umbricht, D., Koller, R., Vollenwieder, F.X. and Schmid, L. (2002) Mismatch negativity predicts psychotic experiences induced by NMDA receptor antagonist in healthy volunteers. Biol. Psychiatry 51:400-406.

Unger, S.E. and Cooks, R.G. (1979) Application of mass spectrometry/mass spectrometry (MS/MS) to the identification of natural products in Psilocybe cyanescens. Analyt. Letters 12:11571167.

Unwin, J.R. (1968) Illicit drug use among Canadian youth: Part I. Canad. Med. Ass. J., 402-407. 
Uyeno, E.T. (1966) Inhibition of isolationinduced attack behavior of mice by drugs. J. Pharmaceut. Sci., 55:215-216.

Uyeno, E.T. (1967) Effects of mescaline and psilocybin on dominance behavior of the rat. Arch. Int. Pharmacodyn., 166:60-64.

Uyeno, E.T. (1967) Hallucinogens and dominance behavior of the rat. Proc. Western Pharmacol. Soc., 10:94.

Uyeno, E.T. (1969) Alteration of a learned response of the squirrel monkey by hallucinogens. Int. J. Neuropharmac., 8:245-253.

Uyeno, E.T. (1971) Relative potency of amphetamine derivatives and $\mathrm{N}, \mathrm{n}$ dimethyltryptamines. Psychopharmacol., 19:381-387.

Valdes, L.J. III, Díaz, J.L. and Paul, A.G. (1983) Ethnopharmacology of Ska Maria Pastora (Salvia divinorum, Epling and Játiva-M.). J. Ethnopharmacol., 7:287312.

Vanhaelen-Fastré, R. and Vanhaelen, M. (1984) Qualitative and quantitative determination of hallucinogenic components of psilocybe mushrooms by reversed-phase high-performance liquid chromatography. J. Chromatogr., 312:467-472.

Ventegodt, S. and Merrick, J. (2003) Psychoactive drugs and quality of life. The Scientific World J., 3:694-706.

Vinar, O. (1968) Psychofarmaka v modernim lékarstvi. Ceskoslov. Farm., 17:496-502.

Vaupel, D.B., Nozaki, M., Martin, W.R., Bright, L.D. and Morton, E.C. (1979) The inhibition of food intake in the dog by LSD, mescaline, psilocin, $\mathrm{d}$ amphetamine and phenylisopropylamine derivatives. Life Sci., 24:2427-2432.

Vetulani, J. (2001) Drug addiction. Part I. Psychoactive substances in the past and presence. Pol. J. Pharmacol., 53:201214.

Vojtechovský, M., Vítek, V. and Rysánek, K. (1966) Experimentelle psychose nach verabreichung von benactyzin.

Arzneimittelforsch., 16:240-242.

Vojtechovský, M., Hort, V. and Safratová, V. (1968) Ovlivnení experimentálních psychóz på psilocybinu inhibitory MAO. Activitas Nervosa Superior 10:278-279.

Vollenweider, F.X., Leenders, K.L., Scharfetter, C., Maguire, P., Stadelmann, O. And Angst, J. (1997) Positron emission tomography and fluorodeoxyglu- cose studies of metabolic hyperfrontality and psychopathology in the psilocybin model of psychosis. Am. Coll. Neuropsychopharmacol., 16:357-372.

Vollenweider, F.X., VollenweiderScherpenhuyzen, M.F.I., Bäbler, A., Vogel, H. and Hell, D. (1998) Psilocybin induces schizophrenia-like psychosis in humans via a serotonin-2 agonist action. NeuroReport 9:3897-3902.

Vollenweider, F.X., Vontobel, P., Hell, D. and Leenders, K.L. (1999) 5-HAT modulation of dopamine release in basal ganglia in psilocybin-induced psychosis in man - a PET study with $\left[{ }^{11} \mathrm{C}\right]$ raclopride. Neuropsychopharmacology 20:424-433.

Vollenweider, F. X., and Geyer, M. A. (2001) A systems model of altered consciousness: Integrating natural and druginduced psychoses. Brain Research Bulletin, 56:495-507.

Vollenwieder, F.X. and VollenwiederScherpenhuyzen, M.F.I. (2003) Halluzinogene, Amphetamine und Entactogene. Therurapeutische Umschau 60:323-328. Vuillon-Caggiuttolo, G. and Balzamo, E. (1971) Effets de la psilocyne sur le comportement, la photosensibilité et lÉEG du singe Papio papio. Comptes rendus des seances de la Societe de biologie et de ses filial Paris 165:2377-2381.

van Vunakis, H., Farrow, J.T., Gjika, H.B. and Levine, L. (1971) Specificity of the antibody receptor site to D-lysergamide: Model of a physiological receptor for lysergic acid diethylamide. Proc. Natl. Acad. Sci. USA 68:1483-1487.

Walker, R.J. and Woodruff, G.N. (1971) Structure-activity studies on a 5hydroxytryptamine receptor of Helix aspersa neurones. Proc. Br. Pharmacol. Soc., ?:415P-416P.

Walters, M.B. (1965) Pholiota spectabilis, hallucinogenic fungus. Mycologia 57:837-838.

Waser, P.G. (1971) Pharmakologische Wirkungsspektren von Halluzinogenen. Bull. Schweiz. Akad. Medizin. Wissenschaft., 27:39-57.

Waser, P.G. and Schaub, E. (1971) The action of some neuro- and psychopharmacological agents on the membrane ATP-ase of cortical synaptosomes. Adv. Cytopharmacol., 1:397-400.

Wasson, R.G. (1957) Seeking the magic mushroom. In: Life Science 49:100-120. 
Wasson, R.G. (1959) Wild mushrooms: A world of wonder and adventure. The Herbarist 24:13-28.

Wasson, R.G. (1961) The hallucinogenic fungi of Mexico: An inquiry into the origins of the religious idea among primitive peoples. Harvard University Botanical Museum Leaflets 19: 137-162.

Wasson, R.G. (1962) The hallucinogenic mushrooms of Mexico: An inquiry into the origins of the religious idea among primitive people. Bot. Museum Leaflets Harvard University 19:137-162.

Wasson, R.G. (1962) The hallucinogenic mushrooms of Mexico and psilocybin: A bibliography. Bot. Museum Leaflets 20:25-73.

Wasson, R.G. (1966) Ololiuhqui and the other hallucinogens of Mexico. In: Summa Antropologica en Homenaje, R.J. Weitlaner (Ed.), Instituto Nacional de Antropologia e Historia, Mexico.

Watling, R. (1997) Poisoning by fungi: Interesting cases. Mycologist (Cambridge) 11:101-102.

Weber, K. (1967) Veränderungen des Musikerlebens in der experimentellen psychose (Psilocybin). Confin. Psychiat., 10:139-176.

Weber, K. (1967) Veränderungen des musikalischen ausdrucks under psilocybinwirkung. Schwizer Arch. Neutologie, Neurochirurgie Psychiatrie 99:176-179.

Weber, K. (1977) Beobachtungen und ûberlegungen zum Problem der Zeiterlebensstörungen, ausgehend von Veränderungen des Musikerlebens in der experimentellen Psychose. Confinia Psychiat., 20:79-94.

Weber, L.J. and Horita, A. (1963) Oxidation of 4- and 5-hydroxyindole derivatives by mammalian cytochrome oxidases. Life Sciences 1:44-49.

Van Went, G.F. (1978) Mutagenicity testing of 3 hallucinogens: LSD, psilocybin and $\Delta^{9}$-THC, using the micronucleus test. Experientia 34:324-325.

Webb, E., Ashton, C.H., Kelly, P. and Kamali, F. (1998) An update on British medical students' lifestyles. Med. Educ., 32:325-331.

Weeks, R.A., Singer, R. and Hearn, W.L. (1979) A new psilocybian specis of Copelandia. J. Natural Products 42:469474.

Weil, A. (1980) Mushroom hunting in Oregon. Mushrooms I-IV. Marriage of the sun and moon. Boston: Houghton Mifflin Company, pp. 43-57.

West, L.J. (1975) A clinical and theoretical overview of hallucinatory phenomena. In Siegel et al. (Eds.) Hallucinations: behavior, experience, and theory, John Wiley and Sons, Los Angeles, pp. 287311.

Westberg, U. And Karlsson-Stiber, C. (1999) Hallucinogena svampar åter i ropet - sold via Internet. Läkartidningen 96:746-747.

Whitaker, P.M. and Seeman, P. (1978) High-affinity $3 \mathrm{H}$-serotonin binding to caudate: Inhibition by hallucinogens and serotoninergic drugs. Psychopharmacol., 59:1-5.

White, P.C. (1979) Analysis of extracts from Psilocybe semilanceata mushrooms by high-pressure liquid chromatography. J. Chromatogr., 169:453-456.

Witt, P.N. (1971) Drugs alter Webbuilding of spiders: A review and evaluation. Behavioral Sci., 16:98-113.

Wolbach, A.B. Jr., Miner, E.J. and Isbell, H. (1962) Comparison of psilocin with psilocybin, mescaline and LSD-25. Psychopharmacol., 3:219-223.

Wurst, M., Semerdzieva, M. and Vokoun, J. (1984) Analysis of psychotropic compounds in fungi of the genus Psilocybe by reversed-phase high-performance liquid chromatography. J. Chromatogr., 286:229-235.

Wurst, M., Kysilka, R. and Koza, T. (1992) Analysis and isolation of indole alkaloids of fungi by high-performance liquid chromatography. J. Chromatogr., 593:201-208.

Wurst, M., Kysilka, R. and Flieger, M. (2002) Psychoactive tryptamines from Basidiomycetes. Folia Microbiol., 47:327.

Yamada, F. (2000) Development of synthetic methods for 4-substituted indoles and their applications for the syntheses of natural products. J. Pharmaceutical Soc. Jpn., 120:363-373.

Yamada, F., Tamura, M. and Somei, M. (1998) A five-step synthesis of psilocin from indole-3-carbaldehyde. Heterocycles 49:451457.

Yamada, F., Tamura, M., Hasegawa, A., and Somei, M. (2002) Synthetic studies of psilocin analogs having either a formyl group or bromine atom at the 5- or 7-position. Chem. Pharm. Bull., 50:9299. 
Yokoyama, K. (1973) Poisoning by a hallucinogenic mushroom, Psilocybe subcaerulipes Hongo. Nippon Kingakkai Kaiho 14:317-320.

Young, R.E., Milroy, R., Hutchison, S. and Kesson, C.M. (1982) The rising price of mushrooms. Lancet i:213-214.
Zilker, T. (1987) Diagnose und Therapie der Pilzvergiftungen (Teil I). Leber Magen Darm 2:97-112.

Zimmer, M. (1986) Blue honey. High Times (October): 48-49. 



\section{Sammanfattning}

Från att ha varit använda i rituella religiösa ceremonier under tusentals år började hallucinogena svampar att brukas som partydroger under slutet av 1960-talet. Vilka de hallucinogena svamparna var som användes i religiösa sammanhang av mexikanska indianstammar klargjordes vid etnomykologiska undersökningar på 1930-och 40-talet, men den första listan över mexikanska hullucinogena svampar publicerades först 1961. Vid den tidpunkten hade redan kemister vid läkemedelsföretaget Sandoz identifierat den beståndsdel av svampen som var orsaken till de eftersträvade effekterna. Det visade sig vara en fosforylerad alkaloid som gavs namnet psilocybin (en fosforsyraester av 4-dihydroxymetyltryptamin) efter den svampart från vilken den ursprungligen isolerades Psilocybe mexicana. Senare studier visade att den hallucinogena substansen är psilocin, som bildas från psilocybin genom defosforylering. Defosforyleringen kan ske i svampen vid skörd eller när den skadas eller i kroppen hos den som konsumerar svampen.

Mykologiska studier har funnit att ett stort antal svampar har förmågan att bilda psilocybin. Ämnet har identifierats i mer än 90 svampar tillhörande olika släkten: Agrocybe, Conocybe, Copelandia*, Gymnopilus*, Hypholoma, Inocybe, (Panaeolina), Panaeolus*, Pluteus, Psathyrella*, Psilocybe, och Stropharia (*flertalet arter i detta släkte innehåller inte psilocybin/psilocin). Dessutom har många andra arter rapporterats ha hallucinogena egenskaper. De kemiska studierna på svamp har också visat att psilocybin/psilocin inte är det enda hallucinogena ämnet av denna typ i svamp. Tre andra fosforsyraestrar av 4-hydroxytryptamin med en, ingen eller tre metylgrupper bundna till tryptamin-sidokedjan - baeocystin, nor-baeocystin, och aeruginascin - har även de hallucinogena egenskaper. Dessa ämnen förekommer dock vid lägre nivåer och i ett mycket mindre antal svamparter.

Viktiga steg vid den kemiska analysen av psilocybin och liknande ämnen i svamp är den extraktionsmetod som används, den kromatografiska metod som används för att separera ämnena och metoden för att identifiera dem. GC-MS och LC-MS är vanliga metoder vid studiet av humanbiologiska prover för att identifiera psilocybin/psilocin.

Den kemiska analysen av hallucinogena svampar har funnit moderata mängder i mycelet, men större mängder i fruktkropparna. Hos de senare innehåller hatten högre nivåer än stjälken. Man har inte funnit något samband mellan storleken på svampen och psilocybinhalt.

Arter med högt innehåll av psilocybin/psilocin inkluderar Agrocybe praecox (Pers.) Fayod., Copelandia cambodginiensis (Ola'h et Heim) Singer and Weeks, Inocybe aeruginascens Babos, Panaeolus cyanescens 
(Berk. \& Br.) Sacc., Panaelous subbalteatus (Berk. \& Br.) Sacc., Pluteus salicinus (Pers. Ex Fr.) Kummer, Psilocybe arcana Bor et Hlav., Psilocybe azurescens Stamets and Gartz, Psilocybe baeocystis Singer and Smith, Psilocybe bohemica Sebek, Psilocybe cubensis (Earle) Singer, Psilocybe cyanescens Wakefield, Psilocybe liniformans Guzmán \& Bas var. americana Guzmán \& Stamets, Psilocybe pelliculosa (Smith) Singer and Smith, Psilocybe samuiensis Guzmán, Bandala and Allen, Psilocybe semilanceata (Fr.) Kummer, Psilocybe semperviva Heim and Cailleux och Psilocybe subcubensis Guzmán. De högsta nivåerna, mer än 15000 $\mathrm{mg} / \mathrm{kg}$ torrvikt, har man funnit i Pluteus salicinus (Pers. Ex Fr.) Kummer, Psilocybe cyanescens Wakefield och Psilocybe semilanceata (Fr. Ex Secr.) Kummer.

Beaocystin återfinns enbart i några få av de arter som bildar psilocybin, vanligtvis under $1000 \mathrm{mg} / \mathrm{kg}$ torrvikt. Högre halter, upp till mer än $5000 \mathrm{mg} / \mathrm{kg}$ torrvikt, har påvisats i Inocybe aeruginascens Babos. Samma svampart har man funnit att kan innehålla upp till 3500 mg/kg torrvikt av aeruginacin.

Av de mer än 90 psilocybin- och/eller psilocin-innehållande svampar som identifierats har cirka 30 återfunnits i Norden. Bland dessa återfinns 6 Psilocybe arter, 6 Panaeolus arter, 3 Gymnopilus arter, 2 Conocybe arter, 2 Inocybe arter, 2 Pluteus arter och en Psathyrella art. Många av dessa är sällsynta men somliga förekommer allmänt.

Insamlandet av hallucinogena svampar kräver stora kunskaper eftersom det finns många förväxlingssvampar, av vilka en del är giftiga. Endast erfarna svampplockare bör därför ägna sig åt denna sysselsättning. Alternativa sätt att komma över hallucinogena svampar är att odla dem hemma eller att köpa dem över internet. Den senare typen av svamp säljs oftast torkad. För att göra den torkade svampen mer lättförtärlig konsumeras den ofta i olika drycker, såsom i te, kaffe eller Coca Cola. Ett alternativt sätt att använda torkad svamp på är att röka dem likt cigaretter. Eftersom psilocybin extraheras vid upphettning i vätska och inte bryts ned så är den totala mängden psilocybin i kokvattnet och i svampen jämförbar med den mängd som ursprungligen fanns i svampen innan den tillagades inför konsumtion.

Bruket av hallucinogen svamp är mest vanligt hos ungdomar, speciellt bland yngre män, särskilt de som även använder andra typer av droger. Bruket är dock inte allmänt. I de nordiska länderna har användningen av hallucinogen svamp studerats bäst i Danmark. Tre procent av högstadiestudenter/gymnasister har som avkoppling använt psilocybininnehållande svamp (1\% har prövat LSD). Motsvarande siffra bland universitetsstuderande och studenter vid en journalisthögskola var nio procent. Detta pekar på att svamp är den vanligaste hallucinogena substansen i Danmark.

Även om man inte kunnat visa på att toxiska effekter uppträder vid användning av hallucinogen svamp, är det välkänt att ett sådan bruk kan föranleda okontrollerade handlingar hos brukaren. I ovanliga fall, där 
bruket av sådan svamp varit påtagligt, har negativa erfarenheter av den tidigare användningen repriserats utan att sådan svamp konsumerats vid det senare tillfället ('flash-backs'). Av den anledningen, men också därför att bruket av hallucinogen svamp inte är ovanligt bland missbrukare av andra droger, har många länder, däribland de nordiska, infört restriktioner för bruket av hallucinogen svamp 